

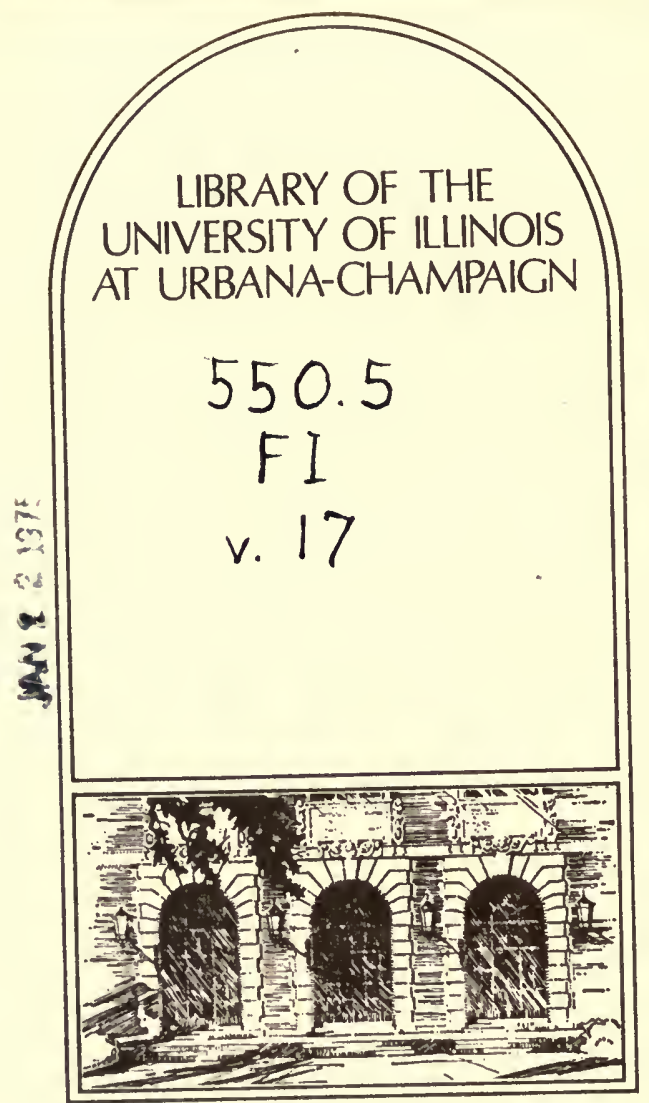

Dersuthy

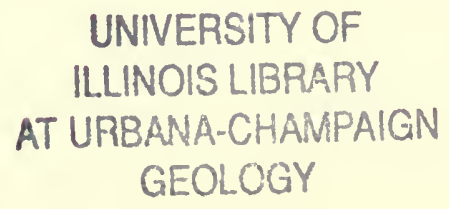






10. 3

\title{
THE FAMILY CASEIDAE
}

\author{
EVERETT C. OLSON
}

FIELDIANA: GEOLOGY VOLUME 17, NUMBER 3

Published by

FIELD MUSEUM OF NATURAL HISTORY

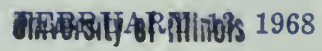

\section{JUL 111968}







\title{
THE FAMILY CASEIDAE
}

\author{
EVERETT C. OLSON
}

Professor, Department of Geophysical Sciences, University of Chicago

Research Associate, Fossil Vertebrates, Field Museum of Natural History

\section{FIELDIANA： GEOLOGY}

VOLUME 17, NUMBER 3

Published by

FIELD MUSEUM OF NATURAL HISTORY

FEBRUARY 13, 1968 


\section{Edited by EDWARD G. NASH \\ Patricia M. Williams}

Library of Congress Catalog Card Number: 67-31601

PRINTED IN THE UNITED STATES OF AMERICA BY FIELD MUSEUM PRESS 


\section{INTRODUCTION}

The family Caseidae is composed of a closely related group of pelycosaurian reptiles known at the present time from the Leonardian and Guadalupian of the Permian of Texas and Oklahoma and the Kazanian of the U.S.S.R. Except for a striking diversity in size, all genera and species conform to a common pattern. This was already established in the first known and oldest species, Casea broilii, and is expressed with relatively little modification in all the others.

The total length of adult individuals varied in the different genera and species from about 4 to 20 feet. In all the head size was very small, as compared with general body dimensions, and the trunk was long, massive and barrel-shaped. All of the caseids appear to have been primarily terrestrial, herbivorous animals. The family is, as far as I know, the first among the tetrapods to accomplish an extensive terrestrial radiation of large, plant-eating animals.

The history of the group has been reviewed recently by the writer (Olson, 1962) and by Stovall, Price and Romer (1966). Only a brief summary is included here. Much of the story of discovery and description is summarized in Table 1. The stratigraphic and geographic positions of the genera and species are given in this table and illustrated graphically in Figure 1. Most of the discoveries of members of the family have been made since 1951. This has resulted from explorations of beds of post-Arroyo age in Texas and Oklahoma and from the find of a single locality on the Pinega River near Karpoga in the U.S.S.R.

After the first discovery of caseid specimens by Miller and the initial descriptions by Williston in 1910 no other definitive assignments of genera or species to the Caseidae were made until 1937. Trichasaurus texensis (Williston, 1913a,) was described in 1910 as Trispondylous texensis Williston and was thereafter tentatively assigned to the caseids in various classifications. Cotylorhynchus romeri Stovall (Stovall, 1937) was the first new caseid to be discovered. It came from the Hennessey formation of Oklahoma. Romer and Price (1940) gave a rather brief description of the genus and species. Much came to be known of this genus among the students of Permian 
TABLE 1.-List of the dates of publication of first descriptions of the genera and species of caseids including the holotypes, the geological age and the locality of the holotype.

1910-Casea broilii Williston (Williston, 1910b). Holotype FMNH UC 656 Arroyo-Vale Boundary, Clear Fork Group Leonardian, Baylor County, Texas.

1910 - Trispondylus texensis Williston $(1910 \mathrm{~b})$, Trichasaurus tenensis (Williston, 1913). Holotype FMNH UC 652, Coffee Creek, Arroyo formation, Clear Fork Group Leonardian, Baylor County, Texas.

1937-Cotylorhynchus romeri Stovall (1937), Holotype UOSM 4-0-S1, Hennessey formation, Enid group, Leonardian, Logan County, Oklahoma.

1953-Cotylorhynchus hancocki Olson and Beerbower (1953). Holotype, FMNH UR 154, San Angelo formation, Pease River Group, Guadalupian, Hardeman County, Texas.

1953-Angelosaurus dolani Olson and Beerbower (1953). Holotype FMNH UR 194, San Angelo formation, Pease River Group, Guadalupian, Knox County, Texas.

1953-Caseoides sanangelensis Olson and Beerbower (1953). Holotype FMNH UR 151, San Angelo formation, Pease River Group, Guadalupian, Knox County, Texas.

1954-Casea nicholsi Olson (1954). Holotype FMNH UR 86, Upper Vale formation, Clear Fork Group, Leonardian, Knox County, Texas.

1954-Casea halselli Olson (1954). Holotype FMNH UR 117, Choza formation, Clear Fork Group, Leonardian, Foard County, Texas.

1954-Phreatophasma aenigmaticum Efremov (1954), assigned to Caseidae by Olson (1965). Holotype PIN 294/24, Bashkirian (Zone I), Kazanian, Santagulov mine, Bashkir Province, U.S.S.R.

1956-Ennatosaurus tecton Efremov (1956). Holotype PIN 1580/17 (designated in this paper, p. 301, Zone II, Kazanian, Pinego River, near Karpoga, U.S.S.R.

1962-Caseopsis agillis Olson (1962). Holotype FMNH UR 253. San Angelo formation, Pease River Group, Guadalupian, Knox County, Texas.

1962-Caseopsis ef. agilis Olson (1962). Holotype FMNH UR 255, Flowerpot formation, Pease River Group, Guadalupian, Knox County, Texas.

1962-Angelosaurus greeni Olson (1962). Holotype FMNH UR 257, Flowerpot formation, Pease River Group, Guadalupian, Knox County, Texas.

1962-Cotylorhynchus bransoni Olson and Barghusen (1962). Holotype FMNH UR 835, Tongue of Chickasha formation in middle Flowerpot formation, El Reno Group, Guadalupian, Kingfisher County, Oklahoma.

1962-Angelosaurus romeri Olson and Barghusen (1962). Holotype FMNH UR 827. Tongue of Chickasha formation in middle of Flowerpot formation, El Reno Group, Guadalupian, Kingfisher County, Oklahoma.

vertebrates but very little additional was published until the recent paper of Stovall, Price and Romer (1966). Exploration of the middle and upper Clear Fork beds in Texas, the San Angelo and Flowerpot formations of this state and the Chickasha formation of Oklahoma yielded many new caseids. These were summarized, as then known, by the writer in 1962 (Olson, 1962). At this time, also, a more complete description of the Russian genus Ennatosaurus was given, augmenting the brief description by Efremov (1956). Phreatophasma aenigmaticum Efremov from the lower Kazanian of the Soviet Union was referred to the Caseidae in this paper. In the same year, Olson and Barghusen (1962) described new materials representing a new species of Cotylorhynchus and of Angelosaurus from the Chickasha 


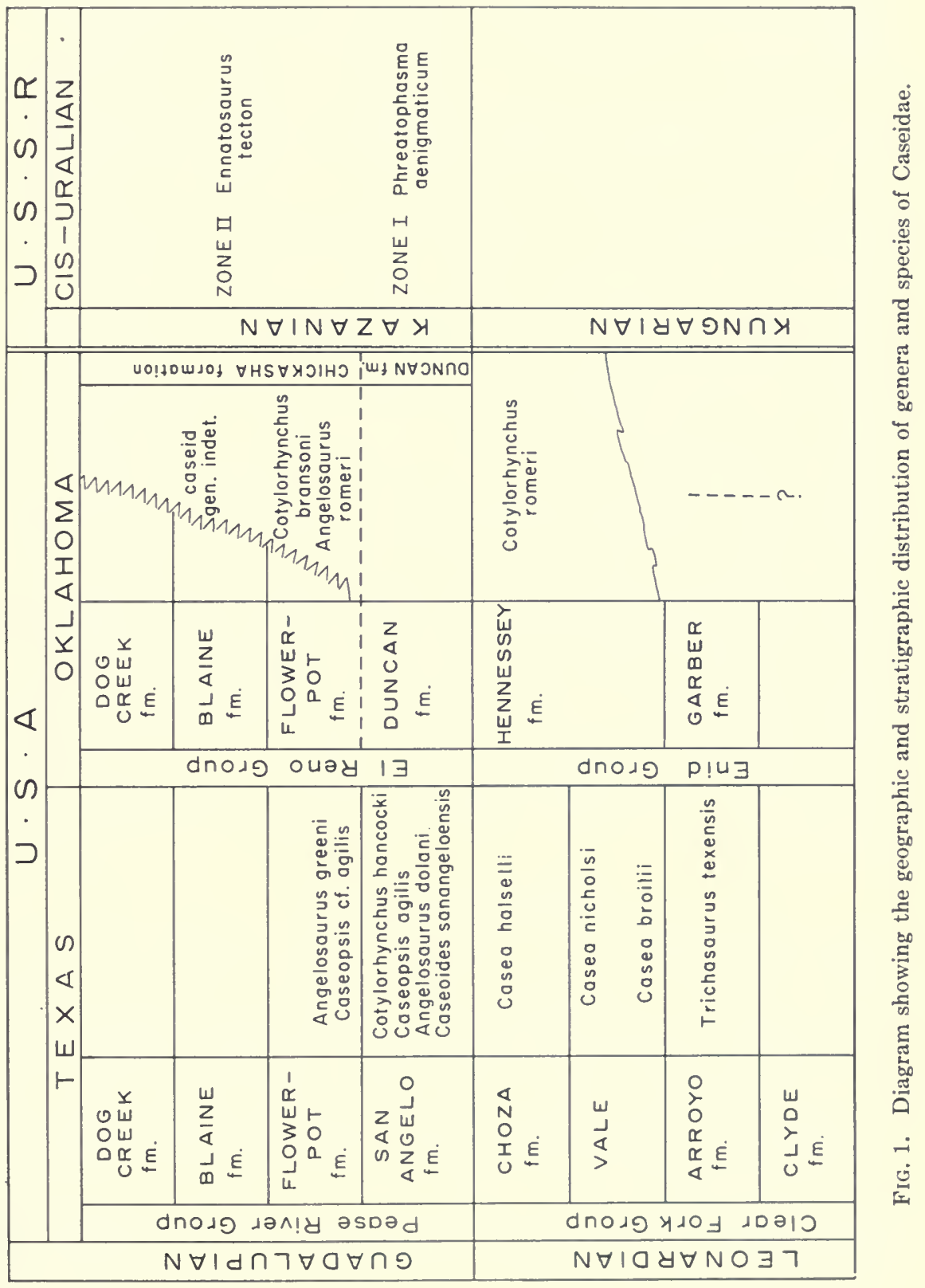


formation of Oklahoma. The paper by Stovall, Price and Romer (1966) included a full description of the postcranium of Cotylorhynchus romeri.

The work that led to the current study has involved many persons other than the writer. Field assistants in its most recent phases were Ted Cavendar, Matthew Nitecki and George Olson. The field studies in Texas have been undertaken with permission of the Texas Memorial Museum and the Bureau of Economic Geology on the campus of the University of Texas. Field studies and collecting in Oklahoma have been with the permission and aid of the Oklahoma Geological Survey under the direction of Carl Branson. Many members of the survey staff have been most helpful and the aid of Robert Fay in many aspects of the study has been critical. Permission to study the materials of Ennatosaurus tecton in the Paleontological Museum in Moscow was graciously granted by Professor Yuri Orlov, Director of the Paleontological Institute, and Professor Constantine Flerov, Director of the Museum. Dr. Peter Chudinov gave me much of his time and invaluable assistance during my studies, in particular during the spring of 1964. Many members of the Paleontological Institute helped in one way or another, and a particular acknowledgement goes to the staff preparators who stopped their other work in order to prepare the materials of Ennatosaurus for my use. Most of the drawings were made by Eleanor Daly.

The study was generously supported by NSF grants B19093 and B2453.

\section{Museum Designations}

AMNH-American Museum of Natural History, New York, N. Y.

FMNH-Field Museum of Natural History: PR, paleontology reptiles, for specimens not from University of Chicago collections; UC, specimens from University of Chicago collections, prior to transfer to FMNH; UR, specimens from University of Chicago collections, numbered after transfer. These designations are used alone, without FMNH.

MCZ-Museum of Comparative Zoology, Harvard University, Cambridge, Mass.

OUSM-University of Oklahoma, Stovall Museum. Numbers of form N-O-SN used alone, as are museum numbers. 
PIN-Paleontological Institute, Academy of Sciences, Moscow U.S.S.R. Mostly $1580 / \mathrm{N}$, indicating Pinega site. This designation used alone, without PIN.

USNM-United States National Museum, Washington, D. C. 


\section{GENERAL MORPHOLOGY}

Members of the family Caseidae show a remarkably constant structure throughout the several genera and species. This represents a well-defined adaptive pattern which was introduced in the primitive members and perfected in more advanced descendants. There appear to be several variants of the basic pattern, represented by Casea-Caseoides, Caseopsis, Cotylorhynchus and Angelosaurus. Ennatosaurus, which has a proportionately small postcranial skeleton, poses a problem in assignment to any one of these lines. It seems to fall closest to the Angelosaurus habitus on the basis of dental morphology, but to be Casea-like in many features of the posteranium. Cranial characteristics had been in large part developed by the time the first known species appeared in the record, being well displayed in Casea broilii. Dental modifications were somewhat more extensive âuring the evolution within the family, although here, too, there is notable constancy, principal variations being in numbers of marginal teeth, the degree of development of cuspules, and modifications in the palatal patterns. In the case of the posteranium, however, and particularly in limb structure, Casea broilii displays in many details only incipient indications of what was to become the fully developed caseid morphology.

\section{The Skull}

\section{(Plates 2, 4, 5; Figures 2-8)}

The skull in all genera and species of the family Caseidae in which it is known conforms closely to a general and unique pattern. Marked differences in size and detailed differences in morphology occur, but the resemblances are for the most part so pervasive that a general description fits all circumstances reasonably well.

The head is small with respect to body size. In general, there is a rough correlation of head size and body size, expressed in some such measure as all over length. The largest skull (fig. 2) is that of Cotylorhynchus hancocki, the giant of the group, and the smallest that of the earliest and smallest member Casea broilii. A striking exception to the general correspondence of head and body size is found in Enna- 

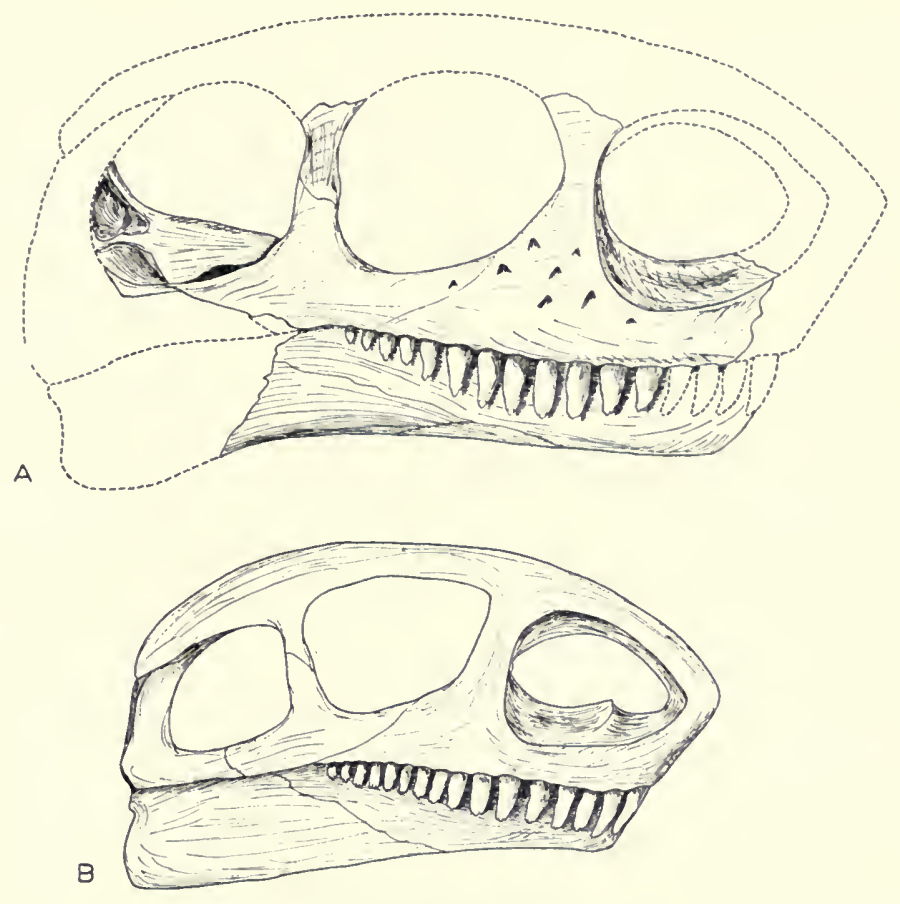

C

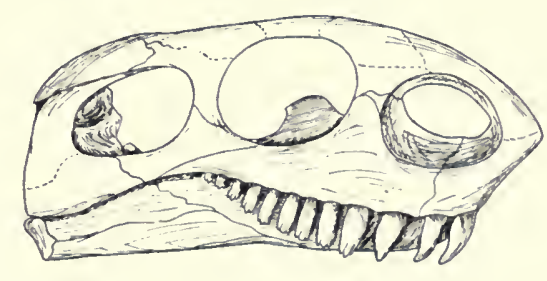

Fig. 2. Reconstructions of lateral views of skulls and jaws of A, Cotylorhynchus hancocki $(\times 1 / 3) ; \mathrm{B}$, Cotylorhynchus romeri $(\times 1 / 3) ; \mathrm{C}$, Casea broilii $(\times 2 / 3)$.

tosaurus tecton from the Russian Permian. The skull is large, only slightly smaller than that of Cotylorhynchus hancocki, but the body is only about one-third the size of that of Cotylorhynchus hancocki in most linear measurements.

The caseid skull is broad and moderately deep in comparison to length. It has been called low (Romer and Price, 1940) but this applies mainly in comparisons to the rather high and narrow skulls of some ophiacodonts and sphenacodonts. The articulation of the jaws lies below the level of the tooth row. The dorsal surface is marked by a rugose pattern which passes onto the sides, especially in 
the area back of the temporal fenestra. The muzzle extends forward into a strong, pointed rostrum, from which the premaxilla slopes postero-ventrally to the dental margin.

The external nares form the most clearly diagnostic single feature of the skull. Each of the pair is large and roughly oval, occupying much of the facial region. Separated from the naris by a rather narrow bar is the large, oval to subquadrate orbit. This in turn is separated from a quadrilateral temporal fenestra by a thin postorbital bar. The temporal fenestra is flanked dorsally by the postorbital and squamosal, in typical pelycosaur fashion. The parietal, or pineal, foramen is very large. It is oval in shape with its long axis normal to the longitudinal axis of the skull. The foramen is completely surrounded by the parietal bone and lies fairly well forward on the dorsal platform, midway between the temporal fenestrae.

The pattern of the dermal bones (figs. 2 and 3 ) is very stable, with differences being confined to proportions. There are resemblances to edaphosaurids, emphasized by the similar shapes of the skulls. The major differences between the two are to be found in the frontals and postfrontals which are much more extensive in edaphosaurids and participate in the formation of a projection of the interorbital region above the orbits. The participation of the frontal in the orbital margin is restricted in caseids but extensive in edaphosaurids. There are also pronounced differences in the facial region, related for the most part to the very large narial openings of caseids. Otherwise the principal differences are found in the occiput, where a broad paroccipital process, a dorso-medially placed post-temporal fossa and a narrow supraoccipital are characteristic of the caseids.

The patterns of the dermal elements of the skull contrast more sharply with those of the sphenacodonts and the majority of ophiacodonts. The differences are, however, largely proportional, associated with adaptations to different modes of life, particularly those related to feeding habits. The most constant differences are found in the parietal regions, where the broad, deep caseid parietal contrasts sharply with that found in other groups, and in the facial region and snout, where the short elements of the caseids are in strong contrast to the elongated bones of most sphenacodonts and ophiacodonts. The shortness of the face is approached to some extent in the varanopsids, but in these the posterior part of the skull is very different, as it is elongated, and the shortening of the face is not related to a reduction in the length of tooth row. Colybomycter, Glaucosaurus 
and Eothyris, usually classed among the edaphosaurians, are examples of other rather short-faced pelycosaurs.

Sutures are obscure in some of the genera and species, so that some question of the constancy of dermal patterns must remain. In cases in which bone limits and relationships have been determined close conformity to a single pattern has been found.

\section{The Dermal Surface (Figures 2 and 3)}

The premaxilla and maxilla are both strongly developed as the hosts of well-developed, marginal teeth. The premaxilla makes up much of the prominent rostrum, carries the two anteriormost teeth and passes into the large narial opening to form the anterior part of its floor. The maxilla completes the floor of the naris and, along with the septomaxilla, forms about one-third of the postnarial-preorbital bar and part of the base of the orbit. It passes posteriorly, narrowing, to terminate just back of the level of the posterior margin of the postorbital bar. It carries the remaining teeth of the marginal series. Beneath the preorbital bar and orbit, the surface of maxilla is slightly to strongly pitted by openings that pass into the bone and appear to have carried either blood vessels or nerves, or possibly both. It would appear that these served in part to supply the facial region.

Neither the premaxilla nor maxilla plays a prominent role in the formation of the palate. The former carries back vertically a short distance as an incisiform process and the latter forms the lateral margin of the internal naris. A septomaxilla is known in Ennatosaurus and in Casea broilii. Presumably it was present in others but was lost during preservation. The bone forms a rather large plate, as shown in Figure 3. It is a somewhat dual structure. The basal part is continuous with the maxilla and makes contact anteriorly with the premaxilla by means of a suture. Above it, continuous with the basal part, is an alar portion.

The anterior opening of the naris passes between the premaxilla and nasal and is flanked posteriorly by the anterior margin of the septomaxilla. Beneath the passage thus created is a notch, possibly the exit of Jacobson's organ (see Romer and Price, 1940). The dorsoanterior part of the septomaxilla appears to rest in a notch in the nasal bone. The dorsal portion consists of the wing mentioned above and this passes back, below a foramen-like notch, to form two processes that pass into the naris deep within the nasal cavity. These processes do not seem to make contact with the nasal bone. The upper, or alar portion, is somewhat cupped laterally and seems to 
have cradled a soft structure. The dorsal, foramen-like notch may have been the opening for passages of a nerve or blood vessel either to or from this soft structure. What the structure was is not determinable from the information at hand.

The ventral part of the septomaxilla is the larger of the two portions. Its anterior part, just above the premaxillary suture, carries the notch noted earlier. The surface of this portion forms a smooth continuation of the maxilla within the nasal opening. On its posterior margin there is a short process that passes posteriorly into the large, posterior nasal opening. It partially divides this opening into a large upper and small lower portion. The lower part corresponds, it would seem, to the septomaxillary foramen described in Dimetrodon by Romer and Price (1940). The larger upper opening appears to find a counterpart in the much smaller orifice of Dimetrodon.

There can be little doubt that the very large naris and large, intricate septomaxillary bone had special functional significance. Just what this may have been is quite a different matter. Romer and Price (1940) have suggested the possibility of different incurrent and excurrent air passages. The nasal capsule of Ennatosaurus is not well enough preserved to give any additional evidence on this interpretation. In Casea broilii, however (see fig. 6), the internal narial fenestra does show some evidence of a narrow lateral channel, seemingly leading to the anterior aperture, and a much larger, poorly differentiated medial portion. This is suggestive, but far from definitive.

The nasal, lacrimal and prefrontal bones complete the outline of the external narial opening. The two genera which have well-developed sutures in this region, Ennatosaurus and Cotylorhynchus, are structurally different. The prefrontal of Ennatosaurus forms a part of the narial rim, whereas in Cotylorhynchus it seems to be excluded by a junction of the lacrimal and nasal just beyond the rim. The lacrimal is consistently a small bone. It forms a part of the bar between the orbit and naris and, together with an ascending process of the maxilla, flanks a deep, medial trough that passes down to the vicinity of the internal naris. Presumably this carried a large lacrimal duct, but the entry into the trough-like passage has not been identified.

The nasals and the prefrontals are large bones. The nasals are short, broad, and meet for a brief distance in a medial suture. Frontals are relatively narrow, but send lateral processes between the pre- and postfrontals to make contact with the orbital margins. Postfrontals are small and generally hard to differentiate from adjacent bones. 

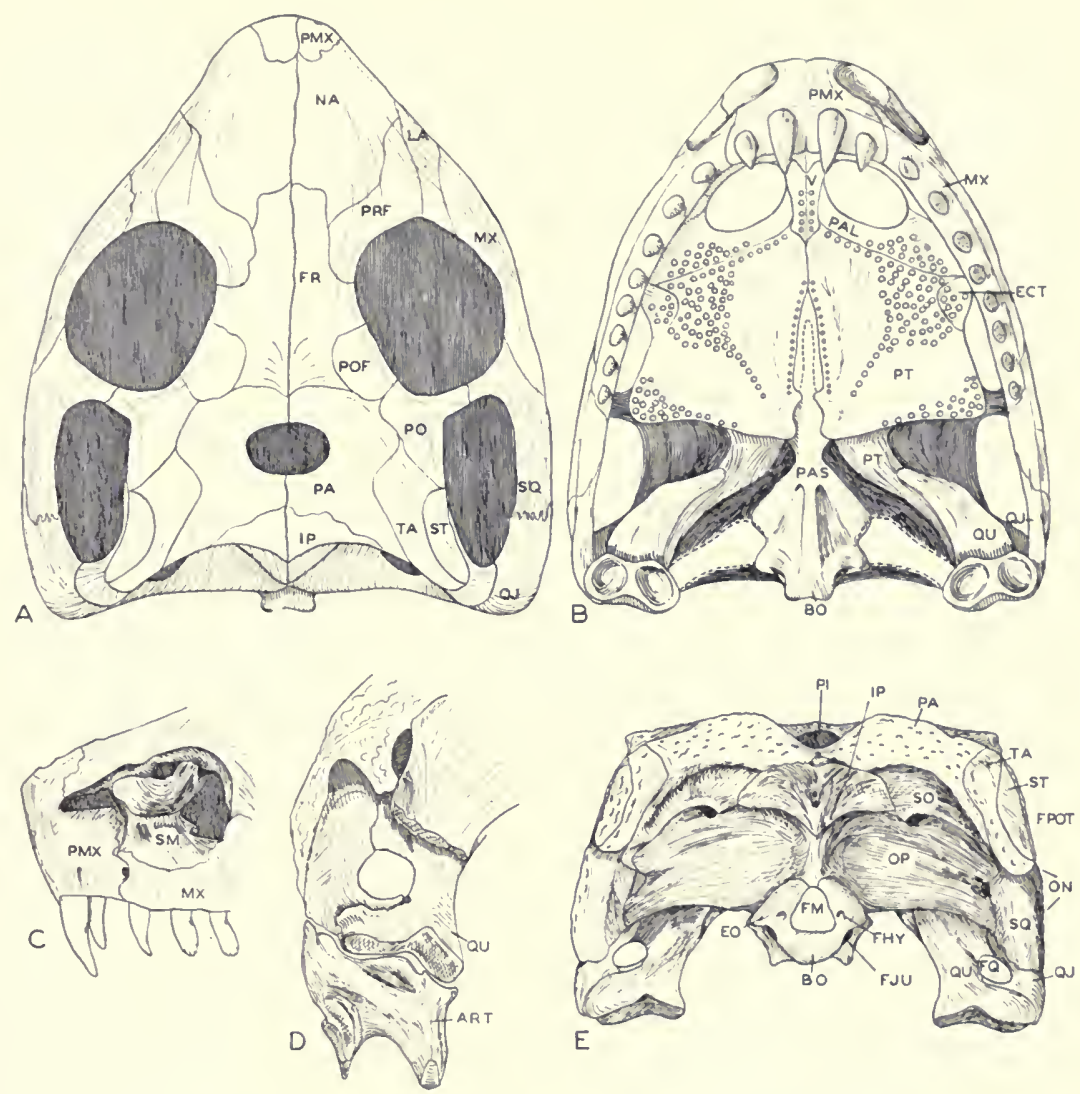

FIG. 3. Ennatosaurus tecton, composite with sutures mainly from 1580/24. A, Skull in dorsal aspect; B, Skull in palatal aspect, based on $1580 / 14,17,19,24$, 122; C, Part of snout, 1580/17; D, Quadrate region showing otic notch, based on $1580 / 14$; E, Occipital view, based on $1580 / 14,17,19,24$. All approximately $\times 1 / 3$. Abbreviations: The abbreviations listed here apply to all Figures 2 through 23. ANG, angular; ART, articular; BO, basioccipital; BPT, basipterygoid process; $\mathrm{BS}$, basisphenoid; CA, canal leading through proötic to sinus below; CAN, anterior coronoid; CP, posterior coronoid; D, dentary; ECT, ectopterygoid; EO, exoccipital; EPT, epipterygoid; FHY, hypoglossal foramen; FJU, jugular foramen; FM, foramen magnum; FPOT, posttemporal foramen; FQ, quadrate foramen; FR, frontal; INA, internal naris; INS, internasal septum; IOS, interorbital septum; IP, interparietal; LA, lacrimal; LJ, lower jaw; MX, maxilla; NA, nasal; OC, occipital concyle; ON, otic notch; OP, opisthotic; PA, parietal; PAL, palatine; PAS, parasphenoid; PI, pineal opening; PMX, premaxilla; PO, postorbital; POF, postfrontal; PRF, prefrontal; PRI, proötic incisure; PRO, prootic bone; PT, pterygoid; QJ, quadratojugal; QU, quadrate; SANG, surangular; SCAN, sinus canal; SET, sella turcica; SIN, sinus in proötic and opisthotic marginal to the braincase; SM, septomaxilla; SO, supraoccipital; SPE, sphenethmoid; SPL, splenial; SQ, squamosal; ST, supratemporal; STA, stapes; TA, tabular; V, vomer. 
They are best known in Ennatosaurus. They may have been somewhat larger in Casea and Cotylorhynchus, but the sutures separating them from adjacent elements are obscure.

The main portion of the posterior platform is formed by the broad parietal bone. This carries a very large parietal or pineal opening. In some species small interparietals can be differentiated partly on the parietal platforms and partly lapping over onto the dorsal part of the occiput.

The temporal region of the caseids is distinctive, but comparable in general structure to that of Edaphosaurus. Lateral to the parietal is a large tabular which is flanked by a supratemporal. The latter lies on the margin of the posterodorsal rim of the large, quadrilateral temporal fenestra. It makes sutural junction with the squamosal, but projects beyond it posteriorly to form a distinct notch. The notch appears in all genera and species in which this region of the skull is known. It is only slightly evident in lateral view, but is clearly shown in posterior and posterolateral aspects (see plate 5, figure 3).

The outer surface of the squamosal is rugose, indicating the presence of an immediate covering of skin, but at the rim of the notch and on the inflected portions and inner surface, the rugosity is missing. Anterodorsally the squamosal passes along the dorsal rim of the temporal fenestra to lie under the postorbital with which it makes sutural contact. From above, the squamosal is not seen as a part of the rim of the temporal fenestra. Completing the margin of the fenestra is a large quadratojugal and a jugal, which forms a part of the postorbital bar.

\section{Palate and Quadrate Regions}

The palatoquadrate complex is well known in Casea broilii, Cotylorhynchus romeri and Ennatosaurus tecton (figs. 3, 5). In addition, some information regarding this complex is available for Cotylorhynchus bransoni and Angelosaurus romeri. Throughout this series the general structure is much the same, with some variation in proportions and wide variation in the distribution of teeth on the dermal elements.

The quadrate bone is large, consisting of a strong ascending plate and a nearly horizontal articular portion composed of a well-developed double articular surface to accommodate the articular of the lower jaw. Laterally, it is joined suturally to the quadratojugal. In Ennatosaurus tecton the quadratojugal-quadrate foramen is very large 

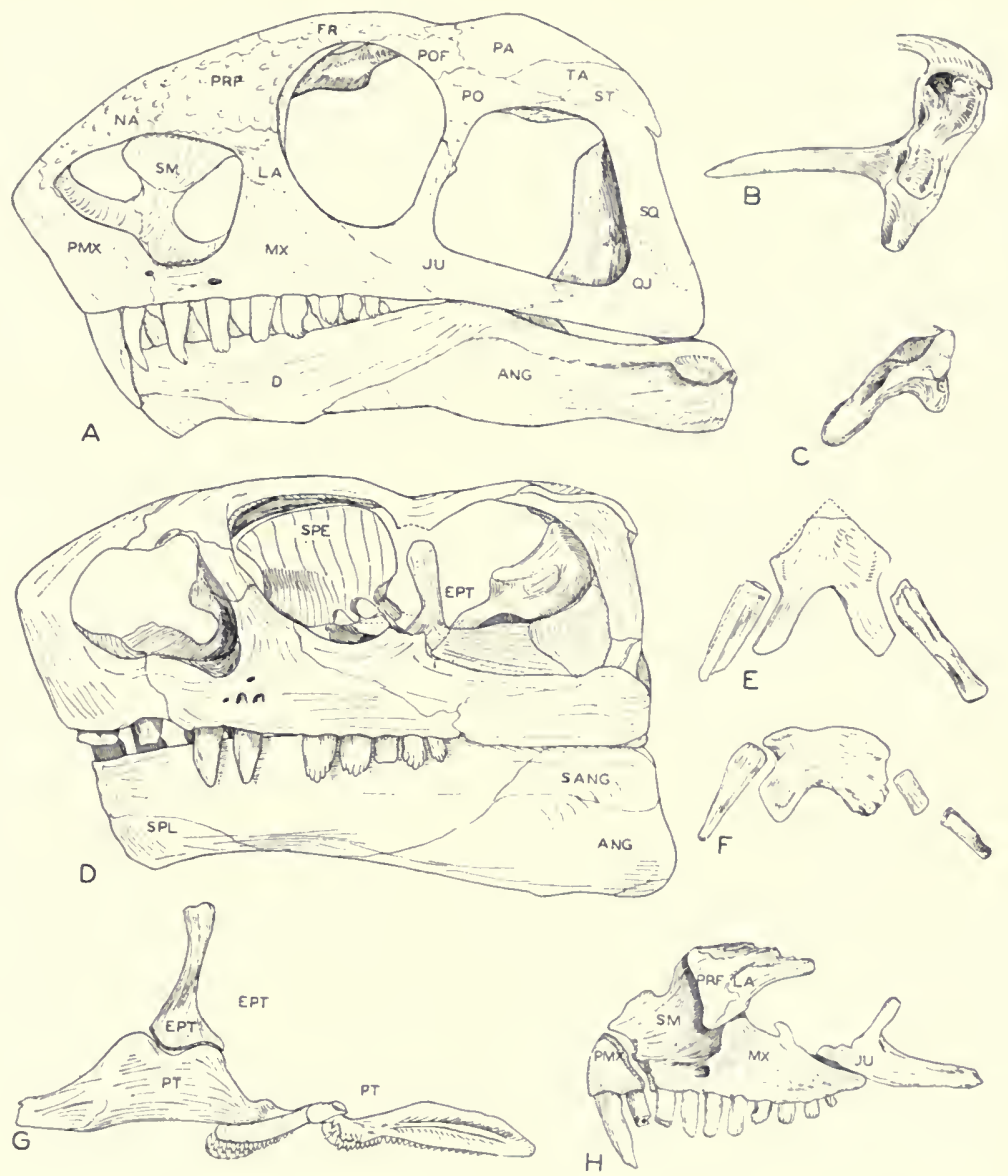

FIG. 4. Ennatosaurus tecton. A, Skull in lateral view, 1580/17, holotype, slightly reconstructed; $\mathrm{B}$, Articular bone, dorsal aspect showing articular surface and strong process for pterygoid musculature, 1580/16; C, Articular bone, posterior; D, Skull of $1580 / 14$ somewhat reconstructed to show braincase structures; $\mathrm{E}$ and $\mathrm{F}$, Hyoid elements from $1580 / 19$ and 14 respectively; G, Pterygoid and epipterygoid in lateral aspect, reconstructed from $1580 / 122 ; \mathrm{H}$, Snout of small individual, $1580 / 122$. A, D, E, F, H, X 1/3; B, C, G, X 1/2. Ábbreviations as in Figure 3.

(fig. 3). Whether this is typical, of the family or not, cannot be determined from the specimens now available.

The quadrate ramus of the pterygoid is strongly joined to quadrate along the medial margin of the latter. At its anterior end the quadrate ramus swings sharply ventrally to meet the plate-like main body of the pterygoid, joining it somewhat in advance of the ventral tip of the descending transverse flange. 
Medial to this junction the pterygoid articulates in a movable joint with the basipterygoid process of the basisphenoid. The dorsal part of this articulation probably is formed by the epipterygoid, but in no specimen has the separation in the area of the joint been observed. The main plate of the pterygoid is very broad. The pair of plates encloses a narrow interpterygoidal vacuity, anterior to which there is a short suture joining the two sides. In Ennatosaurus, and presumably in the other caseids in which it has not been identified, there is a small ectopterygoid or transverse bone at the anterolateral corner of the pterygoid.

The pterygoid plates are variously covered with teeth in patterns that are to some extent at least generically distinct. The patterns are shown in Figures 3, 5, 7 and 8 for Ennatosaurus, Casea broilii, Angelosaurus romeri and Cotylorhynchus bransoni, respectively. Plate 19 of Romer and Price (1940) shows a condition in Cotylorhynchus romeri very similar to that of $C$. bransoni. The almost complete coverage of the palate by a shagreen of small teeth, found in Casea broilii, may be primitive, inasmuch as this is the earliest known species and one that has many primitive features. The pattern, however, is less like that of various primitive pelycosaurs than are the the patterns found in Cotylorhynchus and Angelosaurus. The pterygoid plates in Casea broilii are covered ventrally with a fairly evenly distributed array of teeth that form a shagreen. In other genera the teeth are somewhat more restricted, being arrayed to some extent in rows. The patterns in Cotylorhynchus and Angelosaurus are somewhat similar, but the teeth in the latter are stronger and more robust.

The pterygoids of Casea broilii show a curious feature, one not found as yet in any other genus. Running diagonally across the posterior part of the ventral surface of the plate is a deep, toothless groove. It passes from the lateral margin about midway along its longitudinal extent to the posterior margin of the plate, just posterolateral to the articulation of the pterygoid and the basisphenoid. At the lateroanterior position this groove swings forward to run along the margin of the ectopterygoid and palatine and to enter the internal narial opening along its posterior rim.

One logical interpretation of this structure is that it is connected with the respiratory system. Possibly it represents an unusual means of passage of air from the internal naris to the throat in the course of respiration. If this is the case, the Casea had acquired a functional equivalent of a secondary palate. 
This structure has not been identified in Cotylorhynchus, Ennatosaurus or Angelosaurus. Preservation of this region is good enough in each that had this structure been present and impressed on the bone as in Casea its presence should be evident.

The palatine bone is a relatively small element suturally joined to the pterygoid posteriorly and forming the posterior and medial margins of the large internal naris. It is flanked medially by a very small vomer which sends a slender process laterally along the anterior margin of the internal naris. Both the palatine and the vomer carry teeth, variously disposed in the different genera.

The parasphenoid is a prominent bone of the palate. Posteriorly it is indistinguishable from the basisphenoid and its limits cannot be determined. More anteriorly, but posterior to the level of the basipterygoid process, the parasphenoid develops a pair of descending processes, one on each side of the median line. These are wing-like in Cotylorhynchus romeri, C. bransoni and Angelosaurus romeri. Development is only incipient in Casea broilii and the wings are not strong in Ennatosaurus.

In Casea, the descending processes form tooth-bearing tubera. Two roughly distinguishable areas of small teeth carry forward from the tubera along the ramus in two single rows and reach all the way to the anterior end of the parasphenoid. Cotylorhynchus and Angelosaurus have paired rows of teeth on the parasphenoid. To date, they have been identified in $A$. romeri and in all species of Cotylorhynchus. The condition of $A$. dolani and $A$. greeni is indeterminate. No evidence of such teeth has been found in Ennatosaurus tecton. It is possible that further examination of the specimens, with the condition of Cotylorhynchus and Angelosaurus in mind, might turn up evidence of their presence.

\section{Occiput (Figure 3).}

Romer and Price (1940) described the occiput as an area that was distinctive of the caseids, even as compared with the rather similar edaphosaurids. This was based on two genera, Casea and Cotylorhynchus. The characteristics that they noted occur throughout the family. The occiput is broad and flat and slopes gently backward from its dorsal margin. Part of the dorsal margin is formed by the postparietal, but as a rule this element is fused to the supraoccipital and the limits of the two cannot be determined. Intervening sutures between are found in Casea broilii. The supraoccipital is relatively small and quite restricted laterally. Near its dorsolateral tip is the 
large post-temporal foramen. As described in more detail below, this leads forward to a depression on the lateral margin of the periotic. The paroccipital process of the opisthotic portion of the periotic is broad and passes laterally to the squamosal in the area below the overhanging tabular and supratemporal that make up the "otic" notch. Dorsally it makes contact with the tabular.

The foramen magnum is more or less triangular, but flares somewhat dorsally in relationship to what appears to be the exit of some of the venous drainage of the head (see below). The exoccipitals nearly, but not completely, close over the dorsal margin. Each carries a facet for articulation of the arch of the first vertebra. There is a well-developed jugular foramen in Casea broilii between the exoccipital and opisthotic. In other caseids this structure is either not identifiable or is a very small opening. It appears that at most it can have accommodated the Xth cranial nerve and that the venus drainage left through other channels. The peculiar nature of this drainage in the caseids is described in the next section.

\section{BRaincase AND BASICRANIUM (Figures 5, 6, 7, 8)}

As in all pelycosaurs, the braincase is formed in large part by the otic bones and the sphenethmoid. The opisthotic and proötic are apparently always fused, so may be designated as the periotic. In caseids the otic portion of the braincase tends to be large relative to the overall dimensions of the skull. In some respects the general structure is typically pelycosaurian but in others there are marked differences. There are, as well, rather important differences between the genera within the family.

The floor of the braincase is formed by the short basioccipital and basisphenoid. The condyle is turned sharply downward so that its articular surface makes an angle of 30 to 40 degrees with the plane of the basicranial axis. The skull appears to have been carried with the plane of the palate and basicranium deflected rather sharply from the horizontal plane of the cervical vertebrae. The basioccipital passes without suture into the basisphenoid and this in turn cannot be differentiated from the parasphenoid where the two are in contact. The basisphenoid carries a well-formed basipterygoid process. This lies well forward and the floor of the braincase is quite long posterior to it.

The relationship of the basipterygoid processes to the cultriform process differs markedly in the different genera. In Casea, Cotylorhynchus and Ennatosaurus the cultriform process passes well forward 

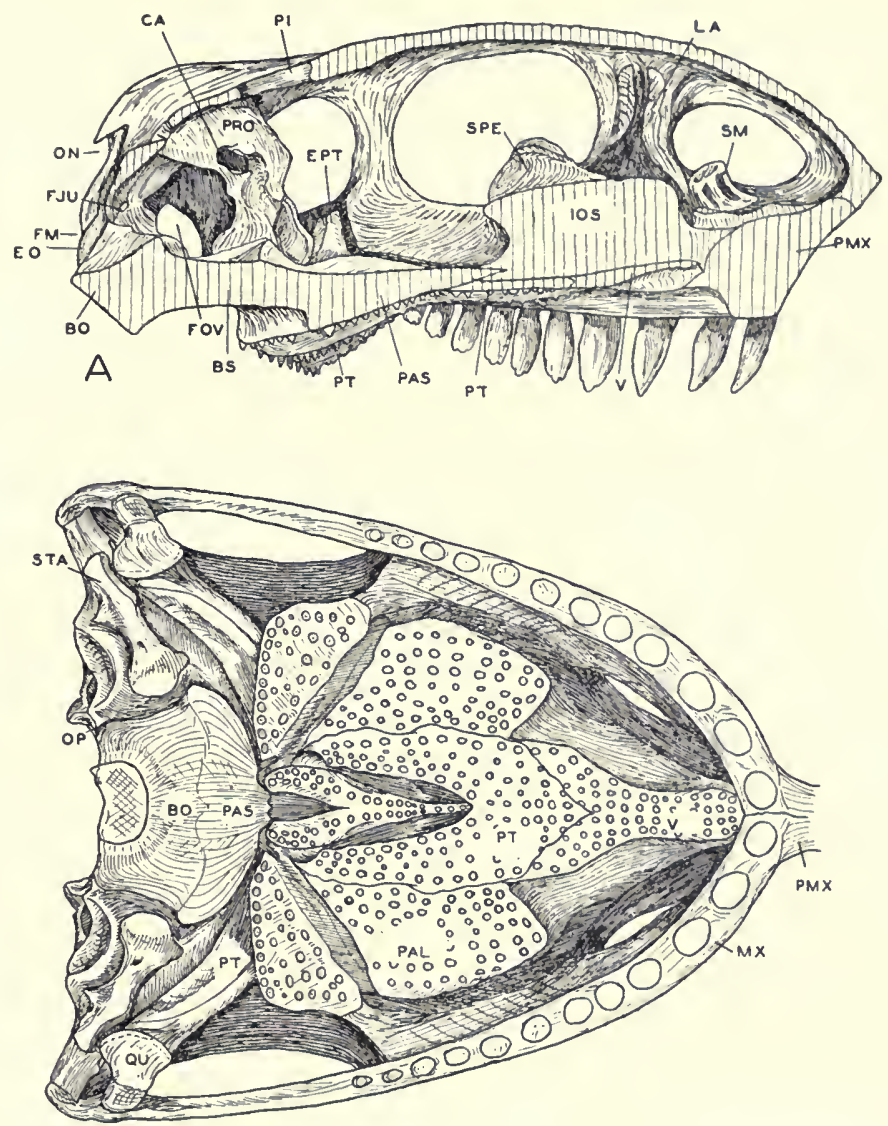

B

Fig. 5. Casea broilii. Reconstructions of skull. A, Sagittal section; B, Palatal view. Based on all known specimens. B, based mostly on UC 698 and UR 1011. Both approximately $\times 3$. Abbreviations as in Figure 3 .

of the basipterygoid articulation, but in Angelosaurus it is short and ends in a whorl of teeth.

The otic portion of the braincase is open and even the recess of the inner ear is but little removed from the rest. The inner end of the large fenestra ovalis opens freely into a very poorly defined saccular and utricular recess. This confluence of the recesses and the area of the braincase proper is not a function of lack of ossification, but a character of the family. It is least well expressed in Casea. In this genus it appears that there was a cartilaginous labyrinth, separated from the braincase. In Angelosaurus romeri and Cotylorhynchus han- 
cocki, for which there are well-preserved braincases, there is no evidence that the semicircular canals were encased in hard tissue, even though ossification seems to have been well advanced. It would appear that the labyrinth had no cartilaginous or osseous housing, but
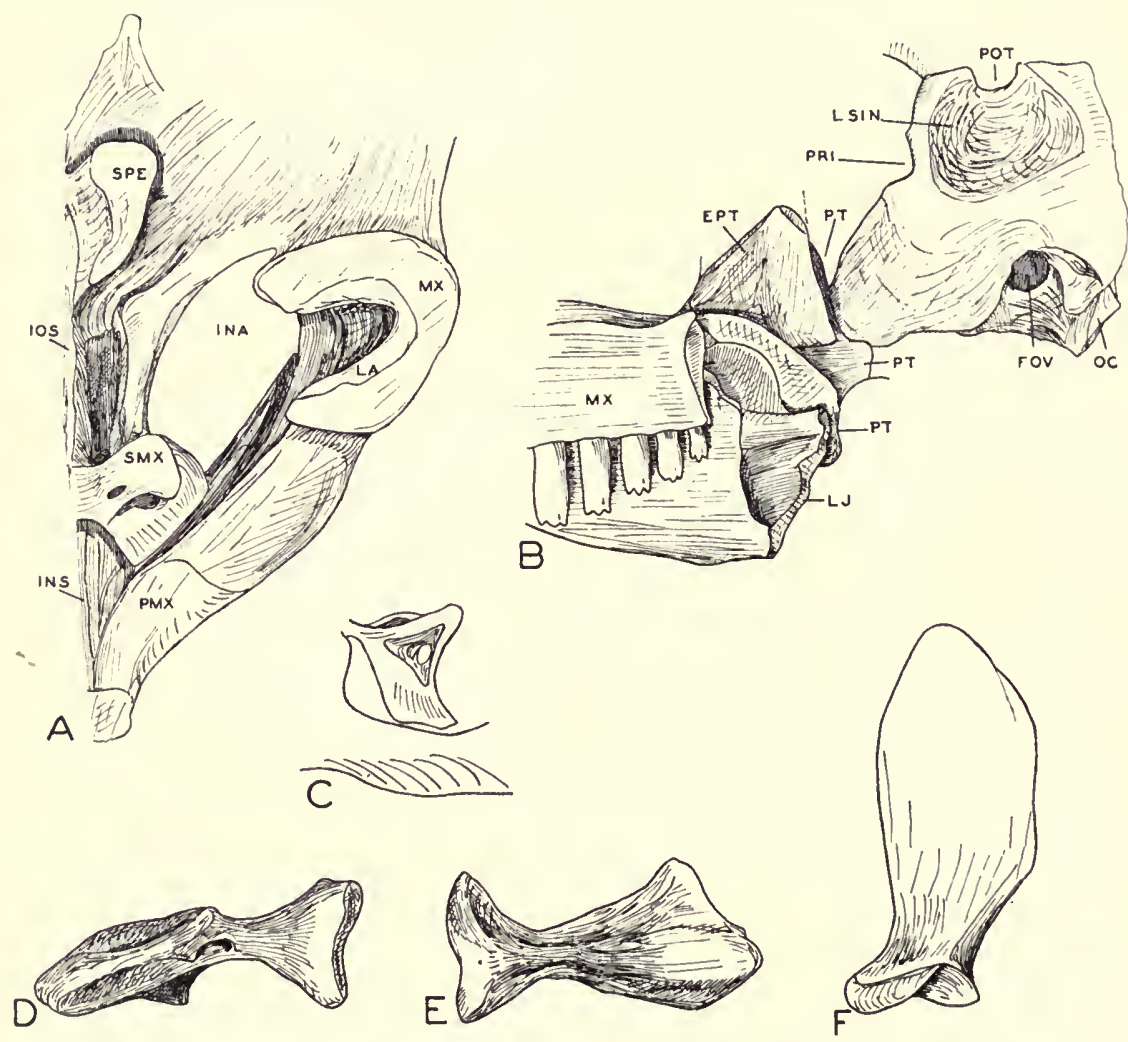

Fig. 6. Casea broilii. A, Narial region from above, $\times 2$; B, Lateral view of part of braincase, skull margin and lower jaw, $\times 1 \frac{1}{2} ; \mathrm{C}$, Wing of septomaxilla from the front, $\times 2$; D, right stapes, ventral; $E$, Left stapes, posterior, both from UC 698, $\times 2$. F, Quadrate, posterior. Abbreviations as in Figure 3.

lay in soft tissue in close association with the braincase. If this is a proper interpretation, the circumstances are quite unlike those in other pelycosaurs, or, for that matter, other reptiles in general. Confirmation from additional specimens is necessary, but from what is now available this appears to be the situation.

Some specimens show the presence of a shallow sella turcica. There is no trace of the "usual" internal carotid canals leading into 
this area. It is not certain whether the basisphenoid or the proötic ossified the dorsum sella.

Above and slightly anterior to the basipterygoid processes are the epipterygoids. They enter into the upper part of the articulation of the palate and the basicranium. The epipterygoid has been identified for certain only in Casea broilii, in which it is short and broad with little ossification of the dorsal portion, and in Ennatosaurus tecton in which more complete ossification has occurred.

A most peculiar condition and one that is difficult to interpret involves a series of cavities, depressions and processes that are present in the otic part of the braincase. These are best seen in Angelosaurus dolani and Cotylorhynchus hancocki (pl. 4 and fig. 7). Some of the features are present in Casea broilii and this suggests that they are thus to be found at least partially developed throughout the family.

On the dorsolateral surface of the opisthotic there is a deep pit which leads by a shallow trough to the posttemporal fenestra. This is similar to Edaphosaurus (figs. 6-8). Anterodorsal to the braincase proper there is a rather broad, gently curved surface of the periotic which faces anterodorsally. This carries a foramen that leads to a canal which passes to a large open space in the periotic. Medially, the recess opens into the braincase. Anteriorly, it is extended by a process of the periotic that passes anteriorly in Angelosaurus and Cotylorhynchus, at least, to make contact with the parasphenoidbasisphenoid just above the wing-like tubera of the parasphenoid. Casea seems to lack this process. At the posterior end of the recess is a small canal that leads into the middle ear, just below the opening of the fenestra ovalis. Ventrally, a tube from the recess leads into a large canal that emerges from the otic complex at the junction of the paroccipital process of the periotic and the basisphenoid. This canal has not been identified in Casea.

It appears that these various features must be related to a venous system. It was noted in an earlier description of $C$. hancocki that there were some oddities of this sort. The anterior bony processes leading to the basipterygoid processes, although they lie above part of the recess, may be related more to strengthening the basicranial complex than to the supposed venous sinus system.

These structures are sufficiently different from those in other pelycosaurs that they must be considered as distinctly caseid. There was progressive development of these features within the family, for they are less well expressed in Casea than in more advanced genera. 

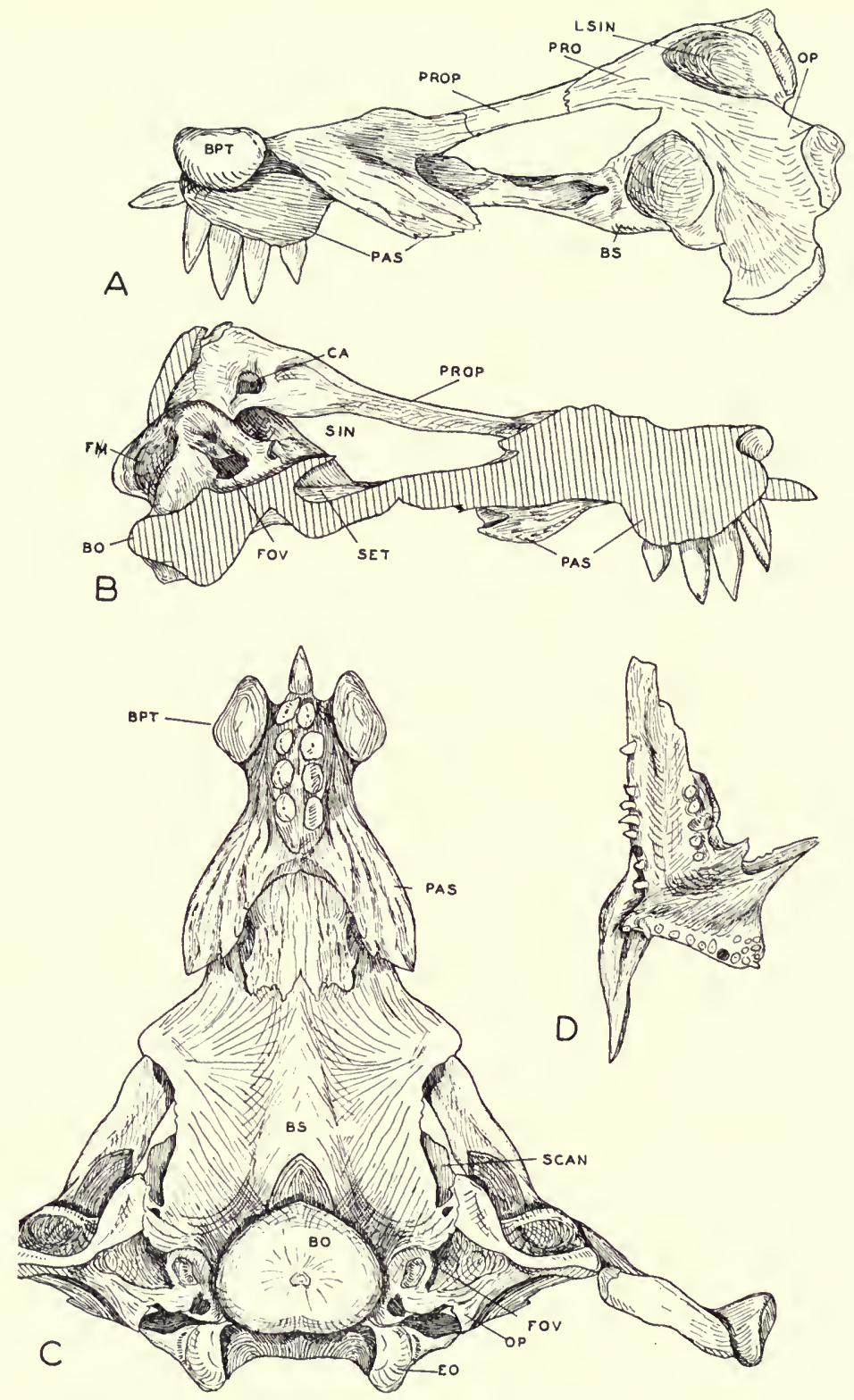

FIG. 7. Angelosaurus romeri, parts of skull based on UR 927. A, Braincase in lateral view; $B$, Braincase in sagittal section; $C$, Braincase in ventral aspect; $\mathrm{D}$, Pterygoid, ventral; A, B, C, $\times 1 ; \mathrm{D}, \times 1 / 2$. Abbreviations as in Figure 3. 
Little is known of the condition in Ennatosaurus, but it does appear that at least the anterior process from the periotic was present.

Evidence on the nature of the sphenethmoid comes only from Casea and Ennatosaurus. The former has only the bases of a pair of small wings except in the holotype where there is a rather badly damaged mass of bone within the skull that may be in part an ossi-
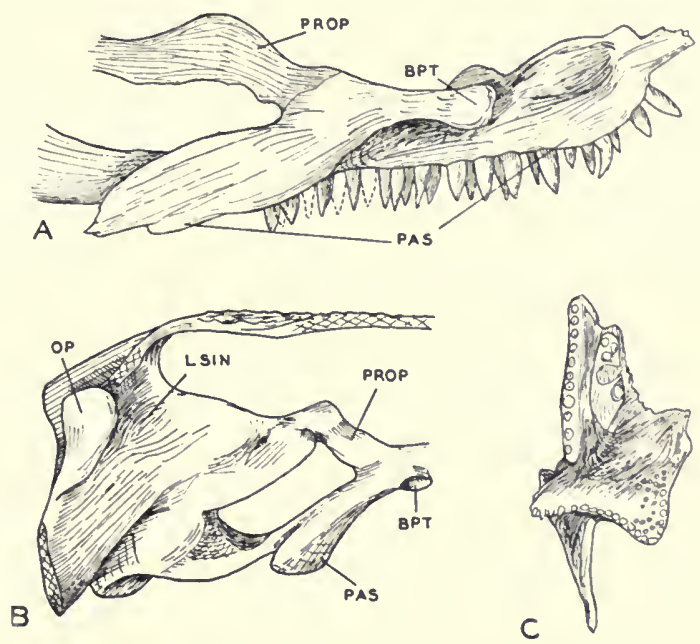

FIG. 8. A, Cotylorhynchus hancocki, lateral view of part of palate and braincase, UR $622, \times 1 ; \mathrm{B}$, Cotylorhynchus romeri, lateral view of braincase and part of basicranium and palate, based on skull from mounted specimen in Geology Building, University of Oklahoma, $\times 1 / 2 ; C$, Pterygoid of Cotylorhynchus bransoni, $\times 1 / 2$. Abbreviations as in Figure 3 .

fied sphenethmoid. In Ennatosaurus the sphenethmoid is large and much like that in other pelycosaurs.

The nasal capsule is not completely known in any genus, but some information on it may be gained from Casea, as described in the treatment of Casea broilii (p. 276), and from Ennatosaurus, as discussed in connection with the description of the septomaxilla (p. 233).

\section{STAPES (Figure 6)}

The stapes is preserved only in one specimen of Casea broilii, UC 698. This is treated under consideration of that genus and species. Probably this stapes is fairly typical of the family as a whole, for it has distinctive features which seem to tie in with associated structures found throughout the family. The foot is very large, the shaft is heavy, and the quadrate facet appears to be on the lateral 
surface of the shaft rather than terminal. There is a strong dorsal process near the distal end of the shaft. There is no stapedial foramen. Details and illustrations are given under the discussion of Casea broilii.

\section{Hyoid Apparatus (Figure 4)}

Hyoid structures are present only in Ennatosaurus and are described under the discussion of that genus. The hyoid consists of a large central plate with a posterolateral process on each side. Each of the lateral margins of the plate carries a facet into which a freelyarticulated rod was set. The plate presumably represents the copula, or body of the hyoid. It appears to have carried forward into a short linguloid process. The fixed posterolateral processes probably represent the second branchial horn, probably the second ceratobranchial, and the free elements the first ceratobranchial.

There is no way of telling whether this sort of structure was characteristic of the caseids as a whole or not, for these elements tend to be lost readily. The hyoid apparatus of Ennatosaurus is very different from the slender structures of Sphenodon, lizards and snakes. There is no basis for comparison with other pelycosaurs. Among modern reptiles the closest resemblances are to some turtles, and there is general resemblance to the alligator as well. Presumably, the tongue was massive, strong and reasonably mobile. This appears to be related primarily to the general jaw structures and functionally to the nature of diet and mastication of food.

\section{The Lower Jaw}

\section{(Figure 9)}

The structure of the lower jaw is quite similar in all genera and species, with differences being mainly those of size, proportion and the number of teeth. The jaw is short and deep and has a regular outline. The outer surface is almost featureless. There is no posteriorly projecting retroarticular process and no angular lamina. The coronoid process is merely a gentle dorsal swelling back of the tooth row. The anterior margin of the jaw is deep and somewhat chin-like, with a ventral protruberance that extends below the line of the ventral margin of the jaw proper.

The largest element is the tooth-bearing dentary. It is exposed primarily on the outer anterior and dorsal surfaces of the jaw. Teeth are carried in a deep groove which has high lateral and low medial walls. Tooth insertion is protothecodont. Anteriorly, the dentary 

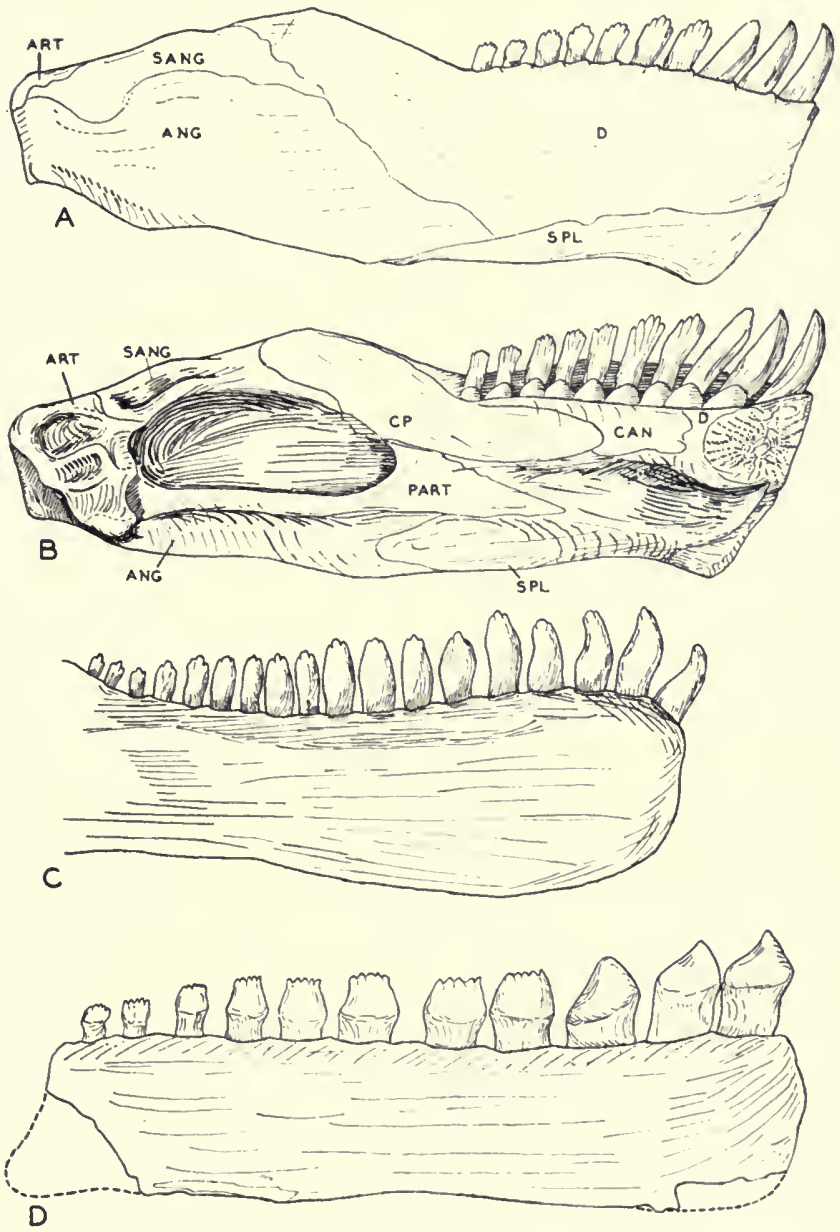

Fig. 9. A, Ennatosaurus tecton, lower jaw, lateral; B, E. tecton, lower jaw, medial: A and B based on 1580/16, 17, 19, 24; C, Colylorhynchus hancocki, dentary and teeth, UR 492; D, Angelosaurus romeri, dentary and teeth, UR 933: A, B, C, $\times 1 / 2 ; \mathrm{D}, \times 1$.

forms the dorsal semicircular part of the symphysial attachment of the jaws.

The anterior half of the lower margin of the jaw is formed by a large splenial. The degree of participation of this element in the formation of lateral surface varies considerably between genera and species. The splenial also occupies a large area on the inner surface of the jaw and completes the symphysis ventrally. 
Above it and posterodorsally in Ennatosaurus are two coronoids, a small anterior one and a larger posterior one. The larger participates in the formation of the low, rounded coronoid process. How general the double coronoid is among the caseids cannot be determined, for this area is not well exposed in most specimens. Romer and Price (1940) state that there is but a single element in Cotylorhynchus romeri and in Casea broilii. The latter, however, as shown by UC 698 and UC 1011 which now have been more fully prepared, does seem to have two elements. The condition in Cotylorhynchus is not entirely clear.

The angular, surangular and prearticular are typically pelycosaurian, with the angular, as noted, lacking the angular lamina found in sphenacodonts. The articular is a rather narrow element with usual articular surface, more or less double and sloping rather sharply medially. Medioventral to the articular surface is a very strong process, presumably for insertion of part of the pterygoideus musculature (see Romer and Price, 1940, for the condition in Dimetrodon).

\section{Dentition}

(Plates 2, 4, 5; Figures 2, 4, 5, 9, 10)

Publications to date have indicated marked differences in the dentition of the various genera and species of the family Caseidae, especially in the development of the denticulated nature of the crown (see Olson, 1962, for summary). It is now evident that the differences are less than was thought and the erroneous assessment arose largely from inadequate data. Except for the number of teeth, which ranges from 20 in one specimen of Cotylorhynchus romeri to 10 in Ennatosaurus tecton, dental differences are relatively minor. They relate mostly to size and proportion. The biggest differences are between those species that have only three cuspules on their teeth and those that have five or more. Most divergent from the general pattern is Angelosaurus romeri Olson and Barghusen.

Both above and below, the cheek teeth are moderately highcrowned and slightly recurved. The bases are more or less circular in cross-section. The center portion of the tooth forms a somewhat bulbous waist and the terminal part of the crown tends to be spatulate in varying degrees.

The anterior teeth above tend to be longer than the rest. They have much the same shape as those more posterior but lack the denticulated crown pattern. The first two teeth, and in some cases more, lack cuspules. The lower teeth show less size differential. As in the 


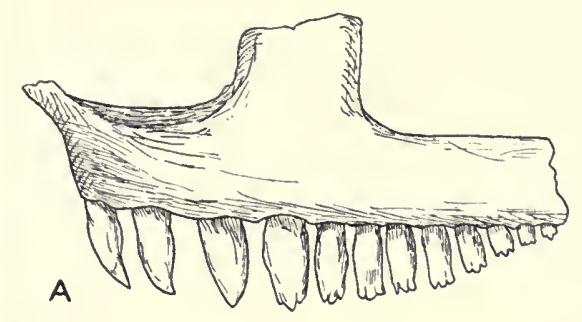

B
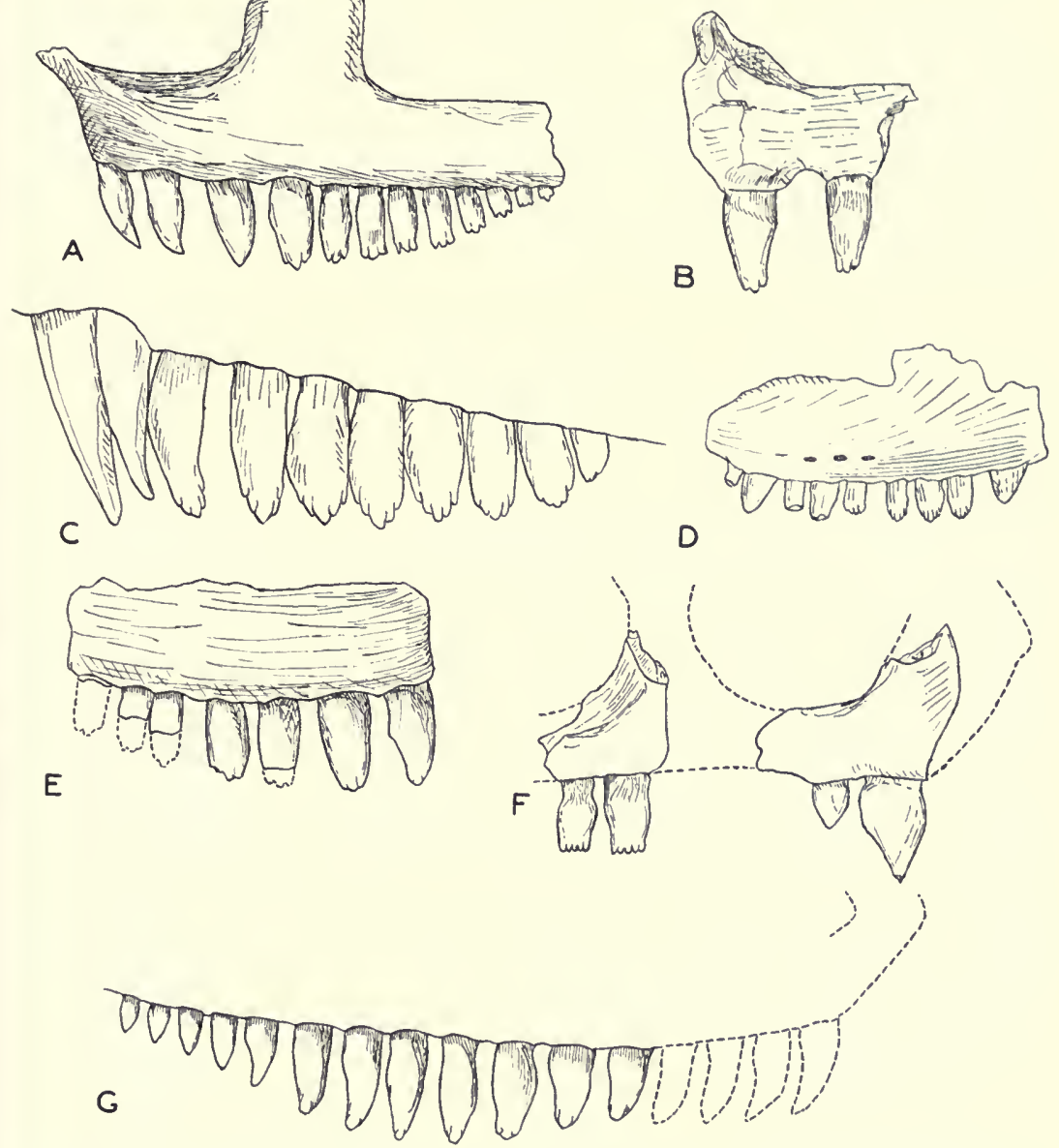

FIG. 10. Upper dentitions. A, Casea broilii, left, UC 698, × 1; B, Cotylorhynchus bransoni, left, UR $841, \times \frac{1}{2} ; \mathrm{C}$, Ennatosaurus tecton, young individual, left, $1580 / 24, \times 1 / 2 ; \mathrm{D}, E$. tecton, juvenile, right, $1580 / 127, \times 1 ; \mathrm{E}$, Caseoides agilis, right, UR 253, $\times 1 / 2$. F, Angelosaurus romeri, right, composite, $\times 1 / 2 ;$ G, Colylorhynchus hancocki, right, UR $490, \times 1 / 2$.

uppers, the anteriormost teeth are not denticulated. The anterior lower teeth in Angelosaurus are thick and blunt, in contrast to those in Casea and Cotylorhynchus.

Dental patterns are diagnostic of genera and may be of value for species differentiation as well. The three species of Cotylorhynchus can be distinguished on the basis of teeth if much of the tooth row is present. If only one or two teeth are available, this is not possible. How far this is possible in other genera cannot be determined. 
Palatal teeth (figs. $3-5,7,8$ ) occur on the pterygoids, ectopterygoids, palatines, vomers and parasphenoids. They are well developed in all genera, and, as in the case of the marginal teeth, the patterns and degree of development of the teeth are diagnostic at the generic level. Particularly so are the parasphenoidal teeth, which exhibit very different patterns in Casea, Cotylorhynchus and Angelosaurus but are not known in Ennatosaurus.

\section{Postcranium}

(Figures 11-21)

\section{The Axial Skeleton}

The major features of the axial skeleton are quite uniform throughout the family except for size and for features that are size dependent. Representative bones are portrayed in Figures 11-13 for the sake of comparisons. The drawings are simple and, in general, have not been corrected for distortion. In some instances, particularly in the case of the humeri, some differences that may appear to be real are due primarily to crushing. There is, however, no reliable way of restoring these elements to the original conditions. Generally, it appears that resemblances are somewhat closer than indicated in the figures. Recently a full and detailed account of the postcranial osteology of Cotylorhynchus romeri has been published (Stovall, Price and Romer, 1966). This serves nicely as a basic reference for the morphology of the family and permits considerations in this paper to be brief and devoted primarily to differences between the genera and species.

\section{Vertebrae}

The number of presacral vertebrae ranges from 24 or 25 to 27 in specimens in which complete columns have been available. Casea broilii was described as having 24 by Williston (1911b) and then later as having 25 (Williston 1916b). The number of 24 appears to be from the mounted holotype, UC 565. Casea nicholsi has 24 presacrals. Cotylorhynchus romeri, on the basis of a mounted skeleton OUSM 4-0-S4 appears to have a total of 27 presacrals and this is the case for Cotylorhynchus hancocki as well. Stovall, Price and Romer (1966) give the number of presacrals for Cotylorhynchus romeri as 25 or 26, based mostly on OUSM 4-0-S6. Both this specimen and 4-0-S4, being mounted, pose some problems with regard to making an accurate count. While 27 would seem to me to be the correct number from my observations, it is possible that the data of 4-0-S6, 

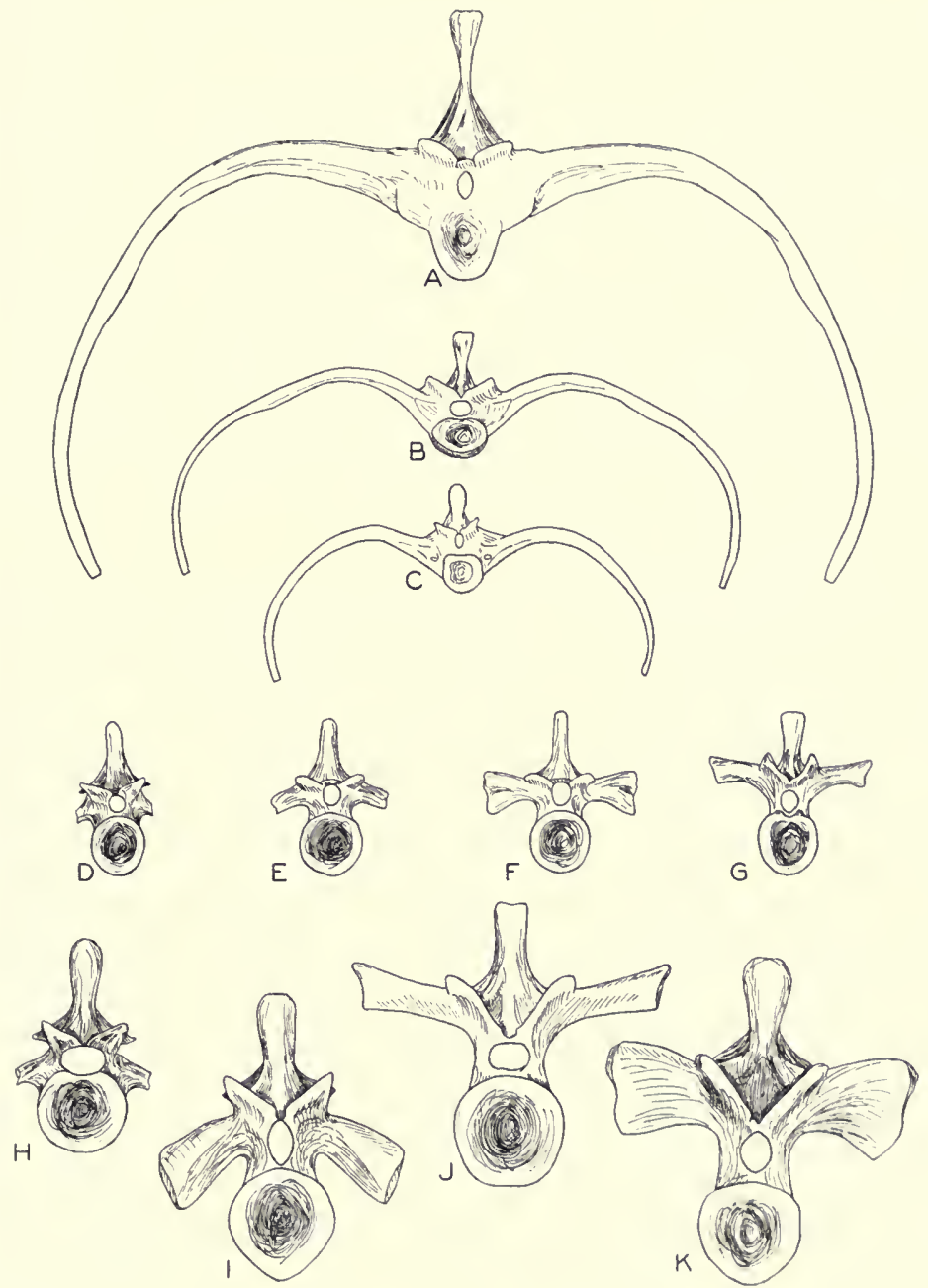

Fig. 11. A, B, C, lumbar vertebrae, presacral 3, in anterior view. (The numbering of these vertebrae and others in this figure express the position anterior to the first sacral vertebra. This is made necessary by the frequent lack of the anterior part of the column.) A, Cotylorhynchus hancocki, UR 621, $\times 1 /{ }_{6} ; \mathrm{B}$, Angelosaurus romeri, UR 916, $\times 1 / 6$; C, Casea broilii, UC 656, X 1/3; D, E, F, Casea broilii presacrals 22, 20, 17 respectively, based on UC $883, \times 2 / 3 ; \mathrm{G}$, Cotylorhynchus bran soni, presacral 16, based on UR 925,$983 ; \mathrm{H}$ through $\mathrm{K}$, Cotylorhynchus hancocki several presacral vertebrae: H, 25th; I, 20th; J, 16th; K, 18th. Sequence in column is $\mathrm{H}, \mathrm{I}, \mathrm{K}, \mathrm{J}$. Based on UR $622, \times 1 / 6$. 
which I was not able to examine in detail in the Stovall Museum, could be more reliable and the number actually is less than 27 .

Of the total, five to seven vertebrae may be considered as cervicals, although there is no sharp break with dorsals. The last five presacrals have fused ribs and, differing in this particular from the rest, can be considered as lumbars. In some specimens full fusion occurs only in the last four presacrals and in Ennatosaurus there is no clear evidence of any fusion. The usual number of sacral vertebrae is three, but in at least one specimen of Angelosaurus romeri there are four, although the number was originally given as three by Olson and Barghusen (1962). There are over 45 caudal vertebrae and probably the total runs about 60. Stovall, Price and Romer (1966) suggest 55 for Cotylorhynchus romeri. There is no complete count for any genus or species.

Details of vertebra morphology are given by Stovall, Price and Romer (1966) for Cotylorhynchus romeri. The following discussion is general and applicable to the family as a whole. Throughout the column the centra tend to be short, with rounded articular surfaces which are shallowly amphicoelous. The lips of the centra are unfinished and somewhat reflected into a broad, rolled surface. There is considerable variation in the length of the centra along the column (see Table 4a). Centra of the lumbars are short. Maximum length is reached in the mid-dorsal region. There is then a slow decrease in length until the cervical region is reached. There is a rapid decrease in central length in the neck, for the anterior vertebrae are very small. Stovall, Price and Romer (1966) indicate that Cotylorhynchus romeri shows an almost complete absence of ossified intercentra, except in the atlas and axis, suggesting that they were present as cartilage. Intercentra do appear to be fused into the sacral complex and to be present in some of the caudals, fused to the haemal arches in some specimens of $C$. romeri. They are present in these regions in Casea, Cotylorhynchus hancocki, C. bransoni and Angelosaurus romeri. Most centra are not keeled, but in very large species such as Cotylorhynchus hancocki Olson and Beerbower a strong keel

FIG. 12. A through $\mathrm{F}$, sacral vertebrae in anterior aspect: A, Cotylorhynchus hancocki, UR 894, X 1/6; B, C. romeri, PR 272, $\times 1{ }^{1 / 6}$; C, C. bransoni, UR $981, \times 1 / 6$; D, Casea broitii, UC 883, × 1/3; E, Angelosaurus romeri, UR 904, ×1/6; F, A. dolani, UR 149, X 1/6; G through $\mathrm{P}$, caudal vertebrae of Cotylorhynchus hancocki, $\mathrm{J}$ and $\mathrm{L}$, anterior, the others lateral, all $\times 1 /{ }_{6} ; \mathrm{G}, \mathrm{L}, 2$ nd, UR $703 ; \mathrm{H}, 4 \mathrm{th}, \mathrm{UR} 621$; I, J, 7th, UR 621; K, 12th, UR 621; M, 22nd, UR 581; N, 27th, UR 581; O, 34th, UR 581, 884; P, 38th, UR 581, 884. 


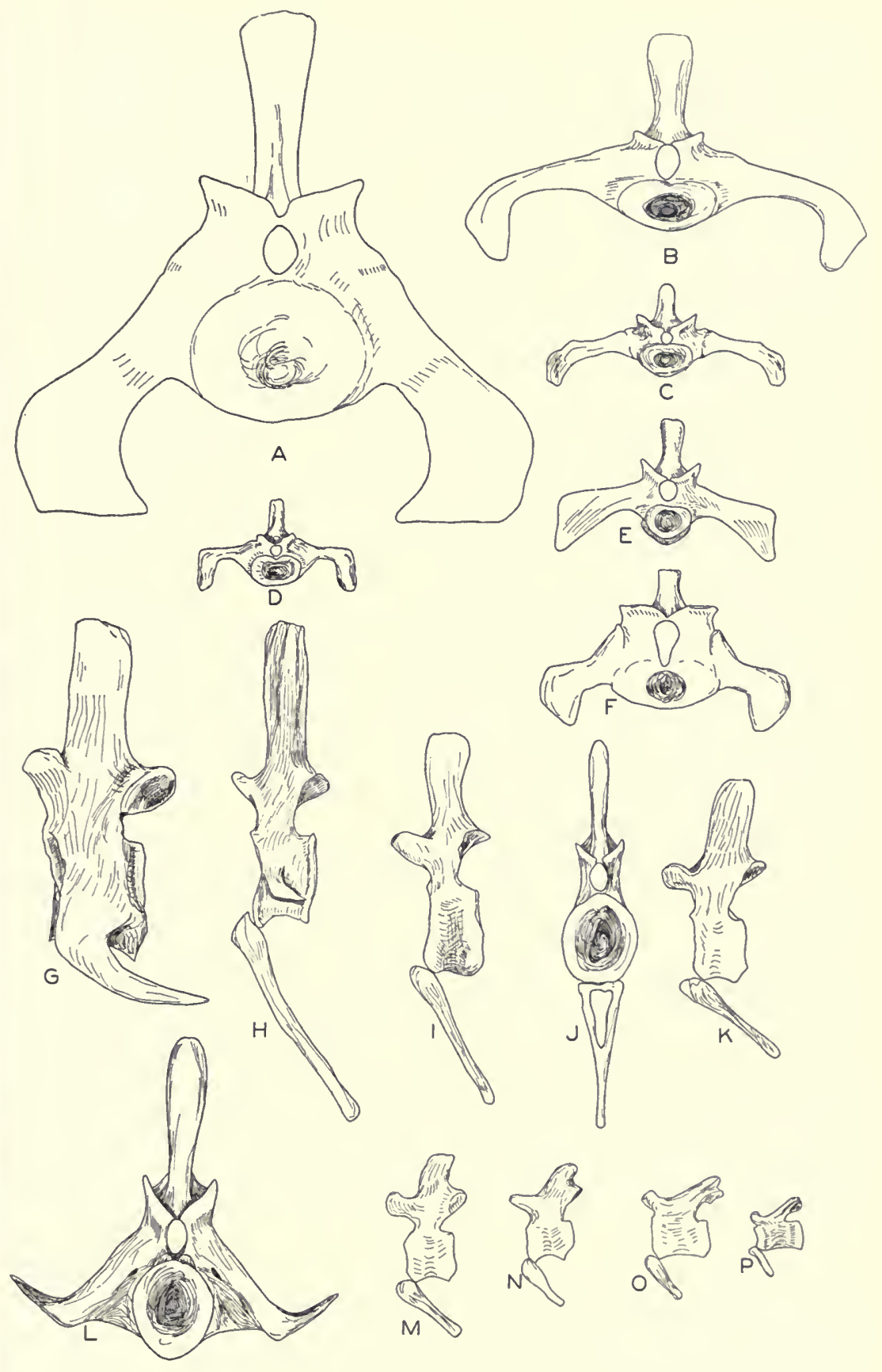


is developed in the area around the sacrum. Intercentra occur in the anterior cervicals and in the sacrum where they are very large and sometimes fused into the sacral series. They are present in varying stages of ossification in the tail from about the fourth caudal on and are fused to the haemal arches.

Neural spines tend to be relatively short and thick, but in the sacral region, in large forms in particular, they are long. There is a great deal of variation in relative spine length, partly but not completely related to size. The anterior and posterior zygapophyses are rather widely spaced in the dorsolumbar region and, narrowing somewhat anteriorly, the articular surfaces become increasingly inclined from the horizontal as the cervical region is approached. In the sacrum the anterior zygapophyses of the first vertebrae are broad and flat but those on the second and third sacrals are much smaller. In the tail there is a rapid transition from fairly broad, horizontal surfaces to narrow ones which approach verticality as the end of the tail is neared.

Transverse processes are long throughout the dorsal region, projecting laterally and slightly dorsally. Maximum length is in about mid-column. Anteriorly, they shorten and widen and as the cervical region is approached they begin to project somewhat ventrally, making a sharp angle with the horizontal in the anteriormost cervicals. Lumbar vertebrae have relatively short processes which join by fusion, or sometimes sutures, to the ribs.

Patterns of the sacral vertebrae are shown in Figure 12. They are quite similar in all genera and species, except that there is one extra sacral in Angelosaurus romeri. A representative suite of caudals from Cotylorhynchus hancocki in Figure 12 shows the major features of these vertebrae.

The axis and atlas probably are quite similar throughout, but they are well known in so few species that no generalizations are profitable. They conform closely to the general pelycosaurian pattern in those forms in which they are well known. A detailed description is available in Stovall, Price and Romer (1966). Also a description and figures are given for Ennatosaurus in this paper.

\section{Ribs}

Two-headed ribs are found throughout the presacral series. Cervical ribs are short, slender and rather straight. Both the tuberculum and capitulum are strongly developed. More posteriorly the ribs 

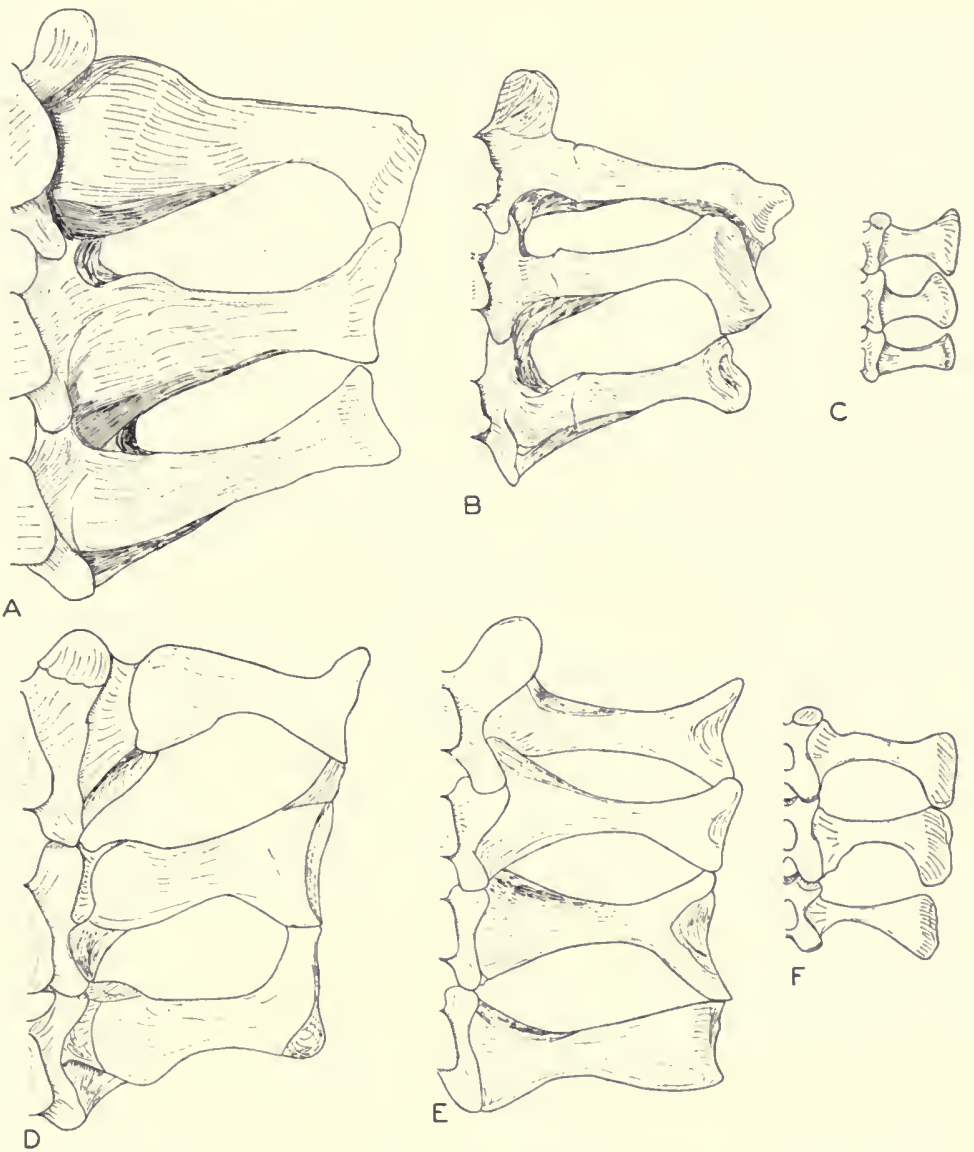

FIG. 13. Sacral vertebrae and ribs in dorsal view, all $\times 1 / 3$. A, Cotylorhynchus romeri, PR 272; B, C. bransoni, UR 981; C, Casea broilii, UC 656; D, Angelosaurus dolani, UR 149; E, A. romeri, UR 904; F, Casea nicholsi, UR 85.

are very long and curved to form the characteristic barrel-shaped trunk region of the caseids (plate 1). The capitulum remains well developed in the thoracic region but posteriorly the tuberculum becomes merely a rather small facet on the curving shaft. Lumbars are two-headed but the heads may coalesce in connection with their fusion to the vertebrae. Both tuberculum and capitulum are strongly developed. The ribs are long on three lumbars but as the sacrum is approached there is rapid shortening, so that on the last lumbar the rib is only about one-third the length of that of the first. Apparently the body tapered very rapidly as the pelvic region was approached. 
Sacral ribs (figs. 12, 13) have heavy double heads, usually with the two heads coalesced. They are fused or suturally joined to the sacral vertebrae. Shafts are fairly long and pass laterally in a more or less horizontal course. The distal ends are turned down sharply to form broad surfaces for attachment to the ilium. The first sacral lies in a grooved area along the anterior margin of the ilium. It projects about one-half of the way down the iliac blade. The second rests on a swollen rugose area and passes farther ventrally, to the level of the top of the acetabulum. The third, like the first, rests in a depression and is developed to about the same extent. In the case of Angelosaurus romeri, the fourth passes somewhat forward to attach over a small area to the ilium. In some species the ribs are fused to each other but in others they are free. How much this is a function of age and size has not been determined.

Strongly recurved, large caudal ribs occur on the first four or five caudal vertebrae. The most anterior are two-headed but posteriorly the articulation shifts onto the centrum. There is a sharp reduction in the rib size on the tail and ribs are generally absent from the level of about the tenth vertebra on.

Gastralia are known in Cotylorhynchus romeri Stovall and they probably were present in all genera and species. Their absence is probably merely a matter of preservation.

\section{The Appendicular Skeleton}

\section{The Girdle and Forelimb}

(Figures 14-18)

Shoulder girdle: The representative scapulocoracoids in Figure 13 show the essential features of this complex in the various genera and species as far as known. Clavicles are very much alike throughout so that those of Cotylorhynchus illustrated in Figure 14 may be considered as representative. The close resemblances between the interclavicles of different genera are evident in Figure 15. The main variation in these elements is in size and size-related features.

The scapula is broad and the tendency toward breadth increases with size. The scapula of Ennatosaurus, although relatively small,

FIG. 14. Scapulocoracoids, left, in lateral view, all $\times 1 \frac{1}{6} . \mathrm{A}$, Cotylorhynchus hancocki, UR 487; B, C. bransoni, UR 919; C, Casea broilii, UC 656; D, Casea nicholsi, UR 85; E, Angelosaurus romeri, UR 907; F, Cotylorhynchus romeri, PR 272; G, Ennatosaurus tecton, 1580/116; H, Caseoides agilis, UR 253. 


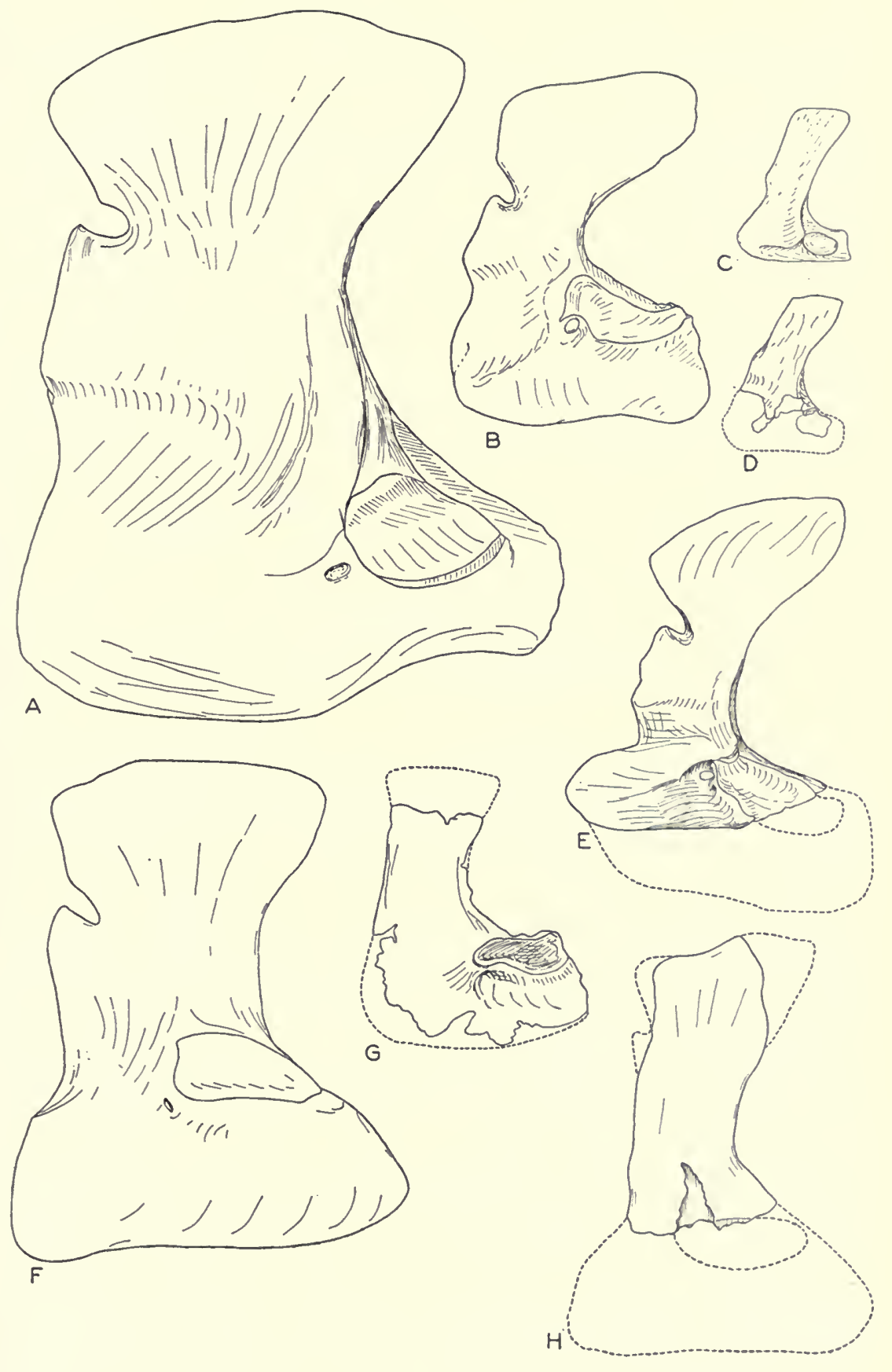




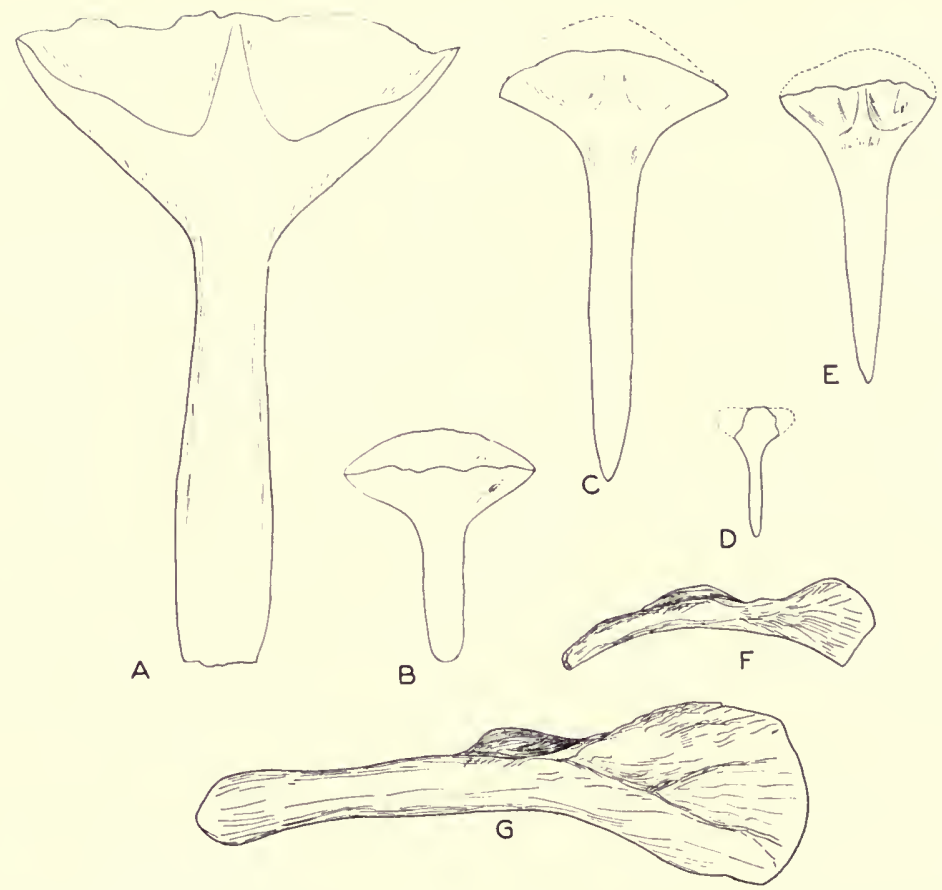

FIG. 15. A through E, interclavicles in ventral view. A, Cotylorhynchus hancocki, UR 622; B, Ennatosaurus tecton, 1580/123; C, Cotylorhynchus romeri, PR 272; D, Casea broilii, UC 656; E, Angelosaurus romeri, UR 933; F, Clavicle, Cotylorhynchus bransoni, UR 912; G, Clavicle, Cotylorhynchus hancocki, UR 822. All $\times 1 / 6$.

is broad, suggesting that the breadth may to some extent relate to a functional pattern within the group as well as to large size. In some genera, certainly in Cotylorhynchus and Angelosaurus and possibly in others, there is a deep notch in the anterior margin of the scapula, marking the position of the termination of the clavicular ramus. The scapular blade tends to extend forward somewhat below this notch and is broad above it. A similar structure, but less developed, occurs in Edaphosaurus.

The acetabulum is large and has the typical pelycosaurian screwshaped outline. No sutures between the scapula and the coracoids or between the two coracoids have been found. The existence of two coracoids, thus, is merely conjectural, based on the condition of other pelycosaurs. There is no supraglenoid foramen. The obturator foramen is large but there is no tendency to form a pubo-ischiatic fossa. The coracoids swing sharply medially below the acetabulum forming 
a broad plate which appears always to have been cartilaginous along its medial border.

Clavicles (fig. 15) were strong and typically pelycosaurian, resembling the clavicle of Edaphosaurus closely. The interclavicle (fig. 14) had a strongly developed triangular head, deeply cut by the markings related to the position of the clavicular junction. The shaft was large and heavy. In undistorted form the anterior part was strongly curved dorsally, but as a rule there was flattening in preservation, destroying this character.

Humerus (fig. 16): The humerus in caseids is characteristically a massive bone, with the shaft short and thick. The condylar areas are strongly formed and the various ridges, tubera and rugosities related to insertions and origins of the muscles and tendons are prom-

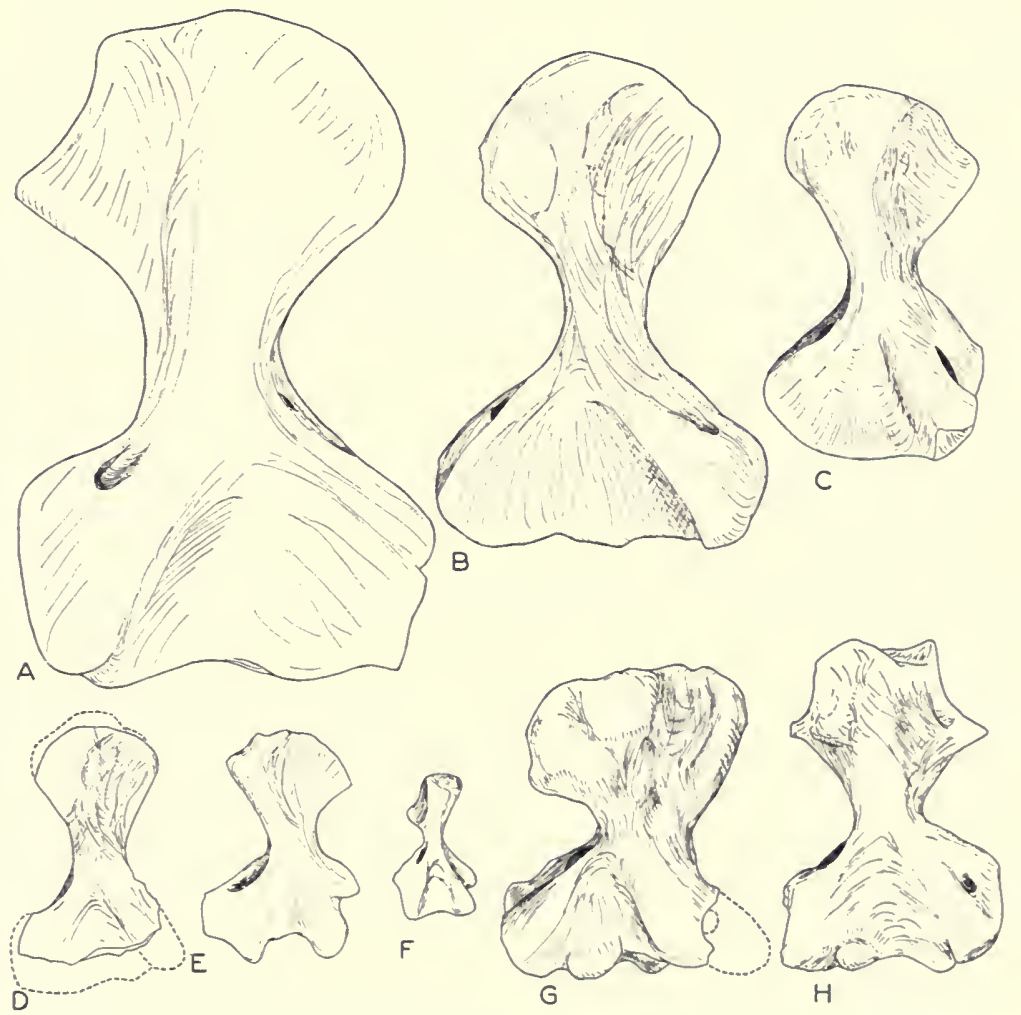

FIG. 16. Humeri in dorsal view. A, Cotylorhynchus hancocki, UR 581; B, Cotylorhynchus romeri, PR 272; C, Cotylorhynchus bransoni, UR 919; D, Caseoides sanangeloensis, UR 151; E, Ennatosaurus tecton, 1580/120; F, Casea broilii, UC 656; G, Angelosaurus dolani, UR 149; H, Angelosaurus romeri, UR 907. 
inent. These characteristics are shown most vividly by larger species and are carried to their extreme in the humerus of Angelosaurus dolani. The radial and ulnar articular surfaces are prominent. The latter often terminate above as a raised area on the dorsal surface of

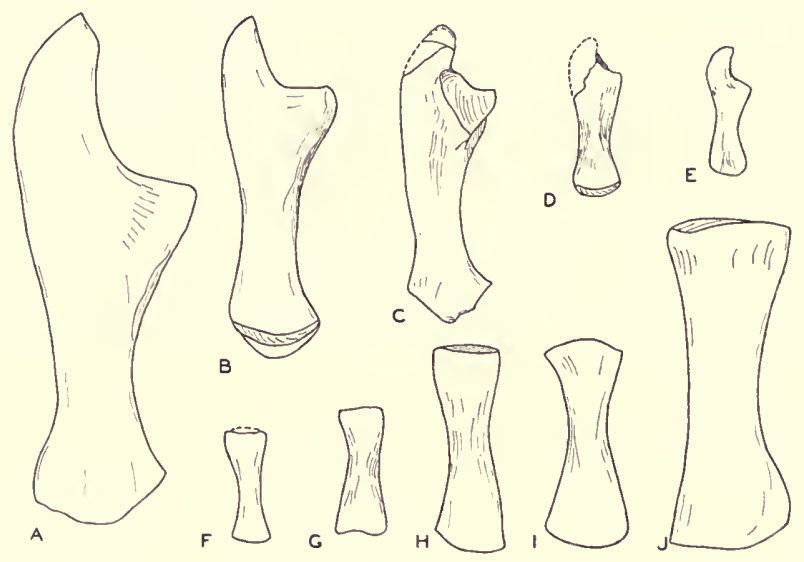

FIg. 17. A through E, ulnae: A, Cotylorhynchus hancocki, UR 703; B, Cotylorhynchus romeri, PR 272; C, Cotylorhynchus bransoni, UR 837; D, Ennatosaurus tecton, 1580/120; E, Casea nicholsi, UR 85; F through J, radii: F, Casea nicholsi, UR 85; G, Ennatosaurus tecton, 1580/120; H, Cotylorhynchus bransoni, UR 837; I, Cotylorhynchus romeri, PR 272; J, Cotylorhynchus hancocki, UR 567. All $\times 116$.

the bone. Both ectepicondylar and entepicondylar foramina are present, either fully formed as in Cotylorhynchus and Angelosaurus or nearly complete as in Casea and Ennatosaurus.

The ectepicondyle is robust whereas the entepicondyle is a broad, flat, rather thin plate. In mature bones both tend to carry strong rugosities.

The humeri, while generally of the same pattern, show enough differences between species that they are useful for diagnosis at least between genera and in some instances between species.

Radius (fig. 17): The radius is generally relatively short and stout, but otherwise not distinctive within the pelycosaurs. There are few distinguishing features between the genera and species except for size and proportions related to size.

Ulna (fig. 17): The ulna is always robust and, in adults, carries a strong olecranon process. The outer surface of this process is marked by very strong rugosities for ligaments. Distally, as well, the ulna carries strong rugosities marking the positions of insertions of ligaments to the carpus, metacarpus and phalanges. The sigmoid notch 
is deep and generally the surface is formed by strongly ossified, massive bone.

Throughout the family the ulna is similar except for size and modifications related to size. What Romer and Price (1940) have indicated for the pelycosaurs as a whole, that the principal differences in this bone lie in the degree of ossification of the olecranon process, holds for this family as well. Except for indications of size, the bone has little diagnostic utility in the caseids.

Front foot (fig. 18): Information on the front foot is less than satisfactory for the family. The best known front foot is that of Casea nicholsi. In addition, the front foot is known in Casea broilii, Cotylorhynchus romeri and Ennatosaurus tecton. Some isolated elements have been found for other species. In all but Casea nicholsi and Cotylorhynchus romeri uncertainty is introduced by the need to restore elements to their presumed positions and to supply those that appear to be absent. Casea nicholsi shows the radiale and ulnare to be relatively small. The intermedium likewise is small but the medial centrale is large. The pisiform is absent but has been identified in Cotylorhynchus romeri. There is no evidence of the existence of a lateral centrale. It may have been present as a cartilaginous element or perhaps it was not developed at all in the rather abbreviated foot. Ennatosaurus tecton appears to have a lateral centrale, but in the only well-preserved specimen the elements have been somewhat crushed and displaced and are hard to follow. One is present in Cotylorhynchus romeri. A restoration showing the presumed position of this element is shown in Figure 18, but this cannot be considered as certainly correct.

Williston gave the phalangeal formula for Casea broilii as 23453, the primitive reptilian formula. Romer and Price (1940) suggested on the basis of Cotylorhynchus romeri Stovall that it might be 22332, but later, on the basis of information from Casea nicholsi modified this assumption (Stovall, Price and Romer, 1966). The formula in Casea nicholsi is 23343 and it is quite probable that the formula in C. broilii was no less than this. Ennatosaurus tecton Efremov has a formula of 22-32. For additional formulae the only basis is extrapolation from the hind foot. In general, the formulae appear to be the same in caseids where both are known.

The ungual phalanges in all caseids are claw-like and the more proximal phalanges tend to be very short. There is, however, considerable variation between the various genera and species. One extreme in unguals is found in the short, broad, blunt claws of Angelo- 

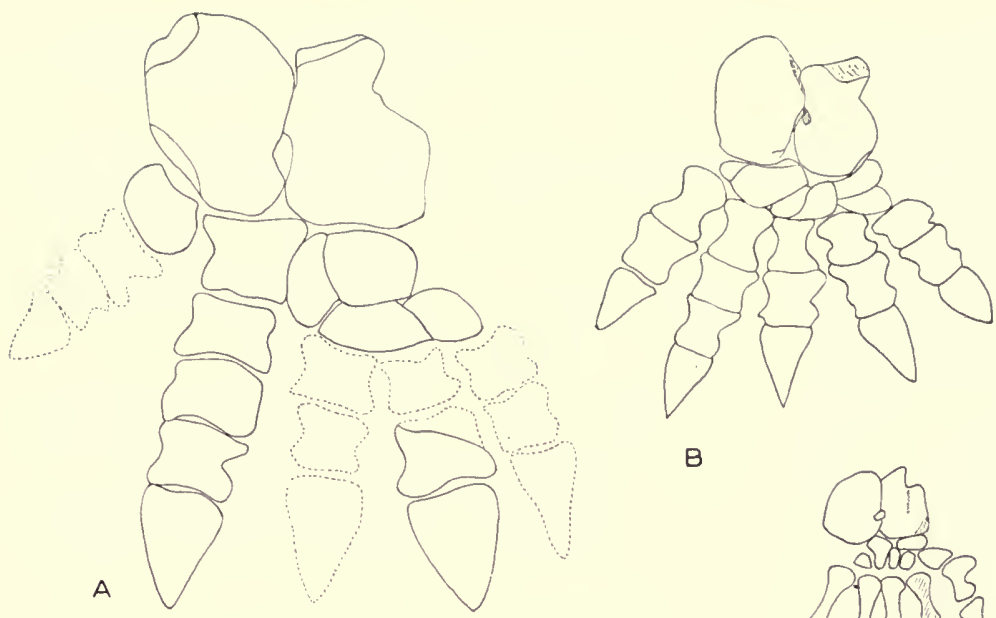

$B$
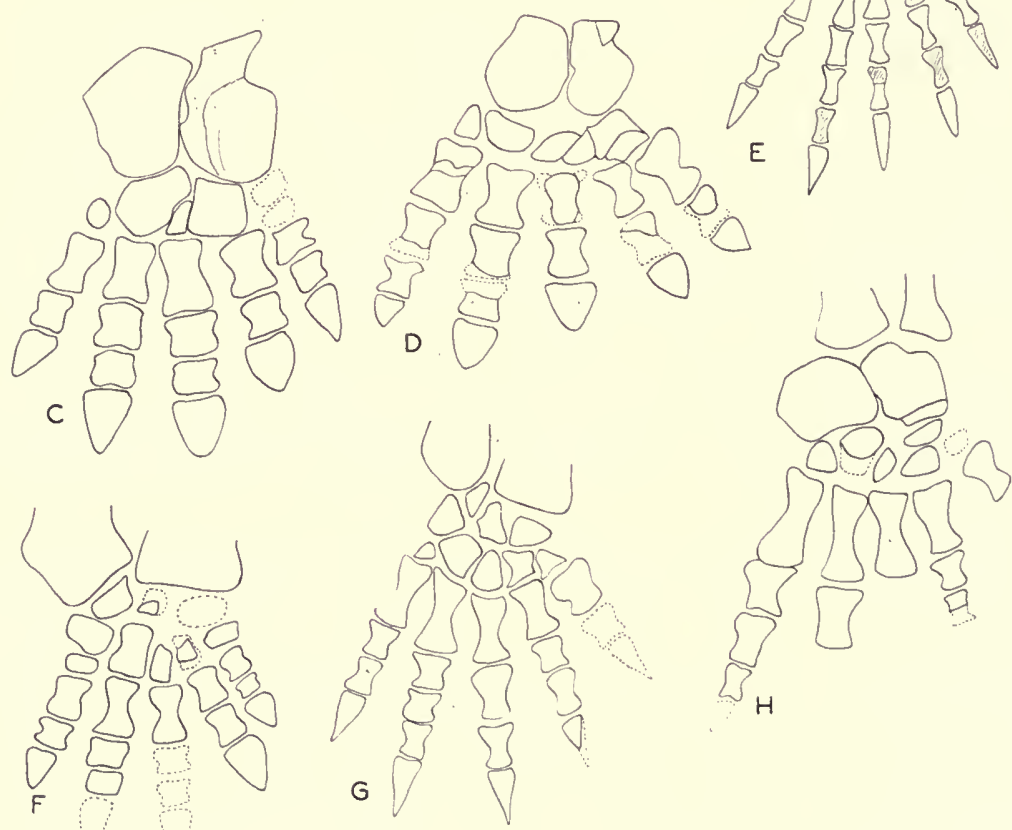

Fig. 18. A through E, and H, left hind feet. A, Cotylorhynchus hancocki, UR 581, $\times 1 / 6 ; \mathrm{B}$, Cotylorhynchus bransoni, UR 836, 988, $\times_{1 / 6} ; \mathrm{C}$, Ennatosaurus tecton, $1580 / 120,126, \times 1 / 3 ; \mathrm{D}$, Angelosaurus dolani, UR 149, $\times 1 \%$; E, Casea broilii, UC 656, × 1/3, after Williston; H, Casea nicholsi, UR $86, \times 1 / 3 ; \mathrm{F}, \mathrm{G}$, front feet: F, Ennatosaurus tecton, 1580/7,102, × 1/3; G, Casea nicholsi, UR 86, X 1/3; $\mathrm{H}$, see above after $\mathrm{E}$. 


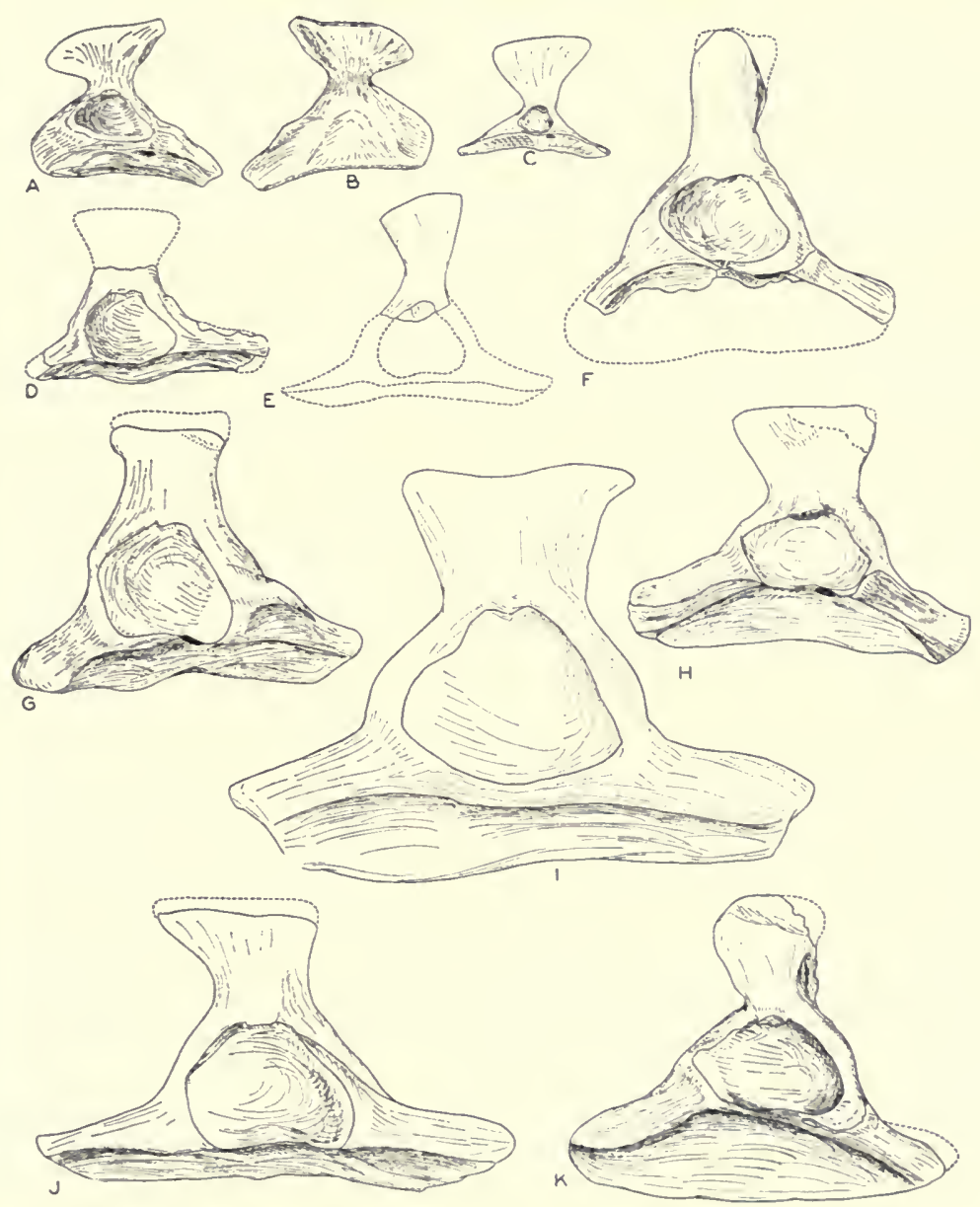

FIG. 19. Right pelves in lateral view. A, B, Casea broilii, UC $833, \times 1 / 4$; A, Lateral; B, Medial; C, Casea nicholsi, UR 86, $\times 1 / 8$ (as are all of following, C through K): D, Casea halselli, UR 117; E, Ennatosaurus tecton, 1580/15, 103, 107; F, Caseopsis agilis, UR 253; G, Angelosaurus dolani, UR 149; H, Angelosaurus romeri, UR 904; I, Cotylorhynchus hancocki, UR 703; J. Cotylorhynchus romeri, PR 272; K, Cotylorhynchus bransoni, UR 835.

saurus, to be contrasted with the rather long, slender claws in Casea, and the broad, strongly recurved claws of Cotylorhynchus.

\section{Hind Limb and Girdle}

Pelvis (fig. 19): The unique construction of the ilium in C. broilii with the narrow neck and anterior and posterior flare was stressed by Williston (1911b, 1916a) and by Romer and Price (1940). This con- 

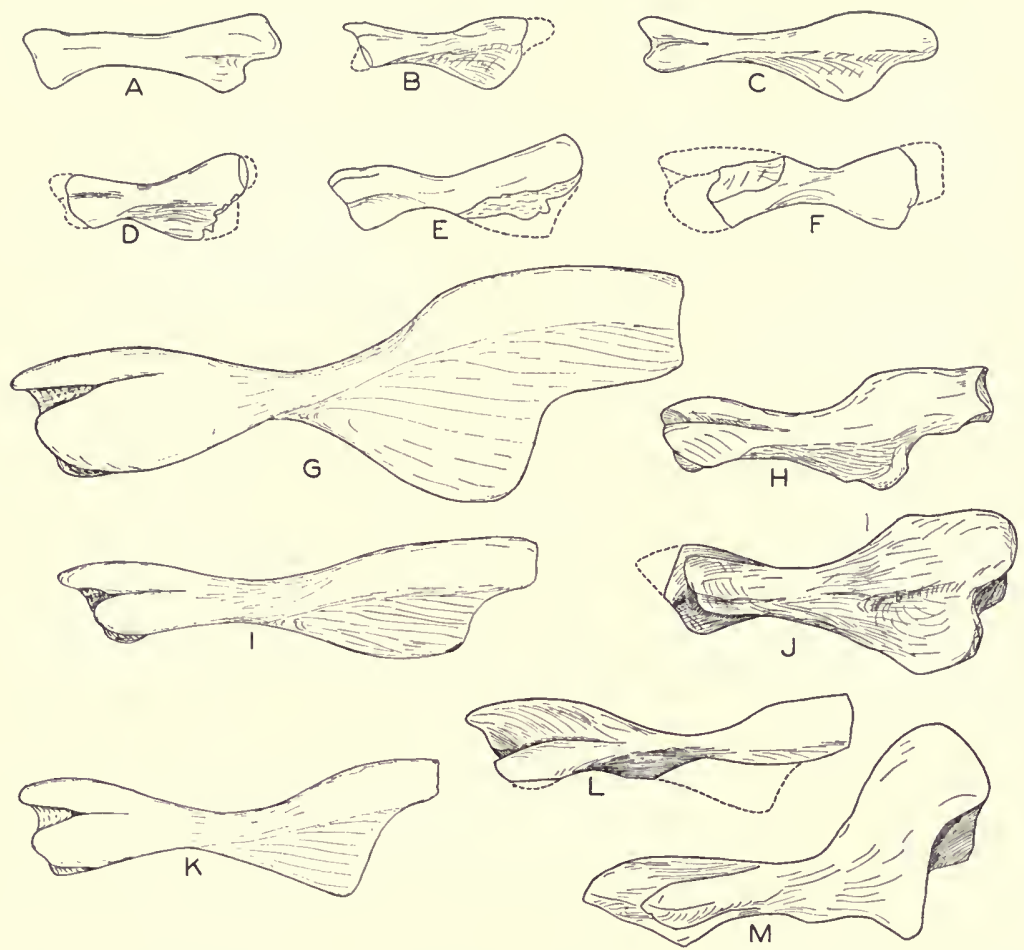

FIG. 20. Right femora. A, Casea broilii, UC 656, × 1/3; B, Casea nicholsi, UR $85,86, \times 1 / 3 ;$ C, Casea halselli, reconstructed from UR $117, \times 1 / 3$; D, Ennatosaurus tecton, 1580/107, × 1/6; E, Phreatophasma aenigmaticum, PIN 294/24, $\times 1 / 3 ; \mathrm{F}$, Caseoides sanangeloensis, UR 151, $\times 1 / 3 ; \mathrm{G}$, Cotylorhynchus hancocki, UR 581, $\times 1 \frac{1}{6} ; \mathrm{H}$, Angelosaurus romeri, UR $717, \times 1 \frac{1}{6}$; I, Cotylorhynchus romeri, PR $272, \times 1 / 6$; J, Angelosaurus dolani, UR $149, \times 1 / 6$; K, Cotylorhynchus bransoni, UR $835, \times 1 / 6 ; \mathrm{L}$, Caseopsis agilis, UR 253, $\times 1 \frac{1}{6} ; \mathrm{M}$, Angelosaurus greeni, UR 257, $\times 1 / 6$.

dition is now known to be characteristic of the genus Casea but not of the family Caseidae as a whole. In many instances it is difficult to judge the nature of the upper part of the ilium, for ossification tends to be incomplete. Thus, for Angelosaurus dolani, Casea halselli and Cotylorhynchus romeri it has been difficult to establish the full shape. The pelvis is not known in Caseoides sanangeloensis, but for the other species, in addition to those noted above, there are excellently preserved ilia.

The ilium tends to be moderately high and narrow. It has only a modest anterior flare in Angelosaurus and Cotylorhynchus and almost none in Ennatosaurus. The degree of posterior extension varies, but in no case is there a well-developed caudal process. 
The inner surface of the ilium usually is highly rugose over the areas of the insertions of the sacral ribs. The least rugosity occurs in Casea, where only the posterior part of the inner surface is somewhat sculptured. The outer surface, near the top, generally shows a line that slopes downward toward the anterior margin, marking, it would appear, the dorsal limit of one section of the muscles to the limb.

The acetabulum is characteristically deep and proportionately large. There is a strong supra-acetabular buttress. The pubis and ischium form a broad ventral plate, meeting in a rather weak median symphysis. The obturator foramen is large but there is no puboischiatic fossa.

Femur (fig. 20): The femur is characteristically short shafted and massive. Its structure is approached elsewhere among the pelycosaurians by Edaphosaurus and Lupeosaurus. In general, this bone is highly characteristic of the family, but its distinguishing features have been developed within the family and are only incipient in Casea broilii.

The head of the femur has a large articular surface, always covered by a cartilage cap in life. The trochanteric fossa is broad and deep. Anterior to it lies a very strong internal trochanter which passes distally into a weak fourth trochanter. Proximally, the shaft and head, as seen in anterior or posterior profile view, assume a somewhat sphinxlike outline. This results from a rapid dorsal flexure of the shaft as it passes to the head and is often emphasized by a raised, highly rugose area for muscle insertion. This feature is found throughout the family, although it is only slightly developed in Casea broilii. Edaphosaurus, in this feature as in many others, shows considerable resemblance to the more advanced caseids.

The femoral shaft is short and the distal condyles are strong and widely separated from each other. This relates to the very broad tibial head. The anterior condyle is relatively short as compared to the posterior one and the two are separated by a deep, intertrochanteric fossa. In mature forms both condyles carry strong rugosities, related to the extensor musculature of the lower limb.

Tibia (fig. 21): The tibia is a highly characteristic bone. Its remarkably broad head is approached elsewhere only in Edaphosaurus, and in this genus expression is much less than that in fully developed caseids. The highly exaggerated condition, however, was developed in the course of evolution of the caseids, for in Casea broilii the tibial head is moderately restricted. Within this genus, in Casea halselli, the broad head became well developed. 
The medial (anterior) division of the head is fairly normal for pelycosaurs, although somewhat above average in its proportional size. The lateral (posterior) head tends to be very much enlarged. The two are separated by a deep groove in mature specimens.

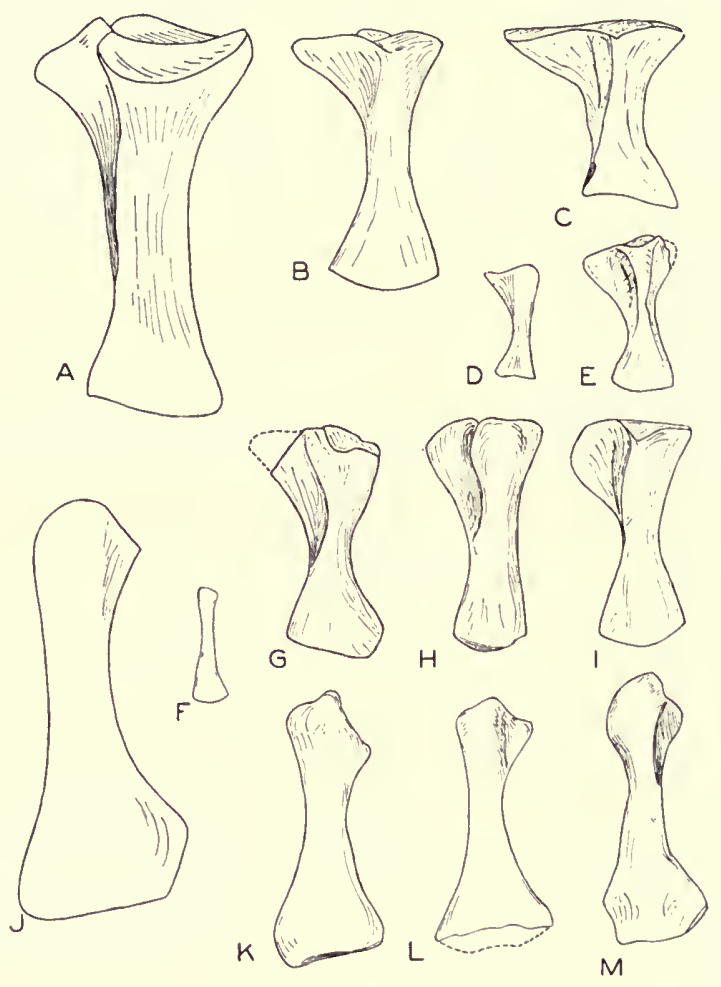

FIG. 21. A through E, and G, H, I, right tibiae, all $\times 1 / 6$ : A, Cotylorhynchus hancocki, UR 881; B, Cotylorhynchus bransoni, UR 836; C, Cotylorhynchus romeri, PR 272; D, Casea nicholsi, UR 86; E, Caseoides sanangeloensis, UR 151; G, Angelcsaurus dolani, UR 149; H, Angelosaurus romeri, UR 911; I, Caseopsis agilis, UR 253. F, J through M, right fibulae, all $\times 11 / 6:$ F, Casea nicholsi, UR 86; J, Cotylorhynchus hancocki, UR 878; K, Cotylorhynchus bransoni, UR 836; L, Coiylorhynchus romeri, PR 272; M, Angelosaurus dolani, UR 149.

The cnemial crest is not sharply defined. Most specimens have suffered considerable distortion which makes interpretation difficult. When undistorted, the shaft is very nearly circular in cross-section. The distal end flares moderately to provide a broad, ovoid distal articular surface which makes contact with the astragalus.

Fibula (fig. 21): The fibula, while much less massive than the tibia, is nevertheless a fairly robust bone. The articular surface of 


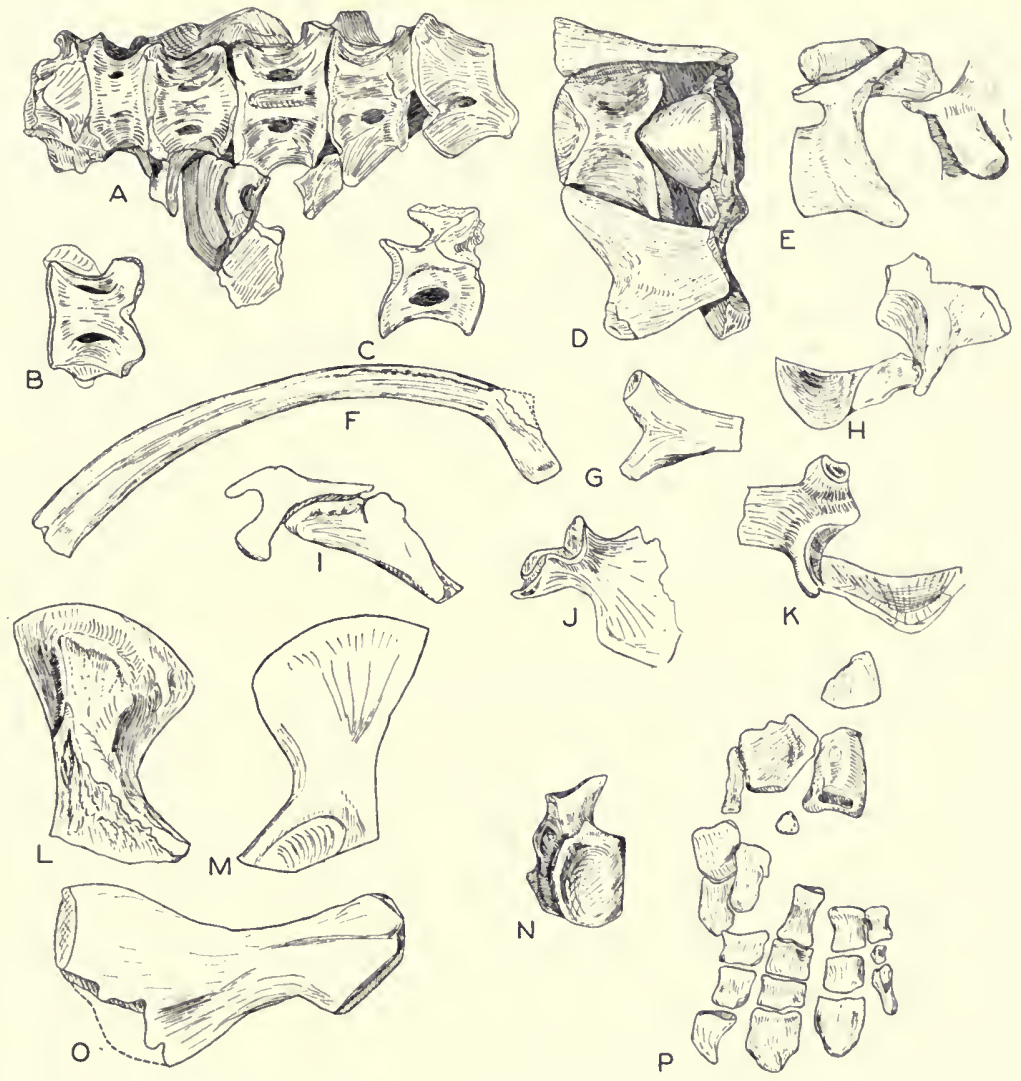

FIG. 22. Postcranial elements of Ennatosaurus tecton. A, Dorsal vertebrae in ventral aspect, $1580 / 111, \times 1 / 3 ; \mathrm{B}, \mathrm{C}, \mathrm{Mid}$-dorsal vertebra in ventral and lateral views respectively, $1580 / 101, \times 1 / 3 ; \mathrm{D}, \mathrm{E}, \mathrm{Axial}$ elements and third cervical (part) in ventral and lateral aspects, $1580 / 14, \times 1 / 2 ; \mathrm{F}$, Anterior dorsal rib, 1580/126, $\times 1 / 3 ; \mathrm{G}$, Head of first cervical rib, $1580 / 19, \mathrm{X}_{1} / 3 ; \mathrm{H}, \mathrm{K}$, Atlas, posterior and anterior respectively, $1580 / 19, \times 2 / 3 ; I$, Dorsal view of head of ilium and third sacral rib, $1580 / 15, \times 1 / 3 ; J$, second sacral rib, $1580 / 110, \times 1 / 3 ; \mathrm{K}$, see under $\mathrm{H} ; \mathrm{L}, \mathrm{M}$, Ilium, medial and lateral respectively, 1580/107, $\times 1 / 3 ; \mathrm{N}$, Astragalus, 1580/120, $\times 1 / 2 ; \mathrm{O}$, Right femur, anterior, $1580 / 107, \times 1 / 3 ; \mathrm{P}$, Partial hind foot as preserved, $1580 / 126, \times 1 / 3$.

the head is well formed and somewhat reminiscent of the sigmoid notch of the ulna in adult specimens. It has a strong rugose knob rising above its proximal end. The medial (anterior) surface of the head carries a strong, rugose ridge. The shaft is rather broad and thin and is twisted about 30 degrees in relationship to the articulation of the distal end with the tarsus. As a rule, this twist has been destroyed by crushing in the course of preservation. 
The distal articular region is broad and rather narrow with its articular surface usually poorly ossified.

Hind foot (figs. 18, 22): A good representation of hind feet is available for the caseids. Ossification was well developed and apparently there were very strong tendinous connections of the various elements which held them together for periods sufficiently long that they were preserved in articulation. There is a common pattern with differences in proportions and in the number of phalanges.

The astragalus and calcaneum are large and, in general, conform to the pelycosaurian pattern. The medial margin of the astragalus has an incisure for an artery and in some instances, as in Cotylorhynchus bransoni, this is developed into a fully enclosed foramen. Both the astragalus and calcaneum are marked by strong rugosities and ridges for the attachment of tendons of the muscles of the lower limb and foot.

Only a single centrale is present in the specimens known. This tends to be large and robust but shows considerable variation, probably the result of differing degrees of ossification. Five distals are present. The fourth is consistently large and in some, but not all, - the second is prominent. The other three are characteristically small, however, in Cotylorhynchus hancocki the fifth is large.

The metatarsals tend to be rather short and broad, but this varies in the different genera. They are proportionately long in Casea broilii and a maximum shortness and breadth are found in Cotylorhynchus. The first metacarpal tends to have a persistent hook shape as emphasized by Williston in Casea broilii. This has been considered diagnostic of the caseids and it is evident to some degree in most of the genera and species. The development is, however, varied and almost non-existent in some cases. Generally, the fourth metatarsal is larger than the others, but it may be matched or even exceeded by either the third or the fifth.

The phalangeal formula is much reduced over the usual pelycosaur formula of 23454. In Cotylorhynchus romeri it is 22332 and in Cotylorhynchus bransoni it is 22232 , the lowest number found within the family. Ennatosaurus tecton has the formula 22332 and $A n$ gelosaurus dolani appears to be 22233. Williston described Casea broilii Wiiliston as having the formula of 23454 . There is no concrete evidence to indicate whether or not this was the actual case. In Casea nicholsi the fourth toe has four phalanges. Two are present in the second toe and there certainly was an ungual, giving the number of three. The third and fourth toes in the front foot have three 
and four elements respectively. This suggests a formula of 23344 for the hind foot, but only on the assumption that there was similar reduction, except for the fifth toe, in the front and hind feet. Casea broilii certainly had no fewer phalanges and may have had more. It could have had the formula 23454 as Williston suggested, although there is no reliable evidence to that effect.

Ungual phalanges, as in the front foot, are claw-shaped, with a range from very blunt claws in Angelosaurus and Ennatosaurus to slender claws in Casea. 


\section{SYSTEMATICS}

\section{Class REPTILIA}

\section{Subclass Synapsida}

\section{Order Pelycosauria}

\section{Suborder Edaphosauria}

\section{Family Caseidae}

The family Caseidae comprises edaphosaurian pelycosaurs characterized by skulls that are very small in proportion to body size and which have very large external narial and pineal fenestrae. The skull platform is deeply pitted. The temporal fossa is moderately large and posterior to it is a vestigial otic notch formed by the supratemporal and squamosal bones. The post-temporal fossa is large and lies high and somewhat medially on the gently sloping occipital surface. The braincase is distinctive in the possession of a series of cavities, presumably related to a complex system of venous sinuses.

Marginal teeth range from 10 to 20 in number in both upper and lower jaws. They have circular bases and somewhat waisted crowns. The anterior teeth terminate in rather blunt, slightly recurved points. The upper premaxillary teeth are long and crown length decreases with moderate regularity posteriorly along the tooth row. Cheek teeth above and below carry a series of longitudinally placed cuspules, three to seven in number, which produce a serrated termination of the crown. The crown is moderately to strongly spatulate. Palatal teeth are well developed but vary in size and arrangement within the family.

Postcranial structure is distinctly edaphosaurian. The trunk is broad and barrel-shaped with very long, recurved ribs. The five most posterior presacral ribs are fused to their vertebrae. There are three or four sacral ribs and a long tail. Limb bones are relatively short, heavy, and well ossified in adults. The tibial head is very broad. Feet have less than the primitive phalangeal formula of 23453(4), except possibly in Casea broilii. Ungual phalanges are very strong and clawlike. 


\section{Casea Williston}

Casea Williston, 1910b, p. 590.

Genotype.-Casea broilii Williston.

A genus of caseids of small to moderate size, possessing the usual caseid features including a relatively small skull, with large nares, large pineal foramen, and large temporal fenestra, marginal cheek teeth with serrated crowns, long, curved ribs forming a barrel-shaped body with the last five fused to the vertebrae, three sacral ribs, and feet, in at least some species, with phalangeal formula less than that of primitive pelycosaurian reptiles; the genus lacks the high degree of specialization of the skull, dentition, limbs and feet found in other genera. The phalangeal formula is greater than that in other caseid genera as far as known. The formula is not known in Casea halselli and in two other genera, Caseoides and Caseopsis.

The genus was first described as the type genus of a new family, Caseidae, by Williston in 1910. Subsequently, the description was elaborated by Williston in 1911b, 1913b, 1914b and 1916a. Many other references were made to the genus, mostly rather casual, up to 1940 when Romer and Price (1940, pp. 416-419) gave a concise but comprehensive review and revision of the morphology. Subsequently, two additional species were described (Olson, 1954), Casea nicholsi and Casea halselli. The most recent references are in Stovall, Price and Romer (1966).

\section{Casea broilii Williston}

(Figures 2, 5, 6, 11, 14, 15, 19, 21)

Holotype.-FMNH UC 656. Skull and skeleton, uppermost Arroyo or lowermost Vale formation, Clear Fork group, early Permian. From Indian Creek, Baylor County, Texas. (Williston, 1910b, p. 590.)

Referred materials. - All known specimens of the species have come from a single pocket known as the Cacops bone bed, discovered and excavated by Paul Miller in 1909 and 1910. The specimens of Casea were in association with skeletal remains of Cacops and Varanops, intermingled in such a way that identification prior to preparation proved difficult. This has given rise to some problems in numbering of referred materials, since in some instances numbers were given to "specimens" that later turned out to include more than one genus. Removal and renumbering of parts was sometimes done. Romer and Price (1940) referred six numbered specimens to the species, as follows. 


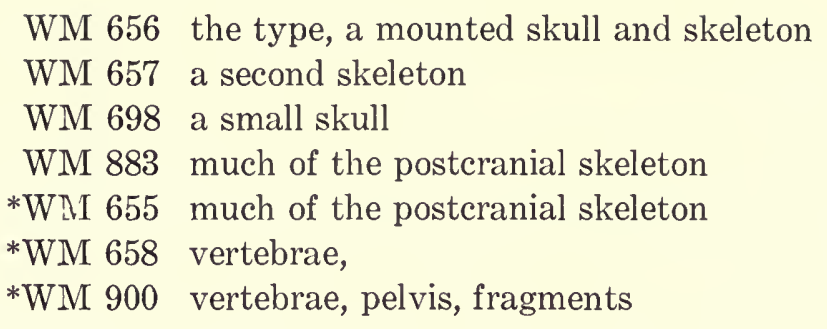

Those marked with the asterisk $\left(^{*}\right)$ are in error as the collections now stand. The rest exist, although not always precisely as described. In addition, there are specimens not listed. Since the time that Romer and Price worked on the collections they have been shifted to the Field Museum of Natural History and all have been given numbers with the prefix FMNH and some indication of the source. Those specimens already numbered in the University of Chicago collections are labelled FMNH UC, this being used both for those earlier given the letter UC or WM, which were used somewhat interchangeably in print. The list that is given below uses the correct designations.

FMNH UC 656. The holotype, a mounted skull and skeleton.

FMNH UC 657. All that now carries this number is a right hind foot. Romer and Price indicate that there is a second skeleton and Williston (1911b) figured some ribs. These references appear to be in error since there is no evidence of such materials and the card catalogue carries no references beyond the foot.

FMNH UC 698. A skull, listed as smaller than UC 656 by Romer and Price, but of approximately the same size in most measurements.

FMNH UC 883. Much of the postcranial skeleton including an excellent column with most of the presacrals, some caudals, and three sacrals. In addition, there is a pelvis, ribs, some limb bones and various fragments. The specimen is only partially prepared.

FMNH UC 901. A partial skeleton of Casea broilii not fully prepared. It includes a front foot, two radii, two humeri, part of the shoulder girdle, some ribs, and vertebrae. This probably is the material numbered with the hind foot under UC 657 , for it corresponds very closely to the materials figured 
by Williston under this number. The history of the change in number is not clear, assuming this to have been the case.

FMNH UC 1011. The lower part of a skull and part of the lower jaws. This is a newly prepared specimen not associated with others listed. It shows in particular the nature of the cheek dentition and the nasal capsular region.

The other referred specimens in Romer and Price (1940) are incorrect as the collections now stand, as follows:

WM 655. There is no specimen of Casea broilii with this number. The material so marked by Williston (1911b) in plates XVII, XIX, XX, XXI, XXII, and XXIII all appear to be part of the type FMNH UC 656 (formerly WM 656). The problem seems merely to be one of error in labels on the plates.

WM 658. There is no specimen of Casea broilii under this number, which is assigned to a poor specimen of Edaphosaurus.

WM 900. This was a number given to a block of material which included a skull and partial skeleton of Cacops and some vertebrae of Varanops. It is the number given to a specimen of Cacops sent to the Texas Memorial Museum, University of Texas in an exchange. Earlier it had been identified as Casea prior to preparation.

Conditions of occurrence and horizon: All of the materials of this species have come from a single pocket, called the Cacops bonebed a few feet in length and breadth and about 2 feet deep. Except for Trichosaurus, which conceivably may have caseid affinities, no other sign of the family has been found in equivalent or older beds of the Texas Permian. The matrix was a red shale, part of the band of even red shale that occurs at this level, above the typical Arroyo beds and below the coarser sediments that make up much of the lower Vale. As noted above, Cacops and Varanops occur as skeletons with Casea and Williston reported Seymouria and Captorhinus present as fragments. Neither Cacops nor Varanops occurs elsewhere, except for the possible presence of Cacops in the Choza (see Olson, 1956). Other dissorophid amphibians, however, do occur in the Arroyo and Vale, 
and Varanodon, which is quite close to Varanops, occurs in the Chickasha formation of middle Flowerpot age in Oklahoma (Olson, 1965).

The red shales were considered as Arroyo by Romer and Price (1940) and by Williston. In 1940, no fossil bearing horizons were known above the level at which the Cacops bonebed was found. Since that time much has been discovered and in 1954 I suggested that the age of the beds was lower Vale rather than Arroyo. This was based upon the supposition that these even red shales marked the equivalent of the Standpipe dolomite to the south. This has not been clarified further, but it is quite clear that the deposits lie above typical Arroyo beds and below the usual coarse clastics of the Vale.

Description: Williston's descriptions and figures in the cited references gave a great deal of information about this genus and species. They were modified and amended by Romer and Price (1940). There are, however, a number of details that have been revealed by additional preparation and some modifications in interpretation that arise as the result of a more complete knowledge of other species and other genera in this family. The descriptions that follow cover these points only and thus are intended to merely be supplementary to the earlier descriptions.

1. The skull (pl. 2; figs. 2, 5). The figures show new reconstructions of the skull of Casea broilii Williston. Various details are shown in Plate 2 and Figure 5 as well. The principal points of importance revealed in this study and illustrated in the figures are as follows:

(a). The occipital condyle is directed rather sharply downward, with the articular surface making an angle of about 40 degrees with the horizontal plane of the basicranium.

(b). The supratemporal and tabular overhang the squamosal to form a small but distinct notch.

(c). The parasphenoid has rather strong posterior tubera which are separate and terminate posteriorly at about the level of the descending process of the transverse flange of the pterygoid. Each carries two somewhat irregular rows of small teeth. Carried forward these pass onto the cultriform process, merging to form two rows and, near the anterior end to form a single row.

(d). The basipterygoid processes arise at the level of the coalescence of the two parasphenoidal tubera and form prominent laterally projecting spurs. These fit into rounded sockets formed ventrally by the pterygoids and more dorsally by the epipterygoids. The joint is widely open and freely moveable. 
(e). As Williston (1914) and later Romer and Price (1940) have indicated, the palatal bones are almost completely covered by teeth. In general, the largest of these occur on the margins and the smallest are in the center of the palate. There exist on the palate, however, rather deep grooves, as described on page 238 and illustrated in Plate 2 and Figure 5. These do not carry teeth and appear to have formed conduits, possibly for air from the internal nares to the throat.

(f). The stapes is as shown in Figure 6, and as described under the general consideration of caseid morphology on page 245. The element is pelycosaurian in many respects but is distinctive in the absence of a stapedial foramen, the distal position of the dorsal process, and the presence of the quadrate articulation on the side of the shaft.

(g). The braincase is shown in Figure 5 in medial aspect. The otic portion is broad and short and rather poorly ossified in the specimen in which it could be seen. The fenestra ovalis is very large and leads directly into the poorly ossified open space in the periotic. Presumably, the sacculus, utriculus and semi-circular canals were in this recess. This appears to be a fairly normal pelycosaurian situation except for the lack of ossification. This is in considerable contrast to that in more specialized caseids (see the general description and also that of Angelosaurus romeri and Cotylorhynchus hancocki). Back of the fenestra ovalis, presumably between the occipital and periotic, is a well-developed jugular foramen.

The periotic is fairly massive and carries a strong paraoccipital process. As in other caseids, it forms the lateral osseous part of the braincase and carries a dorso-anteriorly directed surface lateral to the cranial opening (see stereophotograph on Plate 4 for Angelosaurus). This surface is gently rounded and is host to a large foramen that leads to an unossified region in the periotic.

The ventro-anterior portion of the periotic carries forward, flanked by the ascending wing of the quadrate process of the pterygoid to the base of the ascending ramus of the epipterygoid. There is a slight notch on the anterior surface of the periotic, suggesting the position of a proötic incisure.

On the lateral surface of the periotic, anterior to the post-temporal foramen and leading into it, is a shallow, but well-defined depression.

At the base of the braincase is a very shallow sella turcica. The identity of the ossification forming the dorsum sellae is not determinable. On either side, somewhat anterior to the anterior termination of the dorsum sellae are the broad bases of the ascending rami of the 
epipterygoids. In both UC 698 and 1011, they rise but a short distance and terminate in unfinished bone, presumably being continued in cartilage. The posterior surface of the base of the epipterygoid is somewhat cup-shaped and the cup houses part of the pterygoid. Ventrally, the epipterygoid continues into the socket of the palatalbasicranial articulation.

Ossification is generally poor in the sphenethmoid region. In the skull of the holotype (UC 656) there is considerable bone in this region, but it is badly preserved and not well prepared. Its nature is uncertain. UC 698 possesses a low but rather strong interorbitalinternasal septum. Rising above this is a pair of small wing-like processes. They are short and thick, as shown in Figure 5. Presumably, these represent partial ossification of the sphenethmoid cartilage complex. More posteriorly the dorsal surface of the anterior part of the cultriform process is grooved, presumably in accommodation of a cartilaginous base of a presphenoidal component of this complex.

The nasal region is shown in UC 968 and UC 1011. To either side of the low internasal septum the palatine bone rises to encompass its basal portion. These palatine processes are also raised laterally so that each forms a trough which slopes down anteriorly, reaching the anterior part of the internal naris.

Above the anterior end of this trough in UC 1011 is a complex element that appears to be the septomaxilla. It is somewhat distorted and difficult to interpret. The groove in the palatine noted above carries ventrally to the lateral margin of this element and probably was a conduit for Jacobson's organ. Laterally, above the anterior end of the groove there is a thin plate of the septomaxilla which passes toward the maxilla and nearly reaches it. A triangular opening, seen in anterior aspect in Figure 16, leads to a small foramen which, in turn, passes to a small canal to the posterior surface of the bone. These structures are quite similar to those described by Romer for Dimetrodon. In addition, however, there is a second more medial foramen not described in that genus. The septomaxilla is also present in Ennatosaurus as described and illustrated elsewhere in this paper. The bone in that genus is proportionately much larger than in Casea broilii.

A notable feature of the orbitonarial region is the deep, U-shaped groove in the postnarial bar. This is formed by the maxilla which partially encloses the lacrimal. It seems probable that the lacrimal duct lay in this groove, although the entry to the bone has not been 
identified. A shelf-like horizontal abutment passes under the canal, producing a grooved conduit that leads to the posterior end of the nasal opening.

Clearly, the narial region in Casea is a complex and specialized part of the skull. The similarities of the known parts in other caseids makes it probable that the conditions described in Casea and in Ennatosaurus are representative of those throughout the family.

(2). Dentition (pl. 2; figs. 2, 5, 6). Williston (1911b) and Romer and Price (1940) have cited 11 as the number of upper teeth and Romer and Price indicate 12 in the lower jaw. Preparation of the teeth in the holotype UC 656 and in UC 698 was rather crude and details are hard to make out. UR 1011, in which the cheek teeth have been worked out more carefully, has 13 uppers. The twelfth and thirteenth are very small. While there may have been some variation in number, the chances seem good that all had at least twelve and that breakage and damage in preparation reduced the apparent number in the other specimens.

The front teeth of UC 1011 were broken, but the cheek teeth of the upper jaw are excellent. As seen in Figures 1, 4, 5 and in Plate 2, the cheek teeth carry small cuspules that produce a crown terminating in a tricusped pattern, much like that in Cotylorhynchus. These cuspules were destroyed in preparation in the other specimens. It has not been possible to determine whether or not they also occur on the lowers, but in view of the condition in other caseids there seems no doubt that they are present.

\section{Casea nicholsi Olson}

(Figures 14, 17, 19, 21)

Holotype.-FMNH UR 86. A partial skull and lower jaws and much of the postcranial skeleton. From the upper part of the Vale formation, Clear Fork group, early Permian, Knox County, Texas (Olson, 1954, p. 194).

Referred specimen.-FMNH UR 85 is the only referred specimen. It was found in direct association with the holotype and, like it, consists of a partial skull and much of the postcranium.

Discussion and description.-As no new materials have been found since the original descriptions, relatively little can be added to what was given then. The species is differentiated from other species of Casea by its size, intermediate between $C$. broilii and $C$. halselli. In most measurements it is about 1.25 to 1.35 times greater than $C$. broilii and only .60 to .80 the size of $C$. halselli. 
As in all caseids, with the possible exception of Ennatosaurus, the posterior five ribs of the presacral series are fused to the vertebrae, a point not noted previously. Preparation subsequent to the original description has revealed some more information on the lower hind limb and the hind foot. What is now known is shown in Figure 18. The tibia proves to have a well-developed caseid-type head, in contrast to the situation in C. broilii Williston in which this condition is merely incipient. In other features as well, the pelvis, the femur and the phalangeal formula of the front foot, this species of Casea shows a higher development of the familial specializations than does the earlier species, $C$. broilii.

\section{Casea halselli Olson}

(Figure 20)

Holotype-FMNH UR 117. Pelvic girdle with ilium damaged, partial left femur and tibia, head of right femur, four caudal vertebrae, fragments of lumbar vertebrae. Middle part of the Choza formation, Clear Fork group, early Permian, Foard County, Texas (Olson, 1954, p. 200).

Discussion.-The holotype is the only known specimen of this species. It was fully described in the earlier publication (Olson, 1954). The distinguishing features are its size, the very broad based, flat pelvic plate formed by the pubis and ischium, and the relatively short and heavy limb elements. As noted earlier, this is the largest of the three known species, exceeding Casea nicholsi on the average of the 4:3 in comparable measurements. As far as can be told from the preserved parts, mainly the pelvis, femur and tibia, C. halselli has attained in full complement the characteristic features of specialized members of the family Caseidae. This species shows a trend toward Cotylorhynchus in the structure of the pelvis. It is an approximate contemporary of Cotylorhynchus romeri from the Hennessey formation of Oklahoma. While much smaller, the preserved bones show many resemblances to those of this genus. A principal difference is found in the relative shortness and stockiness of the hind limb bones. Measurements are given in Table 3a.

\section{Caseoides Olson and Beerbower}

Caseoides Olson and Beerbower, 1953, p. 399.

Genotype.-Caseoides sanangeloensis Olson and Beerbower.

The genus includes one species, a caseid reptile of moderate size with very heavy and short limb bones. The head of the tibia is very 
broad, resembling that of advanced caseids rather than the less advanced, such as Casea broilii.

No new material and no additional details have come to light since the original description. Closest affinities are with Casea halselli of the mid-Choza formation.

\section{Caseoides sanangeloensis Olson and Beerbower}

(Figures 16, 20, 21)

Holotype.-FMNH UR 151. Right hind limb and part of foot, part of left femur, humerus, fragments of vertebrae including two centra and scrap (Olson and Beerbower, 1953). The holotype and also referred materials all come from the red shale phase of the middle part of the San Angelo formation, Pease River group, Guadalupian, Knox County, Texas.

Referred material.-There is but a single referred specimen, FMNH UR 152. It consists of a left femur, the top of an ilium, part of the symphysial region of the pubis, vertebral centrum and scrap.

Discussion.-The principal known osteological features of the limb bones of this genus and species are shown in Figures 16, 20 and 21. More complete information is available in Olson and Beerbower, 1953, and Olson, 1962. Representative dimensions are given in Table 3a.

Since relatively little is known of the skeleton and nothing of the skull, precise placement among the caseids is difficult. Clearly, the genus is very close to Casea and in the development of short, stout limb bones it carried on the tendencies shown by this genus during the Clear Fork. As far as the records now show, this marks the end of this particular line of development.

\section{Caseopsis Olson}

Caseopsis Olson, 1962, p. 26.

Genotype.-Caseopsis agilis Olson.

A medium-sized casid genus characterized by relatively lightly built skeletal elements. Limb bones in particular are long and slender and the blade of the ilium is high. The articular surfaces of the limb bones are small in comparison to those of other caseids of comparable size. Cheek teeth are spatulate with three small cuspules disposed in a longitudinal plane. 
Caseopsis agilis Olson

(Figures 10, 20 and 21)

Holotype.-FMNH UR 253, part of the skull and jaws, a lumbar vertebra and fragments of others, part of the left scapula, radius, ulna, pelvis, femur, parts of the tibia and fibula and foot bones. From the base of the upper part of the San Angelo formation, Pease River group, Guadalupian, Knox County, Texas.

Discussion. - The holotype which is the only known individual, was described in some detail in the original publication. The only additional information has come from a re-examination of the teeth after it was noted that a pattern of cuspules was widespread among caseids. It was found that these did exist on the somewhat damaged teeth in Caseopsis. The most striking feature of this genus is the length and slenderness of the limb bones and girdle elements. Measurements are given in Tables $3 \mathrm{a}$ and $4 \mathrm{a}$. In this it approaches most closely to the much smaller species, Casea broilii, and departs widely from later species of this genus, Casea nicholsi and Casea halselli.

\section{Caseopsis cf. agilis Olson}

A specimen from the lower part of the Flowerpot formation, FMNH UR 255 (Olson, 1962, p. 27) has been referred tentatively to this species, FMNH UR 255. The preserved bones are somewhat longer than those in Caseopsis agilis, as known from the holotype. As in that specimen, the tibial head is not markedly enlarged. There is nothing that can be added to the original description or the determination that this Flowerpot specimen is close to Caseopsis agilis and perhaps conspecific with it.

\section{Phreatophasma Efremov}

Phreatophasma Efremov, 1954, p. 316, fig. 68, pl. 27, fig. 3.

Genotype.-Phreatophasma aenigmaticum Efremov.

This genus is based upon a single femur. It has both caseid and edaphosaurid characters. Efremov (1954) assigned it to the Phreatosauridae. Olson (1962) indicated, following a tentative suggestion of Efremov, that it probably was a caseid. This tentative assignment still seems the most reasonable, although it is far from certain.

\section{Phreatophasma aenigmaticum Efremov}

(Figure 20) 
Holotype.-PIN 294/24, a single small femur from the Santagulov Mine in Baskir Province, on the Dema River, U.S.S.R. The basal part of the Kazanian, Zone I, U.S.S.R.

Nothing can be added to the information given in the cited references with respect to this genus and species. The most important point is that it suggests the presence of a rather primitive caseid in the early Kazanian, considerably before the time that Ennatosaurus existed. This hinges, of course, on the assignment to the Caseidae which cannot be validated unless additional materials are discovered, which at present, at least, seems highly improbable.

\section{Trichasaurus Williston}

Trichasaurus Williston, 1913 b, p. 366.

Genotype.-Trispondylus texensis Williston, synonym Trispondylus Williston, 1910 (non Cope). Genotype the same.

This is a genus of edaphosaurian reptile known from only one specimen. It cannot be definitely assigned within the suborder but probably is either an edaphosaurid or caseid.

\section{Trichasaurus texensis (Williston)}

Holotype.-FMNH UC 652. A partial skeleton including part of the vertebral column, pelvis, some limb and foot elements and scrap. From the middle part of the Arroyo formation, Clear Fork group, Leonardian, Permian, Baylor County, Texas.

This specimen has been fully described and discussed by Romer and Price (1940). They explored its position among the pelycosaurs as thoroughly as possible. MCZ 1352, a jaw, was referred to this species tentatively by Romer and Price (1940). As Stovall, Price and Romer (1966) have pointed out, this specimen pertains to Labidosaurikos, not known in 1940. If Trichasaurus texensis is in fact a caseid, it is the oldest representative of the family presently known. Casea broilii, usually accorded this position, occurs at the ArroyoVale boundary 200 to 300 feet higher in the section. It seems probable that Trichasaurus is an edaphosaurid rather than a caseid and that is the assignment considered most likely in the present paper. The genus is not taken up in considerations of caseid evolution.

\section{Cotylorhynchus Stovall}

Cotylorhynchus Stovall, 1937, p. 308.

Genotype.-Cotylorhynchus romeri Stovall. 
This is a large genus of caseid reptile in which many of the familial characteristics find their full expression. It is rivaled in size only by Angelosaurus, and the largest species of Cotylorhynchus far exceeds the members of this genus in overall proportions. Skulls are proportionately small as compared with the large, broad bodies, but they tend to maintain about the same ratio to body length in the different species. Marginal teeth in the upper and lower jaws range in number from 16 to 20 . The anterior teeth are long, slender and somewhat recurved above, shorter and slightly procumbent below. Cheek teeth are typically caseid with expanded waists and serrated crowns. In all species there are three crown cuspules disposed longitudinally. While the tooth row is basically isodont there is some reduction in length of the teeth posteriorly and the degree of difference varies somewhat between the three species. Palatal teeth occur in more or less discrete rows radiating from a crude center near the inner margin of the transverse crest of the pterygoid. All species carry teeth on the cultriform process of the parasphenoid bone.

The posteranium shows few variations from the pattern established in Casea, with modifications in large part related to increase in size. Ribs are very long, heavy, and curved to form a bulbous body. They are present on all presacral and the first several caudal vertebrae. The posterior five presacral ribs are fused to the transverse processes of the vertebrae. There are three large sacral ribs with the middle one the largest.

Vertebrae are typically caseid. In large specimens the neural spines become proportionately longer, especially in the pelvic region. The maximum development is found in Cotylorhynchus hancocki specimens, which appear to have run as much as 20 feet in length. Limbs are short and stout and the feet are terminated by strong, sharp, recurved, clawlike ungual phalanges. Muscle and tendon scars are prominently developed.

Currently, three species are known, C. romeri Stovall, the genotype from the Hennessey formation of Oklahoma, $C$. hancocki Olson and Beerbower, the largest species from the San Angelo formation of Texas, and C. bransoni Olson and Barghusen, a relatively small species from the Chickasha Tongue in the Flowerpot formation, Oklahoma. Size is a fairly dependable species character, and correlates well with morphological features distinctive of the species. As Stovall, Price and Romer (1966) have pointed out, however, in C. romeri, there are two size groups that presumably represent a sexual dimorphism. This seems to apply in $C$. hancocki as well, although it has 
not been as clearly shown. There is no overlap in size between adults of $C$. romeri and $C$. hancocki, but the largest specimens of $C$. bransoni are of about the same dimensions as small specimens of $C$. romeri.

\section{Cotylorhynchus romeri Stovall}

Holotype.-OUSM 4-O-S1, the right side of a skull, part of an interclavicle and a right and left manus. From the Hennessey formation about 200 feet above the Garber-Hennessey contact, approximately $43 / 4$ miles west of Navina, Logan County, Oklahoma. NW 1/4 Sec. 4, T $15 \mathrm{~N}, \mathrm{R} 4 \mathrm{~W}$. The specimen was found in a red shale not associated with any other vertebrate remains (Stovall, 1937, p. 308).

Discussion of the composition of the holotype.--Some problems concerning the make-up of the holotype have come into the literature. In the initial description Stovall (1937) designated the type as above, except that his included only the left manus. He also referred to a second specimen consisting of a skull and some vertebrae. It is now clear that there was no second specimen and that in one way or another an error crept in. There is no second specimen in the collections of the Stovall Museum and a detailed examination of the excellent records of discovery by William Strain indicates that no such specimen was collected either during the initial work or any time prior to publication of Stovall's report. In his characteristically meticulous locality data, Strain reported (in January, 1937):

"Material: Eryops (?). Skull and cervical vertebrae with one complete articulated foot and possibly another."

Preparation, of course, showed this to be a new genus of reptile. It may be that the "possibly another" plus the fact that similar specimens were soon discovered near Norman, Oklahoma were parlayed into the existence of the supposed second specimen in the Navina site. To clarify this matter I wrote to Dr. Strain, now at Texas Western College in El Paso. He conferred with Dr. McAnulty, who had assisted in the collecting and remained at Oklahoma after Dr. Strain had left, and then replied as follows.

"We agree that there are only two small blocks. One contained an articulated foot and the other a part of the skull and what we thought were vertebrae. I think the 'possibly another' meant we thought there might be another foot.

"Dr. McAnulty remained at the University of Oklahoma after I left and he assures me that no other specimens were taken from the locality. I don't know how the confusion arose but am sure 
that the two packages we collected were the only materials from that site."

There is in the collections a right front foot, numbered 4-O-S1, evidently the foot of the second block. The first block did yield a foot, but the supposed vertebrae turned out to be an interclavicle. The holotype properly thus should include the two front feet, the half skull, lower jaw and the interclavicle. No other specimens have come from the site. Recently we covered it thoroughly once again, finding no trace of any vertebrate remains.

Referred materials.- Shortly after the discovery of the specimen that became the holotype, specimens of Cotylorhynchus were found in considerable numbers in the vicinity of Norman, Oklahoma. A total of 37 specimens is listed in the card catalogue of the Stovall Museum. There are duplications in this listing and some specimens are not accounted for. Some specimens have been scattered and several are not identified by any sort of a number. Thus it is impossible to associate specimens with numbers and the sites, in a number of instances. The holotype, for example, is listed as 4-0-S1, 4-1-S1 and 4-17-S1, reflecting the mix-up on the identity of parts of the specimen. ${ }^{1}$

The list in Table 2 is presented in detail for, although it is not complete, it brings together in print materials that give a good idea of what is available for study of this genus. Cotylorhynchus, because of the wide distribution of skeletons, is one of the best known and least written upon of the pelycosaurs. Until the recent report by Stovall, Price and Romer (1966) only the original paper Stovall (1937) and Romer and Price (1940) have any morphological consideration of the species.

Because several skeletons were discovered and a number distributed to other museums, the idea has become widespread that the principal way in which the animals occur is as complete skeletons. While a substantial number of skeletons has been collected, a lot of

1 The numbering system, which is quite useful, is as follows: the first number gives the taxonomic category, here 4 designates pelycosaur; the second number designates the part of the animal: $0=$ skeleton, and so on; the third is the accession number with S indicating Stovall Museum. In addition there are, in some instances, museum numbers as well, thus 4-0-S7, a mounted specimen in the museum, also has the number 1251. In some instances the $\mathrm{S}$ in the last place is not added. In Stovall, Price and Romer (1966) this is not used. The 4-0-1 of their designation and 4-0-S1 used here mean the same thing. This is not the case in most of the collections, where the absence of the $\mathrm{S}$ means the specimen does not belong to the museum. In the list in Table $2(\mathrm{x})$ means that the specimen has been located and associated with its proper number. As accurate a condition as I was able to attain is given in detail below in Table 2. 
TABLE 2.-The specimens of $C$. romeri as determined from the collections, cards and notes in the Stovall Museum, University of Oklahoma.

$(x)$, Specimens identified in collections.

NUMBER (OUSM)

4-0-S1 (x) Holotype, part skull, part interclavicle, two front feet (also 4-1-S1, 4-17-S2)

4-0-S2 (x) Caudal vertebrae, pelvis, hind limb (Mus. No. 1249)

4-0-S3 (x) Partial skeleton of young individual

$4-0-S 4(x) \quad 41 / 2$ caudal vertebrae, pelvis

4-0-S5 (x) Radius, ulna, front foot, part of second foot

4-0-S6 Part of foot

4-0-S7 (x) Most of skeleton, mounted (Museum number 1251)

4-0-S8 (x) Anterior $1 / 2$ skeleton, first 19 vertebrae, ribs, humeri, scapulae

4-0-S9 (x) Miscellaneous fragments, ribs, etc.

4-0-S10 (x) Complete skeleton, left femur, tibia, pes missing

4-0-S11 (x) Foot, tarsals, metatarsals, phalanges, 10 ribs, fragments of vertebrae, pelvis, femur

4-0-S13 Part skeleton

4-0-S14 Ribs, part of foot

4-0-S16 (x) Foot, radius, humerus, tibia, fibula, femur, vertebrae, pelvis

4-0-S17 (x) Fragments, mainly ribs

4-0-S18 (x) Partial skeleton, no skull, hind limbs

4-0-S20 (x) Part of skull, shoulder girdle, left fore limb, foot

4-0-S21 Incomplete skeleton

4-0-S21 (duplicate no.)
Ribs, humerus, right pes and manus, part pelvis

\section{LOCALITY}

Ross Farm, Logan Co., Okla. (see holotype for precise locality)

Pierce Farm, SE 1/4 NE 1/4

Sec. 17 T 9 N R $2 \mathrm{~W}$,

Cleveland Co., Okla.

Near Norman, Cleveland

Co., Oklahoma

Polk Farm, NW 1/4 Sec. 16 T $9 \mathrm{~N}, \mathrm{R} 2 \mathrm{~W}$, Cleveland Co., Oklahoma

Polk Farm, see data 4-0-S4

Boggs Farm, NE 1/4 Sec. 16

T $9 \mathrm{~N}, \mathrm{R} 2 \mathrm{~W}$, Cleveland

Co., Oklahoma

Polk Farm, see data 4-0-S4

Pierce Farm, see data 4-0-S2

SW $1 / 4$ Sec. 7, T 9 N, R 2 W

Cleveland Co., Oklahoma

Boggs Farm, data as for 4-0-S6

Boggs Farm, data as for 4-0-S6

Near Norman, Cleveland Co., Oklahoma

Burton Farm, SW 1/4 Sec. $24, \mathrm{~T} 8 \mathrm{~N}, \mathrm{R} 2 \mathrm{~W}$

Near Norman, Cleveland

Co., Oklahoma

Burton Farm, see data 4-0-S14

Burgess Farm, SE 1/4 Sec. 14 , T 8 N, R 2 W, Cleveland Co., Oklahoma

South of Cedar Lane Golf

Course, SE 1/4 Sec. 15,

T $8 \mathrm{~N}, \mathrm{R} 2 \mathrm{~W}$, Cleveland Co., Oklahoma

South Oklahoma City, Cleveland Co., Oklahoma

Polk Farm, data as for 4-0-S4 
TABLE 2.-The specimens of C. romeri as determined from the collections, cards, and notes in the Stovall Museum, University of Oklahoma-Continued

\begin{tabular}{|c|c|c|}
\hline \multicolumn{2}{|c|}{ NUMBER (OUSM) } & LOCALITY \\
\hline $4-0-\mathrm{S} 23(\mathrm{x})$ & Skull & $\begin{array}{l}\text { Polk Farm, data as for } \\
4-0-S 4\end{array}$ \\
\hline 4-0-S24 & Partial skeleton & $\begin{array}{l}3 \text { miles north of Norman } \\
\text { on Highway } 77 \text {, Cleveland } \\
\text { Co., Oklahoma }\end{array}$ \\
\hline $4-0-\mathrm{S} 25$ & Scapula, ulna, foot, ribs & Same as for $4-0-S$ \\
\hline $4-0-S 26(x)$ & $\begin{array}{l}\text { Partial skeleton, no skull, end of tail, } \\
\text { fragment lower jaw }\end{array}$ & $\begin{array}{l}\text { Richardson Farm, } 21 / 2 \text { east } \\
\text { on Highway } 9 \text {, south of } \\
\text { road, Sec. } 34 \text {, T } 9 \mathrm{~N}, \mathrm{R} 2 \mathrm{~W} \text {, } \\
\text { Cleveland Co., Oklahoma }\end{array}$ \\
\hline $4-0-\mathrm{S} 28$ & Fragments & $\begin{array}{l}\text { Noble, } 21 / 2 \text { miles east } \\
\text { Highway } 77 \text {, Sec. } 25 \text {, T } 8 \mathrm{~N} \text {, } \\
\text { R } 2 \text { W, Cleveland Co., Okla. }\end{array}$ \\
\hline $4-1-\mathrm{S} 2(\mathrm{x})$ & Part skull and lower jaws & $\begin{array}{l}\text { Near Norman, Cleveland } \\
\text { Co., Oklahoma }\end{array}$ \\
\hline 4-1-S3 & Indeterminant bones & $\begin{array}{l}\mathrm{NE} 1 / 4 \text { Sec. } 15, \mathrm{~T} 8 \mathrm{~N} \\
\mathrm{R} 2 \mathrm{~W}\end{array}$ \\
\hline 4-1-S5 (x) & $\begin{array}{l}\text { Skull and jaws (from which cast was } \\
\text { made) }\end{array}$ & $\begin{array}{l}\text { Norman area, Cleveland } \\
\text { Co., Oklahoma }\end{array}$ \\
\hline $4-1-S 10$ & Skull and jaws & Norman area \\
\hline $4-8-\mathrm{S} 1$ & Lumbar vertebrae & $\begin{array}{l}\text { Near Norman, Cleveland } \\
\text { Co., Oklahoma }\end{array}$ \\
\hline $4-10-S 2$ & Caudal vertebrae & Polk Farm, see 4-0-S4 \\
\hline $4-10-\mathrm{S} 2$ & $\begin{array}{l}\text { Vertebral column (these two may be } \\
\text { the same) }\end{array}$ & Polk Farm, see 4-0-S4 \\
\hline $4-11-\mathrm{S} 1(\mathrm{x})$ & 3 ribs & $\begin{array}{l}\text { Pierce Farm, data as for } \\
4-0-\mathrm{S} 2\end{array}$ \\
\hline $4-12-\mathrm{S} 1(\mathrm{x})$ & $\begin{array}{l}\text { Scapula, humerus, radius, phalanges, } \\
\text { foot }\end{array}$ & $\begin{array}{l}\text { Near Norman, Cleveland } \\
\text { Co., Oklahoma }\end{array}$ \\
\hline 4-21 to $24-\mathrm{S} 1$ & $\begin{array}{l}\text { Numbers given to scraps that prob- } \\
\text { ably pertain to other numbered speci- } \\
\text { mens }\end{array}$ & $\begin{array}{l}\text { All near Norman, Cleve- } \\
\text { land Co., Oklahoma }\end{array}$ \\
\hline $4-32-S 1(x)$ & Fragments & $\begin{array}{l}\text { Near Norman, Cleveland } \\
\text { Co., Oklahoma }\end{array}$ \\
\hline $\begin{array}{l}\text { Mus.no.1250 } \\
\text { (OUSM No. ?) }\end{array}$ & Skeleton & $\begin{array}{l}\text { Near Norman, Cleveland } \\
\text { Co., Oklahoma }\end{array}$ \\
\hline $\begin{array}{l}\text { FMNH PR } \\
272(\mathrm{x})\end{array}$ & Skeleton lacking skull & $\begin{array}{l}\text { Near Norman, Cleveland } \\
\text { Co., Oklahoma }\end{array}$ \\
\hline USNM ( $\mathrm{x})$ & Skeleton lacking skull & Same as above \\
\hline $\mathrm{AMNH}(\mathrm{x})$ & Skeleton lacking skull & Same as above \\
\hline $\mathrm{MCZ}(\mathrm{x})$ & Skeleton lacking skull & Same as above \\
\hline
\end{tabular}


fragmentary material, both collected and not collected, has also been found. This, of course, has a bearing upon the nature of disposition of the remains. Also, the species is known only from two areas. It is not found widespread in the very extensive Hennessey exposures. This is not a matter of lack of search. Within the last two years, we have covered most of the Hennessey exposures without finding any signs of this animal beyond the two known localities. The stratigraphic range is likewise limited to about a 100 -foot section in the lower half of the Hennessey formation.

The integrity of the species.-Stovall, Romer and Price (1966) on the basis of the Norman materials showed that there were two size groups present. It was suggested that this could possibly indicate more than one species, but that in all probability it was a matter of sexual dimorphism. The latter interpretation seems well based and there may be assumed to be but one species in the Norman materials. Crushing is usually severe and proportions and other possible small differences are of little value for species determination. Size is of some use but less than fully satisfactory since there seems to be no terminal growth in this genus, as for most reptiles. One thing that does seem useful is dentition. As far as the number of teeth in the jaw can be determined in the various caseid genera and species, it seems to be nearly constant, varying at most by only one tooth. Even this variation may be largely due to the difficulty of determining the existence of a very small posterior tooth. Checks have been possible in Casea broilii, three specimens, Ennatosaurus tecton, Cotylorhynchus hancocki, about 10 specimens each, and the Norman skulls and lower jaws of Cotylorhynchus romeri, four on which counts were possible, show 16 teeth in each jaw. The holotype has 20 above and, apparently, the same number in the lower jaw.

The cheek teeth in both the Norman materials and the holotype have a very weak tricuspid pattern, but the teeth of the holotype are much more longitudinally compressed than those in the Norman specimens. This may be an actual morphological difference, but it may also be in part due to postmortem deformation.

Only this dental difference is detectable. Foot structures and a few skull features offer the only other bases for comparison. The phalangeal formula does differentiate $C$. romeri, both type and Norman materials, from $C$. bransoni, but the same formula certainly cannot be taken as an indication of specific identity. The holotype occurred about 40 miles distant from the Norman materials and no specimens have been found in between. Both, however, are in sim- 
ilar sediments. Stovall states that the holotype occurred about 200 feet above the base of the Hennessey. The Norman materials range through about 100 feet of the section, from about 150 to 250 teet above the base. Thus stratigraphically the materials are approximately the same.

There does then exist some chance that the holotype of $C$. romeri and the referred materials do not represent the same species With only the dentition to go on, however, and very few specimens in the samples, it seems to introduce unwarranted complexities to assume that there are two species. It should be kept in mind as study goes on that this may be the case, but for the present, for the purposes of this study, it is assumed that all the materials in the list are referable to C. romeri and that there is but a single species now known from the Hennessey formation.

Description.-Stovall, Price and Romer (1966) have given a detailed description of the postcranium of $C$. romeri based, except for the front foot entirely upon the materials from the Norman area. No additional description is necessary. The principal bones of this species are illustrated in Figures 12-17 and 19-21 in comparison with those of other species of caseids. Essential dimensions are given in Tables $3 \mathrm{a}$ and $4 \mathrm{a}$.

\section{Skull}

\section{(Figures 2, 8)}

No new description of the skull and jaws has been made since that by Romer and Price (1940). Some new materials have become available since then and new information from other species has made some of the features of $C$. romeri more comprehensible. As far as the descriptions of Stovall (1937) and Romer and Price (1940) could be carried they are excellent and accurate.

New information comes from three specimens, OUSM 4-1-S2, 4-1-S10, and museum number 1250 . All are only partially preserved and somewhat crushed. The internal structures that they preserve correspond closely to those seen in Cotylorhynchus hancocki, Angelosaurus romeri, and Ennatosaurus tecton, affirming the homogeneity of the skull structure in large caseids suggested by these species. A number of important features are shown in Figure 7, based upon 1250.

The basicranium is in very large part covered by a parasphenoid, as Romer and Price (1940) show. The posterior wings of the parasphenoid are thick and flared. The articular face of the occipital con- 
dyle is reflected sharply downward, somewhat more so than shown by Romer and Price. The rostrum of the parasphenoid, the cultriform process, carries teeth. These are shown only in 1250 and even in this specimen are rather obscure. There are two rows posteriorly. They do not pass onto the wings of the parasphenoid. Teeth continue well forward on the process, but it has not been possible to determine anything beyond the fact that they are present and small. The condition of the parasphenoidal rostrum is not shown in 4-1-S5 from which the palatal reconstruction of Romer and Price (1940, pl. 19) was made.

The periotic shows the distinctive caseid structures highly developed, as in Cotylorhynchus hancocki, Angelosaurus romeri and, apparently, Ennatosaurus tecton. The anterodorsal margin of the periotic passes from the level of the inner surface of the skull roof forward and in rather gentle slope. The surface is broad and forms a dorsoanteriorly facing shelf. On one side, in 4-1-S10, there appears to be an oval foramen on this surface, passing into the body of the periotic. From about the half-way point on the sloping surface a strong process passes forward and somewhat ventrally to make junction with the parasphenoid-basisphenoid at the level of the craniopalatal joint. Presumably, the trigeminal nerve issued below this bar.

On the posterior portion of the lateral surface of the periotic, a shallow fossa occurs. It lies close to the post-temporal fossa and seems to have communicated with it. There is almost no detail available concerning features of the structures within the periotic portion of the braincase. Presumably, the distinctive features found in other large caseids were present, but no materials are sufficiently preserved to confirm this.

The only other detail to be seen in these materials pertains to the pterygoid bone. The quadrate process carries a high, very thin wing that passes dorsally and lies closely appressed to the lateral surface of the periotic.

\section{Dentition}

(Figure 2)

The dentition in most respects is much as described by Romer and Price (1940). Two items, however, are of particular interest. As mentioned previously, 16 and not 20 is the usual number of teeth in both the upper and lower jaws. Both the anterior teeth and the cheek teeth conform closely to the general Cotylorhynchus pattern. The crowns are somewhat spatulate and the waists are expanded. 
Beginning with about the fifth tooth the spatulate crowns carry three longitudinally-arranged cuspules. These were not noted in earlier descriptions. They appear only on little worn teeth and are best seen on the inner surfaces of the crowns. It was thought earlier (see Olson, 1962) that the serrated pattern of the teeth had developed within the genus. It is now evident, however, that it is a general caseid feature, present even in Casea broilii, as described in this report.

The pterygoid dentition was described by Romer and Price (1940). As in all species of Cotylorhynchus, the teeth are disposed in rows. They are slender and fine in $C$. romeri contrasting with those of $C$. bransoni which are more robust, but resembling those in $C$. hancocki. The parasphenoidal teeth were noted earlier.

\section{Cotylorhynchus hancocki Olson and Beerbower}

(Figures 2, 8-12, 14-21)

Holotype.-FMNH UR 154. A right humerus and proximal end of a tibia from the upper part of the San Angelo formation, north of the Pease River on the Crowell-Quanah highway, Hardeman County, Texas (Olson and Beerbower, 1953, p. 401).

This is the largest of the species of Cotylorhynchus with linear measurements of the principal elements exceeding those in fairly large specimens of $C$. romeri by 20 to 25 per cent (Tables $3 a$ and $4 a$ ). It differs from $C$. romeri and $C$. bransoni in both size and proportions of elements. The differences are brought out in Figures 11, 12, 14-21 which show comparable elements.

Referred materials.-In Olson (1962) 52 specimens are referred to the species. These range from fairly complete skeletons to individual bones. All are from the San Angelo formation and most of them come from the Kahn Quarry in Knox County, Texas, described in that publication. Nine additional specimens, also from the Kahn Quarry, have been obtained since 1962, as follows: FMNH UR 875, pelvis, UR 877, a clavicle, rib and cervical vertebrae; UR 878, femur and fibula; UR 879, humerus, clavicle, rib, radius, 8 vertebrae, a chevron; UR 881, tibia; UR 892, scapulocoracoid, 2 vertebrae; UR 893, tibia, sacral vertebrae; UR 894, partial pelvis, 2 sacral vertebrae and 1 caudal.

Description.-A full description of this species was given earlier (Olson, 1962). For completeness in this report, figures of the principal bones are given as noted under the heading and measurements are included, Tables $3 \mathrm{a}$ and $4 \mathrm{a}$. Nothing can be added to the de- 
scriptions of the postcranium. Although there are no new skull materials some of the features found in other caseids help in interpretation of the parts of skulls known for $C$. hancocki. A reconstruction of the skull is shown in Figure 2. It is shown as conforming closely to the general caseid pattern inasmuch as this is the case for all features that are known.

Problems of interpretation of the braincase arose from the structure of $C$. hancocki as presented in 1962. These related in part to the appearance of large spaces, seemingly for vascular sinuses in the braincase and lateral to it. It now is known that similar features occur in other caseids. The structure is best revealed in a specimen of Angelosaurus romeri Olson and Barghusen described elsewhere in this paper. As far as can be told, the braincase in $C$. hancock $i$ is very similar to that in $A$. romeri, so that no special description is needed.

In the earlier description of $C$. hancocki a set of "canals" in the occipital and temporal regions was noted but no explanation was found. No similar structures have been found in other caseids and nothing that gives any solution to the problem has been encountered.

C. hancocki has 17 or 18 marginal teeth above and below. They are much like those of $C$. romeri, except larger. The three-cuspule pattern tends to be somewhat more developed in $C$. hancock $i$ than in C. romeri, but less developed than in C. bransoni. The disposition of palatal teeth is not well known. Presumably, it was not different from that in $C$. romeri, for in both species the palatal teeth were slender and short. It is now known that the tooth-bearing bone interpreted as pterygoid in UR 622 (Olson, 1962) is actually a toothbearing parasphenoid (fig. 8). This bone has two rows of small teeth that merge anteriorly into a single one. The new interpretation follows from comparison of the specimen with those of $C$. bransoni in which conditions are clearly shown.

\section{Cotylorhynchus bransoni Olson and Barghusen}

(Plates 3 and 4; Figures 8, 10, 12-21)

Holotype.-FMNH UR 835. Left side of pelvis, left femur, partial sacral rib. From the Chickasha Tongue in the middle part of the Flowerpot formation, Permian, Omega Quarry (KF-1), Kingfisher County, Oklahoma (Olson and Barghusen, 1962, p. 21).

This is the smallest known species of Cotylorhynchus, with its largest members about the size of the smallest individuals of $C$. romeri. It differs from $C$. romeri in proportions, as brought out in 
Olson and Barghusen (1962), in the more distinctly developed serrated pattern of the cheek teeth, and in the dentition of the pterygoid, see Figure 8 and Plate 4, with the teeth fewer in number, larger, and more robust in C. bransoni. There are size and proportional differences between $C$. bransoni and $C$. hancocki, with overlap of adult skeletal dimensions only at extremes of size ranges. The phalangeal formula, 22232, is the lowest known in Cotylorhynchus, with 22332 for $C$. romeri and 223-2 for $C$. hancocki.

Referred materials.-New materials have been found since the original description. Most of these were listed in a more recent publication (Olson, 1965). All specimens unless otherwise specified, are from the Omega Quarry, Kingfisher County, Oklahoma, the site of the holotype. The list is as follows: FMNH UR 836, foot, UR 837, part of forelimb; UR 838, astragalus; UR 839, tibia; UR 840, fibula; UR 841, maxilla, two teeth; UR 842, ungual; UR 843, ungual; UR 905, part of foot; UR 910 cervical ribs; UR 912, clavicle; UR 913, chevron; UR 915, series of vertebrae; UR 918, scapulocoracoid; UR 919, scapulocoracoid; UR 923, sacral vertebrae; UR 929 pterygoid; UR 937, caudal vertebrae; UR 972, caudal vertebrae, locality BC-6; UR 982, 4 dorsal vertebrae; UR 983, dorsal vertebrae, locality BC-2; UR 984, part of humerus, locality BC-7; UR 988, base of pelvis, hind foot, locality BC-7. The localities other than KF-1 are in Blaine County, Oklahoma near Hitchcock (see Olson, 1965).

Description and discussion.-As the list of materials shows, much of the skeleton of this species is now known, but there is little information about the skull and jaws. The only additional skull material is an excellent pterygoid bone. Reference to $C$. bransoni is based upon the rather light structure and the slender teeth. A second pterygoid, which is much heavier and with strong, blunt teeth, is referred to Angelosaurus romeri. Neither is associated with other materials, but inasmuch as these are the only two caseids known among abundant skeletal remains, they almost certainly pertain to these two genera. The relative massiveness and robustness seem to give a clear basis for assignments as made. Figure 8, and Plate 4, show the main features of the pterygoid. The quadrate process rises up above the main ramus in a high, thin sheet much as it does in $C$. romeri and Angelosaurus romeri. There is indication of a somewhat similar structure in Casea, and this pattern may be a universal caseid feature. There is no other additional information on the skull, jaws or dentition. The known cheek teeth and partial maxilla are shown in Figure 10. 
Some additions can be made to the original descriptions of the postcranium. Illustrations of all known skeletal elements are shown in Figures 12 through 21. For those not described previously, the following comments will supplement the figures.

The vertebral column consists of typically caseid vertebrae and ribs. Except for size, they are for the most part indistinguishable from those of other species of Cotylorhynchus. Spines are proportionately less high in the sacral region than they are in the very large species, $C$. hancocki. Vertebrae and ribs also are very similar to those of Angelosaurus romeri, so much so that there is great difficulty distinguishing them in the event of any deformation or other faulty preservation. No full column is present and there is not sufficient overlapping duplication that a count of the numbers of vertebrae in different parts of the column is possible. There were three sacrals as in other species (fig. 13). As in C. romeri the sacral ribs are moderately long and extended rather directly laterally, with the ilia well spread. This is in contrast to $C$. hancocki in which the sacral ribs curve ventrally more sharply and the ilia are (relatively) closely spaced.

The scapulocoracoid (fig. 14) includes a scapula that is somewhat less broad proportionately than in the other two species. The posterior margin swings sharply posteriorly above the rather narrow neck. The anterior margin has the deep supraclavicular notch noted for other species. The glenoid fossa is somewhat longer in proportion to its width than in the other two species and the anterior part of the coracoid plate is less extended anteriorly. Otherwise, the scapulocoracoid resembles that in $C$. romeri and $C$. hancocki closely. Presumably, most of the differences are primarily size dependent.

The humerus is distinctly of the Cotylorhynchus pattern well known in $C$. romeri and C. hancocki. There are no differences evident except those of size. Possibly there were actually minor proportional differences, but the humerus is so susceptible to crushing that these must be considered indeterminate.

The only other point of interest in new materials is the conformation of the phalangeal formula in the hind foot of 22232 , found in UR 988 as well as in UR 836, as previously described.

\section{Angelosaurus Olson and Beerbower}

Genotype.-Angelosaurus dolani Olson and Beerbower, 1953, p. 401.

The genus includes caseids characterized by heavy, massive bones. The proximal elements of the limbs possess extremely well-developed 
ridges, processes and rugosities for muscle and tendon attachment. Species range from moderate to large size, with the largest rivaling Cotylorhynchus romeri in overall dimensions. Skulls are short and stout and the teeth, as known from Angelosaurus romeri, are short and blunt in the anterior part of the tooth row and with spatulate crowns with five longitudinally-arranged cuspules in the posterior part.

Three species are now known, all described in earlier publications, Angelosaurus dolani Olson and Beerbower, A. greeni Olson and $A$. romeri Olson and Barghusen. Only for the last has new information become available.

\section{Angelosaurus dolani Olson and Beerbower}

(Figures 12, 13, 18-21)

Holotype.-FMNH UR 149. Much of the posterior part of the skeleton, some anterior vertebrae, a humerus and fragments of the skull and jaws. From the middle part of the San Angelo formation, Pease River group, upper Permian, Knox County, Texas (Olson and Beerbower, p. 403).

Referred specimen.-FMNH UR 701, which consists of fragmentary remains of vertebrae from the same location is the only referred specimen.

The original description by Olson and Beerbower (1953) was augmented by descriptions and new illustrations by the writer (Olson, 1962). The species is characterized by a very heavy, massive skeleton. It is intermediate in size between the other two species. Skeletal elements are shown in Figures 12, 13 and 18-21, and pertinent measurements are given in Tables $3 \mathrm{a}$ and $4 \mathrm{a}$.

Much of the original and amended diagnosis and description remains unaltered. Further study, however, has modified somewhat the interpretation of the foot. The new interpretation is shown in Figure 18. The phalangeal formula appears to be 22233 for the hind foot. For full description and discussion the reader is referred to Olson and Beerbower (1953), Olson (1962) and Olson and Barghusen (1962).

\section{Angelosaurus greeni Olson}

(Figure 20)

Holotype.-FMNH UR 257. This specimen consists of a femur, vertebrae, parts of ribs and scraps. It is from the lower part of the 
Flowerpot formation, Pease River group, upper Permian, Knox County, Texas (Olson, 1962, p. 25).

Referred specimens.-FMNH UR 258, part of distal and of humerus, UR 264, fragments of pelvis and distal limb elements, UR 259, flattened humerus. All are from the same general horizon and locality as the type.

This is the largest known species. The femur is shown in Figure 20, and a measurement is given in Table $3 \mathrm{a}$. The only basis of differentiation from $A$. dolani is the much greater size. General shape and proportions of the few known elements are much the same. Full description and illustration are given in Olson (1962).

\section{Angelosaurus romeri Olson and Barghusen}

(Plates 3 and 4; Figures 7, 9, 10-16, 18-21)

Holotype.-FMNH UR 827. Pelvis, right femur, 16 presacral vertebrae, 3 (?4) sacral and 4 caudal vertebrae. Ribs in association with five posterior presacral vertebrae. The species is found in the Chickasha formation of middle Flowerpot age, ${ }^{1}$ El Reno group, upper Permian, Oklahoma (Olson and Barghusen, 1962, p. 33).

When this species was established all available materials were used in the description. It was known to be a small species, less heavy, and, in general, less specialized than either A. dolani or A. greeni. Continued excavation of the Omega Quarry in Kingfisher County, Oklahoma has produced a number of new and important specimens. Other characters that distinguish the species from $A$. dolani are now available. The femur was known earlier but the humerus, not known heretofore, adds details that aid in differentiation. New features of the skull and skeleton are brought out in the descriptions that follow.

Referred materials. - The following specimens are now assigned to Angelosaurus romeri. The numbers through 854 were assigned in the original paper (Olson and Barghusen, 1962), and the remainder were cited in a more recent study, Olson, 1966. Those given in the first paper and not in the list that follows were dropped on further study as indeterminate. A few specimens not listed in Olson, 1965, have been added as preparation has been completed. All specimens are FMNH and, unless otherwise noted, all are from the Omega Quarry, site KF-1, Kingfisher County, Oklahoma.

${ }^{1}$ In the earlier description this was given as the Flowerpot formation. Technically, the vertebrates occur in tongues of the Chickasha formation which interfinger with the Flowerpot, Blaine and Dog Creek formations as described by Fay (1964) and in context of vertebrate distributions by Olson (1965). 
UR 828, 2 sacral, 2 presacral vertebrae; US 844, right side of pelvis, ischium missing; UR 845, right pubis; UR 846, interclavicle; UR 847, anterior dorsal rib; UR 848, mid-dorsal rib; UR 849, middorsal rib; UR 850, anterior dorsal rib; UR 851, posterior dorsal rib; UR 853, 4 anterior caudal vertebrae; UR 854, fragment of snout, 2 teeth, UR 904, sacrum, 4 sacral vertebrae, 3 presacrals, 18 caudals, toe bones; UR 907, right scapulocoracoid, right humerus; UR 908, 20 presacral vertebrae; UR 909, left scapulocoracoid; UR 911, rather poorly preserved tibia (assignment in some question); UR 914, 4 toe bones; UR 916, 3 presacral vertebrae and ribs; UR 917, large left femur; UR 926, maxillary with 2 teeth; UR 927, brain case and part of palate; UR 928, large rib; UR 931, pterygoid bone; UR 932, anterior dorsal rib; UR 933, clavicle; UR 940 about 3rd presacral rib; UR 941, anterior dorsal rib; UR 942, single tooth; UR 933, pair of lower jaws; UR 944, 2 mid-dorsal ribs; UR 945, anterior dorsal ribs; UR 971, 20 caudal vertebrae, with ribs on anterior ones; UR 978, pubis; UR 979, ilia and ischia of young individuals; UR 980, right and left pelves.

Description and discussion.-The earlier descriptions can be augmented considerably on the basis of the new materials. What was given before was fairly detailed and will not be repeated here. It may be found in Olson and Barghusen, 1962. The bones described previously are illustrated in this paper in Figures 7, 9, 10-16, 18-21. Important measurements are given in Tables $3 \mathrm{a}$ and $4 \mathrm{a}$.

\section{Skull and Lower Jaws}

A fragment of an upper jaw with two teeth (FMNH UR 854) was tentatively assigned to $A$. romeri in 1962 . Nothing approaching a complete skull has been found, but a new fragment of maxilla, a braincase, a pterygoid and a pair of lower jaws that quite certainly pertain to the genus and species have been found. They are caseid, but clearly not Cotylorhynchus, and being from the same quarry as the holotype, are accepted as Angelosaurus romeri and assigned to that genus and species. All parts are consistent in showing a rather short, stout, heavy skull, with strong short teeth.

The major features are shown in Figures 7, 9, 10 and Plate 4. The braincase was described in fair detail in the general presentation of caseid morphology. It shows a strongly developed and complex sinus system which apparently is quite similar to that seen less well in Cotylorhynchus hancocki. Presumably, this was a vascular system related to collection and drainage of blood from the cranial region. 
A number of rather odd features in addition to the system of sinuses show up in the braincase, as they do in the braincase of C. hancocki. Some are visible in the stereophotographs of Plate 4. The large fenestra ovalis appears to open directly into the cranial cavity, with very little differentiation of the sacculus and utriculus from the braincase proper. This leads, in addition, to the somewhat disturbing conclusion that there was no osseous labyrinth, for no openings of the semicircular canals into the periotic can be found.

It is tempting to consider that the large fenestra in question is not the ovalis and such a thought is somewhat encouraged by the fact that no jugular canal is to be found. It would be convenient to consider the large opening the jugular canal, except for the problems that this creates. First of all, it leaves no fenestra ovalis at all. Secondly, the opening identified as the fenestra ovalis is in the "proper" position and in the same position relative to other structures as is the large opening in Casea broilii into which the foot of the stapes fits and which is flanked posteriorly by a normal jugular foramen.

This is clearly a structure that is odd among the pelycosaurs. It is found in both Angelosaurus romeri and Cotylorhynchus hancocki, and probably was present throughout these two genera. Casea broilii appears to have its labyrinth encased in cartilage and it does have a jugular foramen. A jugular foramen is present in Ennatosaurus tecton. No specimen of Cotylorhynchus romeri is well enough preserved for positive interpretation and, of course, we have no skulls of $C$. bransoni, $A$. dolani or A. greeni. It is possible that the less than perfect preservation of the specimens of $A$. romeri and $C$. hancock $i$ have led to a faulty interpretation. Only better preserved material can answer this, but at present the description as given appears to be correct.

A second odd feature of the braincase, noted in the general description, is the apparent forward extension of the periotic (proötic portion) in a process that goes to the basisphenoid-parasphenoid in the vicinity of the basipterygoid process. This, too, is found in $C$. hancocki and C. romeri, and it seems to be present in Ennatosaurus tecton. Presumably, this ramus represents the ossification of a cartilaginous process of the periotic, but it is very unlike anything found elsewhere among the pelycosaurs.

The dorsoanteriorly directed surface of the proötic, which contains a large foramen leading into a more ventral "sinus," has been noted in the family description and is well shown in the stereophoto- 
graphs of Plate 3. This again is so distinctive that its nature and function can only be guessed.

The occipital condyle turns sharply downward in this species, as it does in Cotylorhynchus hancocki and Casea broilii. The head appears to have been carried with its basicranial axis sharply deflected from the axis of the neck.

The pterygoid bone is relatively heavy and carries strong teeth, as shown in Figure 7 and Plate 4. The position of the pterygoid teeth is unlike that in Casea broilii, but resembles that in Cotylorhynchus, especially $C$. bransoni, rather closely. The teeth, however, are stronger and blunter than in Cotylorhynchus. They are disposed in a row along the transverse process of the pterygoid, merging with a small patch laterally, in a row along the margin of the palatal part of the pterygoid, and in a short row of very strong teeth more laterally.

The quadrate process of the pterygoid is short and stout and rises in a thin sheet that flanks the periotic much as in Casea broilii and Cotylorhynchus bransoni. Anteriorly, the two pterygoids appear to form a short median sutural connection anterior to the interpterygoidal vacuity. Laterally, there was sutural connection with the ectopterygoid and palatine.

The basipterygoid process of the basisphenoid appears to have inserted in a small open recess just anterior to the confluence of the pterygoid process and body of the pterygoid. Here a short basal portion of the epipterygoid appears to participate in the formation of the joint. There is no evidence of any other portion of the epipterygoid. The part that is present is a process that runs a short distance along the pterygoid proper and then fuses indistinguishably to it. There may have been an ascending ramus, as in Ennatosaurus, but in Angelosaurus, as in other caseids with the exception of Ennatosaurus, the ascending process has not been found. It may have been lost in each, but more likely it was formed only in cartilage.

The rostrum of the parasphenoid, Figure 7, appears to have laid in a narrow but open interpterygoidal vacuity. Lateral to it were the rows of teeth on the inner margins of pterygoids. There were strong teeth on this process, ending in a short whorl anteriorly. The craniopalatal joint, being open, permitted considerable differential movement between the parasphenoidal and pterygoidal teeth.

There is very little evidence concerning the lateral configuration of the skull as a whole. The premaxilla shows that the external narial opening was large and the maxillary fragment shows the existence of a large orbit. Both suggest that the skull elements were quite mas- 
sive as compared to those in Cotylorhynchus of comparable size. One gets the impression of a skull with the same basic pattern as that in other caseids, but a somewhat more solid and rugged version of this pattern.

The lower jaw and dentition are known from UR 943, which consists of a pair of lower jaws. Little but the dentary and dentition are preserved (pl. 4; fig. 9). The dentary is short and heavy and the symphysis is strong. There is a moderately strong and broad shelf at the ventral margin of the symphysis.

\section{Dentition}

The palatal dentition has already been discussed in connection with the structure of the skull. All that is known of the upper dentition comes from four teeth, two in the premaxilla and two in the maxilla, Figure 10. The first premaxillary tooth is very different from that of other genera of caseids, being thick at the base and tapering to a blunt termination of the crown. The second tooth is similar in shape, but much smaller. Neither shows any cuspules. The two maxillary teeth, while rather short and blunt, are typically caseid. The bases have a circular cross-section, waist is expanded, and the crown is spatulate. The crown is terminated by a rather flat, serrate edge, marked by five small, longitudinal cuspules. This approaches the condition in Ennatosaurus more closely than does any other known genus of caseid.

TABLE 3.-The wear pattern of lower teeth in Angelosaurus romeri. Teeth num-

bered from anterior to posterior 1 through 12 . S, slight wear; M, moderate; $\mathrm{H}$, heavy wear; $\mathrm{R}$, being replaced, thus absent; - , lost during preservation.

$\begin{array}{lcccccccccccc} & 1 & 2 & 3 & 4 & 5 & 6 & 7 & 8 & 9 & 10 & 11 & 12 \\ \text { Right } & \text { M } & \text { H } & \text { S } & \text { R } & \text { M } & \text { S } & \text { M } & \text { S } & \text { H } & \text { H } & \text { S } & - \\ \text { Left } & \text { M } & \text { H } & - & \text { R } & \text { M } & \text { S } & \text { M } & \text { M } & \text { M } & \text { H } & \text { H } & -\end{array}$

The lower dentition is shown in Figure 9 and Plate 4. Anterior teeth are short and blunt, with very expanded waists. The more posterior teeth are short and resemble the uppers rather closely. The five cuspules on the dorsal margin of the crowns are very distinct and blunt. There are 11 teeth on the right side and 12 on the left, counting as present those that are in the process of being replaced. Apparently 12 is the correct number, the lowest in any of the known North American caseids and approaching Ennatosaurus, in which there are 10.

The front teeth in the specimen at hand are very worn. Some of the more posterior teeth are worn and others are not. The cuspules 
are removed quickly with wear and the final stages produce a buttonlike crown with the surface formed by the rounded-off, bulbous waist of the central part of the tooth. The wear pattern is as given in Table 3.

\section{Postcranium}

Several parts of the postcranium were described in the initial publication on this species. New specimens have confirmed most of the details of this description and have added considerably to what was then known. The measurements in Tables $3 \mathrm{a}$ and $4 \mathrm{a}$ and Figures $12-$ 21 summarize this information. It can be seen by a comparison of the range of dimensions of specimens now known and those known previously that the size range in this species is considerably greater than was recognized. The largest known specimen, FMNH UR 917, compares favorably in size with specimens of Cotylorhynchus bransoni. Main points that can be added to the original descriptions are as follows.

Vertebrae and ribs (figs. 11-13). These are typically caseid and very difficult to differentiate from the vertebrae and ribs of Cotylorhynchus bransoni. It was thought at the time of the original descriptions that size provided a basis for differentiation, with $C$. bransoni larger. Now, however, as noted above, there is known to be a slight size overlap. Beyond this negative result, the one important find with regard to this part of the column is that UR 904, a specimen of Angelosaurus romeri, has four rather than the usual three sacral ribs. A fourth is added at the posterior end of the series, as shown in Figure 13. Only three were described in the holotype, but it is possible that the fourth was present and lost along with its vertebra. Four vertebrae may be the usual number in Angelosaurus romeri, but it is possible that UC 904 is aberrant in this regard. There are only three in the larger species, $A$. dolani.

Intercentra are well developed in the sacral region. In some specimens these are fused to the vertebrae and in others they are free.

Scapulocoracoid (fig. 13). Two scapulocoracoids are now known. As compared to those of Cotylorhynchus bransoni the scapula is rather narrow and the top is more flared, with the dorsal rim slanting sharply anteroventrally. The notch at the dorsal termination of the area of attachment of the clavicle is very deeply recessed and strongly buttressed.

Humerus (fig. 16, pl. 3). The humerus has been known heretofore only in Angelosaurus dolani in which it is extremely heavy and 
in $A$. greeni from a badly crushed specimen, which seems to be somewhat more lightly constructed. Preserved in association with the scapulocoracoid of FMNH UR 907 is an excellent humerus of $A$. romeri. It is a broad and heavy element with the ridges and processes strongly expressed. It does not, however, match the massiveness of A. dolani and is much more typically caseid.

Femur (fig. 20). The femur was described earlier as a distinctly massive, short element with the usual caseid features considerably accentuated. Additional femora have increased the known size range but otherwise are similar to the ones described previously.

Lower limbs. No lower limb elements that can be definitely assigned to $A$. romeri have been identified. A few foot bones were associated with UR 904, a poorly preserved tibia, UR 911, may be assignable, and four toe bones, UR 914, may belong. Other lower limb elements found in the Omega Quarry resemble those of $C$. branson $i$ very closely. It may well be that, as in the case of the vertebrae and ribs, resemblances between the species are so close that differentiation is not possible on the kinds of material available. If so, some of the bones assigned to $C$. bransoni could actually pertain to $A$. romeri.

\section{Ennatosaurus Efremov}

Ennatosaurus Efremov, 1956, p. 1091.

Genotype.-Ennatosaurus tecton Efremov.

A genus of the family Caseidae from zone II of the Russian Kazanian. The skull is very similar to that of Cotylorhynchus in most respects but the dentition contains only 10 teeth per jaw above and below. The teeth in the cheek region have strongly serrated crowns with 5 to 7 cuspules arranged in a longitudinal plane. The postcranium, while typically caseid, is small in proportion to the skull as compared to that in any other known caseid.

\section{Ennatosaurus tecton Efremov}

Plate 5; Figures 3, 4, 10, 14-20, 22, 23

Holotype.-PIN 1580/17, an adult skull and lower jaw. This is the specimen listed as PIN $1580 / 25$ by Olson (1962). ${ }^{1}$ This speci-

1 There has been some confusion concerning the numbers. Since I first studied the materials new specimens have been prepared and in some cases numbers were consolidated, new numbers given to specimens for which parts had been previously numbered, and so on. The numbers used in the paper are those permanently affixed to the specimens in the museum. Where there have been changes they are noted in the listing or text. 
men is hereby designated as the holotype, for none was named in the original description. There has been some confusion about the names of the genus and species. Efremov (1956), in his description, gave credit to Vyushkov on the basis that he was to publish a description, presumably before Efremov's publication. With the untimely death of Dr. Vyushkov this was not carried through. I followed Efremov in crediting Vyushkov in my first study of Ennatosaurus (Olson, 1962). As has been pointed out, however, in the "Fundamentals of Paleontology" (Orlov, 1962), the only mention of the genus and species by Vyushkov was in 1958, two years after Efremov's description and the name must be credited to Efremov. Efremov's description is adequate and the name should stand as it is with credit to him for the genus and species (Efremov, 1956, p. 1091).

Horizon and locality.- The type and all referred materials have come from a single locality on the bank of the Pinega River near the town of Karpoga. A concentration of specimens was found in red shales, not closely associated with any other vertebrates. The zone, in the system of Efremov, has been designated as II. The stratigraphy is not worked out in detail, but this would appear to place the genus as equivalent to or younger in age than any known North American caseid.

Referred specimens.-All referred specimens are PIN 1580/n, indicating the Pinega locality. Some were listed in Olson, 1962. Number changes are noted as necessary. A great deal of preparation was carried on in the Paleontological Institute of Moscow in order that I might make a complete study, for which I am most grateful, as expressed in the acknowledgements. As a result it has been possible to study in detail all of the available material of the genus and species. Many specimens not available for study earlier are included. A rather detailed listing is given, since these materials form the whole basis for the analyses that follow and are not available for first-hand study by most paleontologists outside of the U.S.S.R. The specimens now known are as follows. PIN $1580 / 5$, a fibula, isolated; $1580 / 6$, poorly preserved pelvis and scrap; $1580 / 7$, tibia, fibula and part of a hind foot of an immature individual; 1580/11, distal end of a humerus; $1580 / 12$, right humerus, part of scapula; $1580 / 10$ ribs; $1580 / 14$, skull with jaws and some vertebrae attached, this also carried the number $1580 / 20$, but see $1580 / 24$ below, another specimen given number $20 ; 1580 / 15$, ilium, head of tibia; $1580 / 16$, a lower jaw; $1580 / 18$, two dorsal vertebrae; $1580 / 19$, skull and jaws; $1580 / 22$, dorsal vertebrae; $1580 / 23$, ilium and sacral ribs; $1580 / 24$, a small 
skull and jaws of an immature individual. This also carried the number $1580 / 20$. It was listed as $1580 / 21$ in Olson (1962). The number $1580 / 20$ is discarded to avoid confusion. There is now no number 25 in the collections; $1580 / 25$ was used by Olson (1962). 1580/101, partial skeleton, 16 vertebrae and ribs, part of shoulder girdle, femur, ulna, radius (this and all subsequent specimens have not been noted or entered into the descriptions before publication of this report); $1580 / 102$, radius, ulna, carpus, scapula and part of coracoid; 1580 / 103 , ilium and sacral ribs; $1580 / 104$, single large vertebra; $1580 / 105$, four vertebrae, part of indeterminate limb bone and head of tibia; $1580 / 106$, three rather poorly preserved vertebrae and scrap; 1580 / 107, seven presacral and seven or eight caudal vertebrae, femur, ilium; 1580/108, humerus, part of radius and ulna, fragment of scapula, foot bones; 1580/109, fragments of vertebrae, part of scapula, radius; $1580 / 110$, two radii, small fibula, centrum, toe bone, sacral rib, all except radii quite immature; $1580 / 111$, centra of five and onehalf large vertebrae; $1580 / 112$, two partial maxillae with teeth; $1580 /$ 113, large interclavicle; $1580 / 114$, part of ilium; $1580 / 115$, part of two large anterior dorsal vertebrae; $1580 / 115$, scapulocoracoid; 1580 / 117, interclavicle, clavicle, scapulocoracoid, pterygoid with teeth, scrap; 1580/118, part of pelvis, right femur, head of tibia and scrap; $1580 / 119$, fibula; $1580 / 120$, part of scapula, humerus, radius, ulna, part of clavicle, foot bones; $1580 / 121$, ulna and part of humerus; $1580 / 122$, front part of left side of skull, showing part of palate, most of left lower jaw and part of right; 1580/123, scapula, part of two ribs, part of interclavicle, a very flat limb bone, fibula; 1580/124, crushed ulna and humerus; 1580/125 part of scapulocoracoid; 1580/ 126 , left pes of young individual; $1580 / 127$, right dentary of very young individual including nine teeth.

Description.-The following descriptions and illustrations are based upon first-hand studies of the materials. Both descriptions and illustrations are as complete as warranted by the specimens as presently prepared.

\section{Skull}

\section{Plate 5; Figures 3, 4, 10}

There are five fairly well-preserved skulls with lower jaws, a dentary of a very immature individual, two partial maxillae with teeth, a lower jaw and some separate palatal elements. Some of these specimens were described earlier (Olson, 1962) but additional preparation 
has added many details and new information comes from newlyprepared partial skulls and jaws. ${ }^{1}$

The basic skull structure is very close to that of Cotylorhynchus and thus is not far removed from the primitive condition revealed in Casea broilii. Restorations and figures of various specimens (figs. 3, 4 and 10, and pl. 5) show the degree of similarity. The shape of the skull is best shown by the holotype $1580 / 17$ and suture patterns are most clearly seen in the young individual $1580 / 24$. Brain case features have been taken in large part from 1580/14 and details of the palate from 1580/122. The composite figures have been reconstructed from these sources as appropriate and noted in the captions.

Dorsal and lateral surfaces: Measurements of skull are given for Ennatosaurus in Table 1a. As in all caseids, the external naris is very large. Lying in it in Ennatosaurus is a large septomaxilla (figs. 3 and 4). This was the principal basis for description of the caseid septomaxilla. No elaboration is needed here.

Orbits are large, subcircular and separated from the temporal fenestra by a narrow postorbital bar. The temporal fenestra is quadrilateral and relatively large.

The dorsal and lateral views in Figures 3 and 4 show the significant features of the dermal surface. The patterns of the constituent elements are fundamentally similar to those in all other caseids in which they are known. Figure 3 and Plate 4 show the posterior projection of the tabular and supratemporal which form a small "otic" notch. Figure 3 illustrates the relationship of the quadrate, quadratojugal and, in posterior view, a reconstruction of the occipital area. The presence of this notch was described in the general consideration of the caseid skull. It is most clearly seen in Ennatosaurus, presumably because this genus has much the best preserved skull materials There is no evidence that the stapes sent a process to this notch, but the stapes is known only in Casea broilii and no definitive statements can be made for Ennatosaurus or any other caseid genus.

${ }_{1}^{1}$ To clarify the current numbering, assignments, and specimens involved in earlier descriptions, the following list has been compiled:

Current Reference

PIN 1580/14, also has 20 on specimen......1580/19(1), Olson, 1962

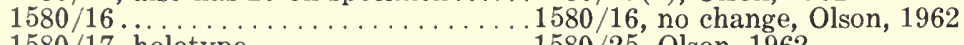

$1580 / 17$, holotype . . . . . . . . . . 1580/25, Olson, 1962

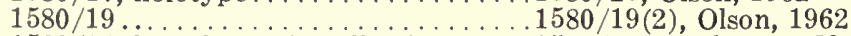

$1580 / 24$, has also 20 in collections . . . 1580/24, no change, Olson, 1962

$1580 / 112 \ldots \ldots \ldots \ldots \ldots \ldots \ldots \ldots$. . . . . . . . . .

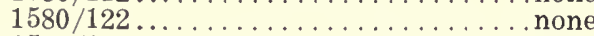

$1580 / 127 \ldots \ldots \ldots \ldots \ldots \ldots \ldots \ldots$ none 
Palate: A reconstruction of the palate is shown in Figure 3. It is based on details from several skulls. Most problematical is the anterior part, in particular the precise nature of the internal naris. The vomer appears to be a small paired element and to carry teeth. The palatine is not clearly shown as a separate element in any of the skulls, but in 1580/122 the position of its posterior medial edge is indicated by the pterygoid margin. The condition of the epipterygoid and pterygoid may be seen in Figure 4. As in other caseids, the quadrate process of the pterygoid bends ventrally to meet the transverse process and is deep and very thin. The pterygopalatal joint is freely open. In this genus, in contrast to at least some other caseids, the epipterygoid does not appear to participate in the formation of this joint.

Occiput and basicranium: The occipital region is rather badly distorted in all specimens in which it is present. Figure 3 shows a restoration based on $1580 / 14,17,19,24$. Sutures are not clearly shown in these specimens. The exoccipitals very nearly close above the triangular foramen magnum. The supraoccipital and opisthotic are fused, even in the youngest individual. The postparietal laps over onto the occipital surface but it is not altogether clear that there is a suture along the ventral line as shown in the figure. As in other caseids the post-temporal fossa is medially disposed. The significance of this has been noted in the general description of the caseid skull. The ventral aspects of the occiput and basicranium are shown in Figure 3.

The parasphenoid covers most of the basisphenoid and perhaps the basioccipital as well, but there is no sutural separation to indicate limits. The cultriform process of the basisphenoid is not preserved in any of the specimens. There is no evidence of teeth on the posterior part of the bone, but they may have been present more anteriorly without the posterior development, as in Angelosaurus and Cotylorhynchus. The pattern of palatal teeth otherwise is fairly similar to that of Cotylorhynchus.

Braincase: What is known of the braincase is shown in Figure 3 based on 1580/14. Had the braincases of Cotylorhynchus and Angelosaurus been fully studied at the time Ennatosaurus was worked out, it might have been possible to obtain a more complete understanding of the braincase of the genus. As it is, some of the interpretations are based on drawings made without recognition of the significance of certain features shown in the sketches. Some interesting points emerge. First, Ennatosaurus does have a well-developed 
jugular foramen in contrast to at least some other caseids. There is a large fenestra ovalis suggesting a large stapedial foot, but no stapes is preserved. In $1580 / 17$ a bone which could be the stapes lies near the appropriate area. It is $39 \mathrm{~mm}$. long, rather slender, and one end is enlarged. Quite likely this is the stapes, but it shows no detail of any importance other than general size.

On the lateral surface of the periotic there is a deep recess, like that in other caseids. The lateral aspect of the periotic has a generally caseid look and it appears to send a process forward to the area of the pterygopalatal articulation as is the case in Angelosaurus romeri, Cotylorhynchus hancocki, C. romeri and presumably other members of these genera.

Only in $1580 / 14$ is a sphenethmoid present. As shown in Figure 2, this is a large element, apparently single, lying in the interorbital region. The upper portion flares into a pair of wings and the lower portion forms a long, single, median keel. A notch occurs near the base of posterior margin and, anterior to it is found what appears to be a foramen. Anterior to this is a second foramen or pit. What these structures represent is not known. They may be related to sinuses and the circulatory system, for these are peculiarly developed in the caseid skull. There is no well-preserved sphenethmoid in any other known caseid.

\section{Lower Jaw}

Figures 3, 4 and 9

The lower jaw is typically caseid and resembles that of Cotylorhynchus very closely. The articular surface of the jaw is large, double and inflected strongly to face mediodorsally. Medioventrally to this surface is a very strong process, undoubtedly for insertion of part of the pterygoid musculature. There is essentially no retroarticular process. The articular bone has a long anterior process as shown in Figure 4. The adductor fossa is large and the posterior half is marked by a depression and ridge that appear to indicate the position of a strong, somewhat differentiated portion of the adductor musculature. The coronoid process is merely a low prominence back of the tooth row. It is formed medially by the posterior and much the larger of the two coronoid bones. As in all caseids, the outer surface of the lower jaw is smooth and nearly featureless. Anteriorly, this jaw terminates in such a way as to produce a somewhat chin-like profile. 


\section{Hyoids}

Plate 5; Figure 4

Part of the hyoid apparatus is preserved in two specimens, 1580/ 14 and $1580 / 19$, described under the general descriptions of the family, as these are the only known examples of the bones in this family.

\section{Dentition}

Figures 3, 4, 9, 10

The dentition was first described by Efremov (1956) and then by the writer (Olson, 1962). The upper teeth are shown in Figures 3 and 4 and the lowers in Figure 9. Measurements are included in Table $2 \mathrm{a}$. The dentition is typical for caseids with the anterior teeth somewhat recurved, elongated cones with some expansion of the waist and cheek teeth with spatulate crowns marked by serration. Cuspules range from five to seven, more or less the same in number as in Angelosaurus romeri.

Anterior teeth of the upper jaw are long. There is a more or less uniform decrease posteriorly. Front teeth in the lower jaw are proportionately shorter, although again the longest in the series.

Figure 10 shows the teeth of a young individual, $1580 / 24$. They are exceptionally long and little worn. How much of the difference from adults, such as shown in Figure 3, is due to wear and how much to actual modifications in teeth during ontogeny is not certain. It is evident, however, that more than just wear is involved and that there are important differences between generations of teeth. This may have interesting implications with respect to possible change of diets during ontogeny. Replacement did occur, but apparently at widely spaced intervals for any one tooth. The series tends to be fairly uniform with respect to wear, but an occasional strongly worn tooth does occur in a less worn series. Heavy wear took place prior to replacement.

Every specimen in which there was a complete tooth row has 10 teeth above and below provided that empty sockets along the tooth row are included. This is the lowest number among the caseids in which the full dentition is known. Palatal teeth have been noted earlier and can be seen in Figure 3.

\section{Postcranium}

Figures 14-20, 22, 23

In contrast to the skulls and jaws, for which materials are excellent, the postcranial materials of Ennatosaurus tecton are not abun- 
dant and not well preserved. Many of the bones are immature and it was suggested earlier (Olson, 1962) that this was generally the case. New specimens, however, show that completely mature elements are present. Although these are generally larger than the immature bones, they are nevertheless very much smaller than would be expected with skulls of the size of the adults in the collections in view of the skull-body size relationships in other caseids. This poses some very peculiar problems which are to be considered later. While there is little association of skull and postcranial material there is some and this shows without any question that the postcranial material, small as it is, does go with the relatively large skulls.

Table 3a shows a comparison of a few elements of Ennatosaurus tecton, Cotylorhynchus romeri and $C$. hancocki to give an idea of this matter of proportions. Although size variations would alter the ratios in the table somewhat, the discrepancies are striking. The postcranial dimensions of $E$. tecton are about one-half those of $C$. romeri, although skull lengths are about the same. A more or less similar relationship exists between Ennatosaurus and the large $C$. hancocki.

Vertebrae and ribs (fig. 22): Fifteen specimens include vertebrae and ribs. The most complete series is that in $1580 / 101$ in which there are 16 small, immature presacrals. The next largest number is seven in specimen 1580/7. Most of the vertebrae are crushed. The numbers of vertebrae in the various regions of the column cannot be determined and details of changes along the column cannot be worked out. In spite of these limitations some interesting points have turned up.

First, the vertebrae are much smaller in proportion to skull dimensions than in any other genus of caseid. Secondly, the centra have a deep pit on each side, as shown in Figure 22. Nothing of this sort occurs in any other genus, although in some large specimens intense crushing tends to produce a weak dimpling in this area.

The atlas is preserved in two specimens, in each case in articulation with its skull. The vertebra is lightly built and small. The articular surface for reception of the occipital condyle is present on the centrum and extends up onto the arches (fig. 22). There is a strong basal transverse process and a prezygapophysis that articulated with a movable joint on the exoccipital. A rather large atlantal rib was present.

The axis resembles the more posterior cervical vertebrae. It has a normal neural arch and a long, dorsal transverse process. A large 

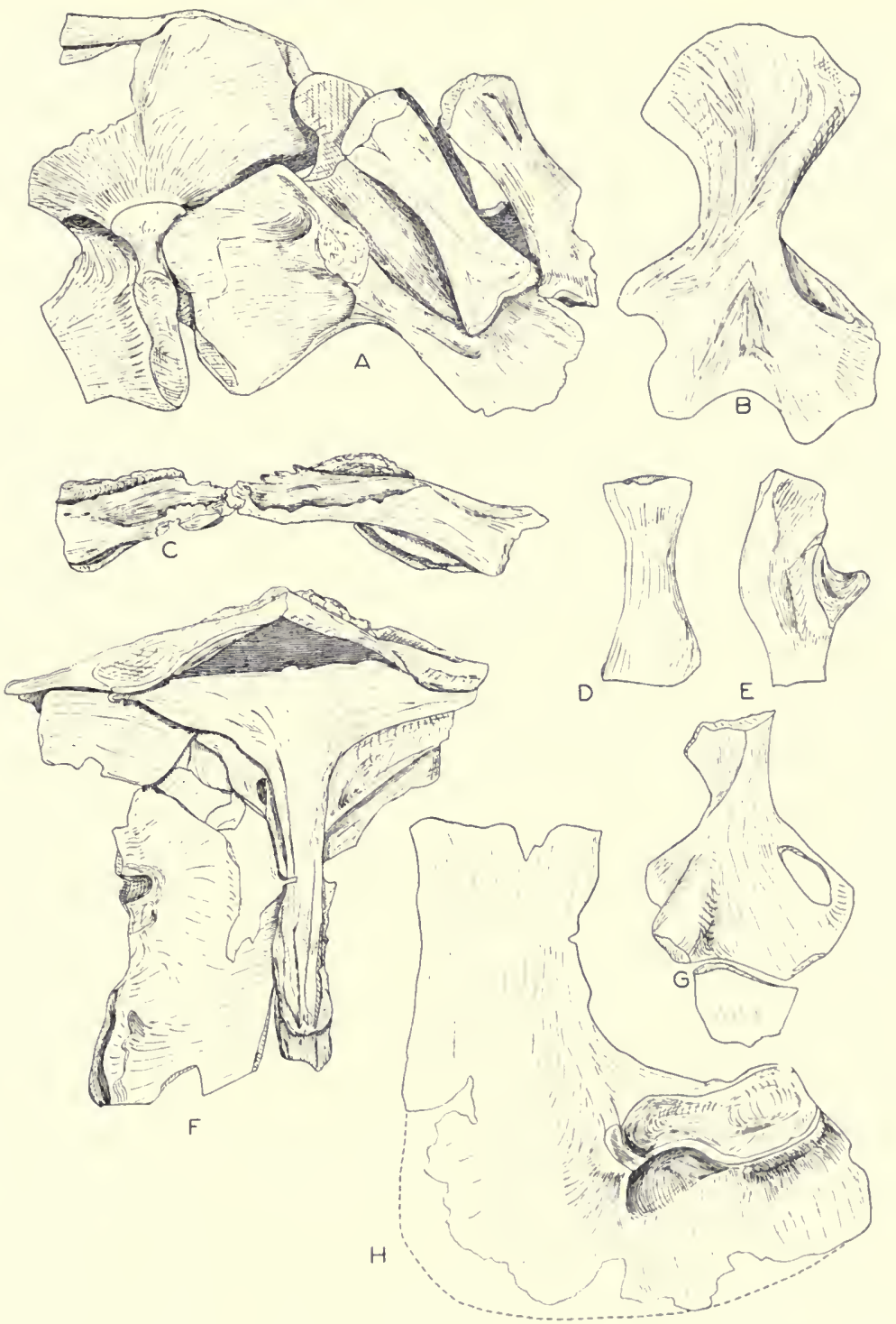

FIG. 23. Postcranial elements of large individuals of Ennatosaurus tecton as preserved, all $\times 1 / 3$. A, Part of scapulocoracoid, clavicle, humerus, radius and ulna, 1580/120; B, Humerus, dorsal, 1580/120; C, Clavicle and interclavicle in anterior aspect, see F below, 1580/117; D, Radius, 1580/110; E, Proximal end of large ulna, 1580/108; F, Clavicles and interclavicle, parts of scapulocoracoids, in ventral view, $1580 / 117$, see $\mathrm{C}$ above; $\mathrm{G}$, Humerus and head of radius, 1580/101; $\mathrm{H}$, Scapulocoracoid in lateral aspect, $1580 / 116$. 
intercentrum lies in front of the pleurocentrum (fig. 22). The remaining cervicals, thoracics and lumbars compare rather closely to the pattern in other caseids, except for the pitted centrum. Spines are short, transverse processes long and zygapophyses rather widely spread. Trends along the column are best shown in $1580 / 101$. There is some increase in central length (see Table 4a) from the cervicals through the thoracic region. Spine heights show little change. Transverse processes increase in length to reach a maximum at about the seventh or eighth thoracic. Thereafter they decrease.

Lumbar vertebrae are present in a very badly crushed partial skeleton 1580/111. No others have been identified. In other caseids ribs occur on all presacrals with the last five in the series fused to the transverse processes. This is to be expected in Ennatosaurus, but as far as can be determined from the badly preserved $1580 / 111$ fusion between the posterior ribs and vertebrae did not occur. More information is needed for a definite conclusion on this point.

Ribs are typically caseid being long, two-headed and curved into broad open arcs. No details are to be had from the specimens.

The sacral vertebrae were much like those of other caseids, but -there is no evidence of the specialization of the spines and of the sacral ribs such as are found in large species. Specimen 1580/111 shows the presence of three sacral vertebrae and three ribs. A rib from the first caudal extends forward to a position just back of the iliac blade and very nearly forms a fourth rib, like that found in Angelosaurus romeri. There probably was a ligamentous attachment between this rib and the ilium. In other features as well, the sacrum seems to resemble that of $A$. romeri more than that of Casea or Cotylorhynchus.

There is little that can be said about the caudals, for very few are preserved. As far as can be told they do not differ importantly from those of other caseids.

Shoulder girdle and forelimb (figs. 14-18, 23): Forelimb and girdle remains are found in a large number of specimens. Mostly they are scrappy and many of the bones are immature. Nonetheless a good idea of the nature of these structures can be had from what is present. Measurements of representative elements are given in Table 3a and the various bones are shown in comparison with other caseids in Figures 14-18.

The collection includes several partial shoulder girdles, but none is complete. The best scapulocoracoid is specimen 1580/116 (fig. 23). 
The total height of the scapulocoracoid in the largest specimen cannot have been over $150 \mathrm{~mm}$., or about one-third the height of that of $C$. hancocki. The blade is rather narrow and the posterior margin is only moderately concave. There is no deep incisure at the dorsal margin of the clavicular attachment to the scapula.

The coracoids form a broad plate which extends well back of the scapular blade, much as in Casea and in contrast to Cotylorhynchus and Angelosaurus. Clavicles are represented only by incomplete bones. $1580 / 102$ includes a dorsal fragment in position on the scapula and $1580 / 117$ includes the base, in position with respect to the interclavicle. These are shown in Figure 23. There are no special features to distinguish the clavicles from those of other caseids.

The anterior end of the interclavicle of $1580 / 117$ is poorly ossified. This is a feature found in various caseids. The stem is long and the wings are very wide, with a deeply depressed region for the insertion of the clavicles.

The humerus (figs. 16, 23) is like that of other caseids in many respects. The proximal and distal parts are broad and the shaft is short and stout. In contrast to the humeri of Cotylorhynchus and Angelosaurus, the ectepicondylar foramen is not completely closed. The radial condyle is moderately prominent, but the ulnar condyle is rather weak and deeply incised as compared with those of other medium-sized caseids. The ectepicondyle is not strong and the supinator shelf is small. The humerus resembles that of Casea and Trichosaurus (a probable edaphosaurid) more closely than it does the humeri of other caseid genera.

The radius and ulna are represented in a number of specimens. Their principal features are illustrated in Figures 17 and 23. In full development the olecranon is large, much as in Cotylorhynchus. The radius shows no distinctive features. Two specimens, $1580 / 7$ and $1580 / 102$, give most of the information on the front foot. $1580 / 7$ is an immature individual and the bones in $1580 / 102$ are badly displaced. These specimens were figured earlier (Olson, 1962). A more recent interpretation, based on fuller understanding of the caseids as a whole, is shown in Figure 18 of this publication. The phalangeal formula as preserved is 223-2. Since the hind foot has 22332, it is probable that this applied to the front as well. The feet of Ennatosaurus were rather small and lightly built as compared to those of other medium-sized caseids.

Pelvis and hind limb (figs. 18, 19, 20, 22): For the most part, the pelvic girdle and hind limb are represented by inadequate materials. 
Of the pelvis, only the ilium is recognizable, although there may be some fragments of pubis and ischium. It appears that the sutures were open, as a result of immaturity, and that separation of the pelvic bones was the rule. No mature specimens have been found. The ilium and a reconstruction of the pelvis are shown in Figure 19. The blade of the ilium is high and narrow, with only a moderate posterior flare near the dorsal margin. The inner surface shows the presence of three sacral ribs, one encasing the anterior margin, a second capping a thickened medial area, and a third in a deep posterior depression.

There are two fairly complete femora in specimen 1580/107 (figs. 20,22 ). The proximal portion shows the typical caseid dorsal flexure to give the bone a "sphinx-like" contour. Distal condyles are strongly differentiated. The femur is very short and broad, somewhat reminiscent of the femur at Casea halselli and Caseoides sanangeloensis. Three partial tibiae are present. One, in spite of considerable crushing, shows the head to have been very broad, with the two portions divided by a deep sulcus. In this, as in all other features, the tibia is distinctly caseid. Fibulae, for the most part, come from very young individuals and are poorly ossified. They are clearly caseid in general features and show no distinguishing characteristics.

A reconstruction of the hind foot is shown in Figure 18. This was based in large part on $1580 / 120$ and $1580 / 126$. The latter, having been newly prepared since it was used as the basis for a figure (Olson, 1962), shows details not available when it was described and figured earlier. The phalangeal formula is 22332 . The toes are short and are terminated by small, blunt, clawlike unguals. 


\section{ORIGINS AND RELATIONSHIPS}

The descriptions of the genera and species of caseids in earlier sections of this paper show the family Caseidae to be a very tightly knit taxonomic group, much more so than had been realized heretofore. Variations are in general moderate and are in large part related to size, along with some modifications in teeth, limbs and details of cranial and posteranial structures that appear to be size independent.

Early in the history of the study of this group, when only Casea broilii was known, emphasis was placed upon the distinctiveness of this genus and all other pelycosaurs. Watson (1917) even suggested that it was not a pelycosaur at all. Williston (1912) and later Case (1915) considered that Casea pertained to a distinct suborder, Caseasauria. Romer and Price (1940), after a careful restudy of Casea and with recognition of Cotylorhynchus as a second caseid genus, reached the conclusion that the impressive array of structural resemblances between edaphosaurids and caseids showed them to be variants of the same basic type and placed them in a single suborder Edaphosauria, as one of several families.

Later I (1962, fig. 69) suggested that there might be a subordinal differentiation based upon the supposition that the caseids and edaphosaurids both stemmed from a common ophiacodont ancestry, but that they arose at very different times and hence could not be considered part of the same radiation pattern. The basic stock was supposedly a persistently primitive one such as is seen in various small pelycosaurs of the Wichita group and the early part of the Clear Fork. Langston (1965) independently arrived at this conclusion, elaborating his proposal rather thoroughly in terms of possible ancestors among the small pelycosaurs. He used Williston's term Caseasauria to designate the suborder.

There is no question concerning the degree of morphological resemblance between caseids and edaphosaurids. If there actually had been a dual origin from a primitive stock at different times, and thus a separate attainment of many of the features that indicate relationship, then there would be a reasonable basis for assignment of the families to separate suborders. This becomes a matter of judgment and convenience. A search for ancestors, which has been thought to 
have met with partial success has been made by such students as Watson, Vaughn, Langston and Fox. If the small pelycosaurs that have been considered as very close to the actual ancestry or at least tangentially related do occupy this position, then there must have been the necessary long lag between the time of origin of edaphosaurids in the Pennsylvanian and of the caseids in the lower, but far from lowest, Permian. Stovall, Price and Romer (1966) have presented a summary of the search for ancestors within the Family Eothyrididae. It is emphasized that this family is extremely loose, considered as a "wastebasket" when proposed (Romer and Price, 1940), and that the formality with which it has been treated over the years is greater than intended in the original proposal. The views of Vaughn (1958a) and Langston (1965), following Watson (1957), that Eothyris might be related to the caseids is criticized in this paper (Stovall, Price and Romer, 1966). The enlargement of teeth in the "canine" region of Eothyris is cited as strong evidence that evolution was not proceeding in the direction of the caseids which were characterized by isodont dentitions.

While not accepting the concept that some of the "eothyrids" might be fairly close to the ancestry of the caseids, Stovall, Price and Romer (1966) agree with the idea that edaphosaurids and caseids may have arisen at somewhat different times from a bradytelic line of primitive pelycosaurs. Much of the problem of assignment, given this condition, would depend upon whether this bradytelic stock was considered as edaphosaurian or ophiacodont. They note Petrolacosaurus of the Pennsylvanian Garnett Shale of Kansas as a possible edaphosaurian, thus providing a possible framework for inclusion of the two families in a single suborder. Protoclepsydrops Carrol from Westphalian B of Joggins, Nova Scotia, indicates the ancient nature of the stock of ophiacodont reptiles and may, like Petrolacosaurus, have some features that are edaphosaurian.

There is no question that some of the small Permian reptiles such as Colybomycter (Vaughn, 1958a), Oedaleops Langston (1965), which Romer, in Stovall, Price and Romer (1966) considers very close to Nitosaurus Romer (1937), Delorhynchus Fox (1962), Mycterosaurus Williston (1919b), Bayloria Olson (1939), Glaucosaurus Williston (1915a), and even Eothyris Romer (1937), possess features that are in general edaphosaurian and in some respects caseid. Now, however, that much more is known about the caseid skull and postcranium, it is clear that there is a suite of definitive caseid characters not found even in an incipient guise in any of these supposedly closely 
related types. Only in general resemblances in proportion, related in part at least to the small size of the skull, and in some general similarities in disposition of dermal bones, do these small pelycosaurs suggest relationships to caseids. Except for a few modest specializations, and these are modifications of features expressed in Casea broilii, the caseid pattern was fully established in $C$. broilii. The following features are especially characteristic of this pattern:

1. Proportionately very small skulls.

2. Extremely large external nares and a very short snout.

3. A projecting rostral angle of the snout.

4. Extremely large pineal opening.

5. Characteristic marginal dentition with crowns somewhat waisted throughout; long, bluntly-terminated anterior teeth in the upper jaw, a gradual decrease in size posteriorly both above and below; serrated, spatulate crowns in the chec's area.

6. Toothed parasphenoid and high development of palatal teeth.

7. Braincase with forward projecting processes from the proötic, passing to the region of the basipterygoid articulation with the palate in late genera.

8. Lower jaw with rounded posterior edge, nearly lacking retroarticular process.

9. Ribs fused to 4 or 5 vertebrae just anterior to the sacrum, ribs forming barrel-shaped body.

10. Moderately to greatly reduced phalangeal formula

Any caseid ancestor should show the incipient development of at least some of these characters. It is true, of course, that none of the genera in question as possible ancestors is well enough preserved to allow a point for point comparison. It is equally true, however, that as far as comparison is possible they show no evidence of the development of this suite of characters, and for the most part little or no development of any one of the characters. General resemblances are in very large part the rather short snout of some of the skulls and the similarities to be expected among members of a suborder.

As far as can be seen, then, we do not have any close relatives or ancestors to caseids in the Cutler formation of New Mexico, or from the Wichita or Clear Fork beds of Texas, and their equivalents in Oklahoma. Work is now going on in various Oklahoma deposits, other than that at Richard's Spur, which has received much atten- 
tion lately. As yet no sign of anything resembling a case ${ }^{\text {d }}$ has turned up in pre-Hennessey formations.

This, then, raises the question as to the authenticity of the argument that there was a long time lag between the origin of edaphosaurids and caseids. At present there seems no basis for it and there seems no bar whatsoever to considering the caseids and edaphosaurids as members of the Suborder Edaphosauria.

Where, then, was the ancestry of the caseids? There is no answer other than that it must have been developing in some area for which there is no known record. The known caseid history, as has often been pointed out, has odd distributional aspects. Casea broilii has been found only in the Cacops-bone bed at the Vale-Arroyo boundary. Here it was associated with Varanops, also unknown elsewhere, and Cacops, a genus confined to this bed, except for a possible Choza occurrence (Olson, 1956), but a representative of a family that does occur in other Permian beds of Texas. ${ }^{1}$ Also associated were Seymouria and Captorhinus (Williston, 1910a), both represented by fragments. The assemblage is unique in the Texas Clear Fork. Casea nicholsi of the upper Vale of Knox County, Texas and C. halselli from - the Choza of Foard County, Texas, both were found without other tetrapod associates in red shales. Put in another context, caseids do not form a part of the typical and abundant Clear Fork assemblages marked by the presence of such genera as Dimetrodon, Trimerorhachis, Diplocaulus, Captorhinus, Labidosaurus, Trematops and Xenacanthus.

The faunal complex of which caseids were a part is not that which was commonly tapped by the processes that formed the typical deposits of the Texas Permian. Only very occasionally do traces of this chronofauna, or more broadly, this evolving community (Olson, 1966), become preserved. There may be various explanations of this, the most reasonable and simplest being that the habitat of the caseid complex was not geographically in the area of preservation. It could have been very close by, however, with the difference more ecological than geographic. Evidence bearing on matters such as this, is, as usual, very slight.

Recent studies in the Permian of Oklahoma have shed some additional light on the problem (Olson and Barghusen, 1962; Olson, 1965,

${ }^{1}$ Wann Langston in a personal communication informs me that Aerosaurus of the New Mexican Cutler formation has proven to be very similar to Varanops, as suggested by Romer and Price (1940). A similar reptile, Varanodon Olson, occurs in the Chickasha formation (Flowerpot equivalent) in Oklahoma (Olson, 1965). 
and work in progress). Since 1937 (Stovall, 1937) the presence of the large caseid, Cotylorhynchus romeri Stovall, has been known in the Hennessey formation around Norman and also about 40 miles to the north of Norman. A curious feature of the occurrence of this genus and species has been the absence of associated species. Captorhinikos chozaensis Olson and Lysorophus (Vaughn, 1958b; Olson, 1962) have been reported from the beds in the vicinity of Norman. A recent rather thorough search of the Hennessey, far beyond the limits of known production, has failed to turn up any new areas where fossil vertebrates occur. From a pocket southeast of Norman, in which Captorhinikos and Lysorophus were known from previous work, an abundance of new material has been obtained containing some very small reptiles and, probably, amphibians other than Lysosophus. It is evident that animals that contributed to this assemblage were living in the area in which they were buried. Lysorophus, for example, was preserved in the state of aestivation. Also in the collection are teeth and fragments of the lungfish Gnathorhiza, an aestivator.

Cotylorhynchus has been found within about one-half mile of this site in beds of about the same age. Many specimens of Cotylorhynchus romeri occur as fairly complete skeletons. This has given rise to the somewhat erroneous understanding that this is the usual way of occurrence. There is, in addition, considerable scrap and many individual bones, so that, although many complete specimens have been found, there are also other kinds of preservation. There is no evidence whatsoever of any large carnivores in the region. Close to the skeletons of $C$. romeri, in at least most instances, there are clayball conglomerates and other evidences of stream action. It seems probable that specimens of $C$. romer $i$ were floated some distance before they were deposited. They do, however, tend to occur right side up, which has suggested that they may have been bogged and died in traps, where they were buried. This would mean that they lived on or close to the soft mudflats near the margins of a sea apparently with no associates other than those small creatures mentioned above. This is possible, but the floating hypothesis, with orientation of carcasses in the water as the result of their structure seems more probable as of now.

The absence of carnivores is curious, but is by no means unprecedented. What does seem peculiar, however, is that Dimetrodon, which is so common in lower Permian beds, has not been found. This is a large genus and one that is extremely easy to recognize even from scraps. It occurs in equivalent beds in Texas, in the Choza, and it 
occurs in the earlier Permian beds of Oklahoma, the Wellington and Garber, as rell as at the transition between the Garber and the Hennessey. It may, of course, turn up in later collecting, but to date, in spite of an intensive search, there is no sign of it.

The Cotylorhynchus bearing Hennessey beds range from about 150 to 250 feet above the base of the formation, that is above the Hennessey-Garber contact. The Hayward member of the Garber, which underlies the Hennessey is primarily a sandstone, whereas the Hennessey is predominantly a shale. The contact is not precise but ranges over about a 50-foot section in which there are alternations of sandstone lenses and red and green shales, with some mudstones. Although the Hayward sandstone of the Garber has yielded only scraps, mostly Dimetrodon, the transition beds carry Dimetrodon giganhomogenes, Diplocaulus and, in a site near Crescent, Oklahoma, Labidosaurikos meachami (Stovall, 1950). Whether members of these transition beds have been called Garber or Hennessey depends principally upon the sedimentary composition of the particular bed involved.

The fauna of the transition beds, as far as known, is clear cut and is similar to the fauna of the Vale of Texas in the presence of the Labidosaurikos, Dimetrodon giganhomogenes and Diplocaulus assemblage. On the basis of Captorhinikos chozaensis, the Cotylorhynchusbearing Hennessey beds of Oklahoma are Choza in age, thus later than the transition beds by some considerable amount, although only 150 feet above them in the section. Dimetrodon does occur in the Choza of Texas but Cotylorhynchus does not, as far as is known. An isolated specimen of Casea halselli is the only known caseid. Lysosophus suggests similarities between the Cotylorhynchus-bearing Hennessey and the Texas Choza, but the absence of Captorhinus, Diplocaulus, Trimerorhachis and Eryops from the Hennessey suggests a generally different faunal regimen.

The caseids of the San Angelo formation of Texas pose difficulties for faunal analyses since they are commonly found in stream deposits and evidently have been transported along with their physical associates. One point of interest is that the carnivore assemblage in the San Angelo formation is distinctly different from that in the underlying Clear Fork beds. Dimetrodon, however, is present, although it has not been found in close association with Cotylorhynchus and was not among the many specimens taken from the Kahn Quarry where Cotylorhynchus predominated (Olson, 1962). A second point of in- 
terest, since it agrees with the faunal associations of Cotylorhynchus elsewhere, is the near absence of amphibians from the San Angelo.

Finally, and possibly of great significance in this matter, is the presence in a tongue of the Chickasha formation in the middle Flowerpot of Oklahoma of an assemblage including caseids, Cotylorhynchus bransoni and Angelosaurus romeri, a varanopsid Varanodon-very close to Varanops, and a dissorophid, readily derivable from such a form as Cacops, although equally derivable from other dissorophid genera of the Clear Fork. This assemblage also includes Xenancathus, Rothia, Cymatorhiza, a gymnarthrid, a trimerorhachid-like amphibian, Nannospondylous, paleoniscoids and a very large, as yet undetermined, tappenosaurid or sphenacodont reptile (Olson, 1965). The caseid, varanopsid, dissorophid assemblage strongly suggests the Cacops-bone bed assemblage and poses the possibility that this is a continuation of the chronofauna that was tapped in that unique deposit.

From this necessarily somewhat complex set of data seems to emerge the picture that at least from late Arroyo times on caseid evolution took place in context of an evolving community different from that found in the well-known Clear Fork deposits of Texas. Geographic separation was probably not very great, but ecological isolation appears to have been complete, except for some few genera that possibly existed under both sets of circumstances, Captorhinikos and Lysorophus being the most probable examples.

The beds of New Mexico and Colorado are becoming better known through the continuing work of Langston and of Lewis and Vaughn (1965). Except in the presence of the Varanops-like Aerosaurus and the possible pre-caseid position of Oedaleops (Langston, 1965), they give little indication of including the caseid chronofauna.

The advanced nature of Casea when it first appears and the distinctive associations with forms also unknown previously suggest a long rather than short period of isolated existence prior to the time of formation of the Cacops-bone bed assemblage. This leaves us without any clear concept of the origin of the caseids except that they had a general edaphosaurian source. Under these circumstances, it seems much the wisest procedure to follow Romer and Price (1940) and consider this family as belonging to the Suborder Edaphosauria.

\section{HABITS AND EvOLUTION}

A great deal is now known about the hard anatomy of the caseids and some sound inferences concerning parts of the soft anatomy can 
be made. Yet it is difficult to arrive at any very clear and detailed concept of the ways of life of the creatures in this family. Part of this results from an inadequate knowledge of the organic associates of the caseids, but more important is the lack of any satisfactory analogues among living reptiles. Probably the closest morphological analogue is to be found among the mammals, rather than the reptiles, in the form of some of the ground sloths. Like the large caseids, they had massive, solidly-built pelvic regions, relatively small heads, heavy-boned limbs and strong, large claws. The many major differences, however, make it unlikely that there were any close resemblances in habits.

A few general conclusions do appear to be fairly sound. First, it seems evident that the caseids were predominantly herbivorous rather than carnivorous. The dentitions, small heads and barrel-shaped bodies all point to such a conclusion. Secondly, they are primarily terrestrial rather than aquatic. The high degree of ossification throughout the skeleton and particularly in the extremities, the short feet and heavy claws, the strong extensor musculature of the limbs and the strong sacrum provide evidence. These features do not necessarily imply that the caseids did not spend some time in the water and along water margins, but merely that locomotion on dry land was an important aspect of their way of life.

When more specific conclusions are sought the results are rather discouraging. Regarding diet, the great volume of the rib case suggests a massive digestive system and the ingestion of large amounts of food, low in nutrient value. Marginal teeth are well adapted for slicing and cutting vegetation. Palatal teeth and a large, mobile tongue suggested by the hyoid structure, appear to be well suited to coping with bulky materials. The front teeth in all but Angelosaurus are fairly long, slightly recurved and probably suited to aid in gathering vegetation into the mouth. Some shift in dietary habits may be indicated by the front teeth of Angelosaurus.

The extensor muscles of the front limbs were strong and highly tendinous. This plus the strong claws suggest some sort of digging or tearing action by the forelimbs. If this was connected to food procurement, and it is less easy to explain in any other context, it is tempting to speculate that the caseids dug in the earth for their vegetable food. But a very simple question arises as to what sort of roots or "tubers" might be present to form an abundant food supply. The answer seems to be that none is known. Perhaps, then, caseids stripped vegetation from large plants with their claws and powerful 
forelimbs. It is possible to relate the firm supporting buttress of the sacral region to some such action, although it is a little difficult to visualize these creatures rearing up on their hind limbs in a fashion often pictured for ground sloths.

In the associated floras two elements appear in greatest abundance, conifers of the Walchia-group and large ferns-both true ferns and seed ferns. In addition, Sphenophylum and Calamites occur in some abundance and other Permo-Carboniferous', plants in lesser numbers. The foliage of any of these could have provided a food source suitable to the dentitions and digestive systems of the caseids. The dominance of conifers and ferns gives a cast to the flora that is somewhat different from that in the areas where more typical and better known Permian faunas are found in North America. Perhaps the caseids utilized their strong forelimbs for tearing up and stripping plants, ferns or small conifers, for example, with the strong hind quarters forming a stable base of operations and the dentitions a device for cutting up the harsh bulk and passing it to the digestive system.

All of this is highly speculative and may be far wide of the mark. Some of the distinctive features of caseids, the large nares, the odd vascular system of the head, and the large pineal opening and organ have not been considered. Quite possibly the heavy limbs and claws were related to other functions. It has been suggested, informally, that caseids were fossorial. Their great bulk makes this seem somewhat questionable. An obvious possible use of the limbs and claws is for defense, but the problem arises as to defense against what? These were certainly the largest animals of their times. We do not, however, know much of the associated carnivores. Dimetrodon does not appear to have been an associate, but in the San Angelo there were some moderate sized "pre-therapsids" (Olson, 1962) that might have been important as predators. There is also the possibility that the massive limbs and claws were somehow related to intraspecies activities, to combat in the course of mating activities, for example. In this respect there is an interesting item. Almost every specimen from the San Angelo C. hancocki in which a series of ribs is preserved shows from 1 to 10 ribs broken and healed during life. There are several broken ribs in series in a few instances.

Whatever the actual mode of life may have been, it does appear to have been one that was established by the time the family first enters the record. The way of life appears to have been very successful and to have been retained by all members of the family with only 
relatively minor variations upon the central mode. Caseids probably were the first large and highly successful herbivores among the terrestrial reptiles. They represent an early stage in the break of reptilian faunas with their aquatic habitats (Olson, 1966). Earlier, Edaphosaurus may have been an herbivore, but it was at least partially aquatic and never abundant in the record as preserved. Diadectes was fairly large, partly terrestrial, and perhaps an herbivore, although presumably with the rather specialized diet. Again, it occurred as a member of a fauna closely associated with aquatic life and was not abundant. Captorhinomorphs, at least those with multiple tooth rows such as Captorhinus and its larger relatives, were clearly terrestrial. They may have been herbivores, although the dentitions in the smaller genera at least, suggest either omnivorous or insectivorous habits. If the larger ones, Rothia for example, were herbivores, then they rivalled the caseids as early and abundant herbivores and occurred in the same fauna complex. They were adapted to a quite different way of life whether herbivorous or not and, of course, did not match the size or abundance of caseids in the post-Leonardian beds.

Caseids, for the first time in reptilian history, followed the radiation pattern which was to be characteristic of dominant herbivores in many phyla in later times. Features of this pattern are:

1. Acquisition of a habitus suitable to the utilization of some dominant floral element of the particular ecosystem.

2. Rapid increase in body size in the course of evolution.

3. Moderate morphological differentiation in separate phyla, as different lines exploited the limited but distinct aspects of the environment provided by their developing specializations in relationship to the associated plants, animals and physical conditions.

4. Proliferation of numbers so that the individuals of the various phyla made up a numerically very significant part of the terrestrial vertebrate fauna of which they were an element.

Figure 24 shows a diagrammatic interpretation of the phyla of caseids as they may be sorted out on a morphological basis. The phyla represent different modifications of the caseid habitus, which took place while the dominant central pattern was maintained virtually intact. It is assumed that Casea broilii lies close to the general initial pattern. There are some details of the palatal condition that suggest that this species was actually somewhat off the line to others, except those in the Casea phylum, but in most regards it fills the posi- 


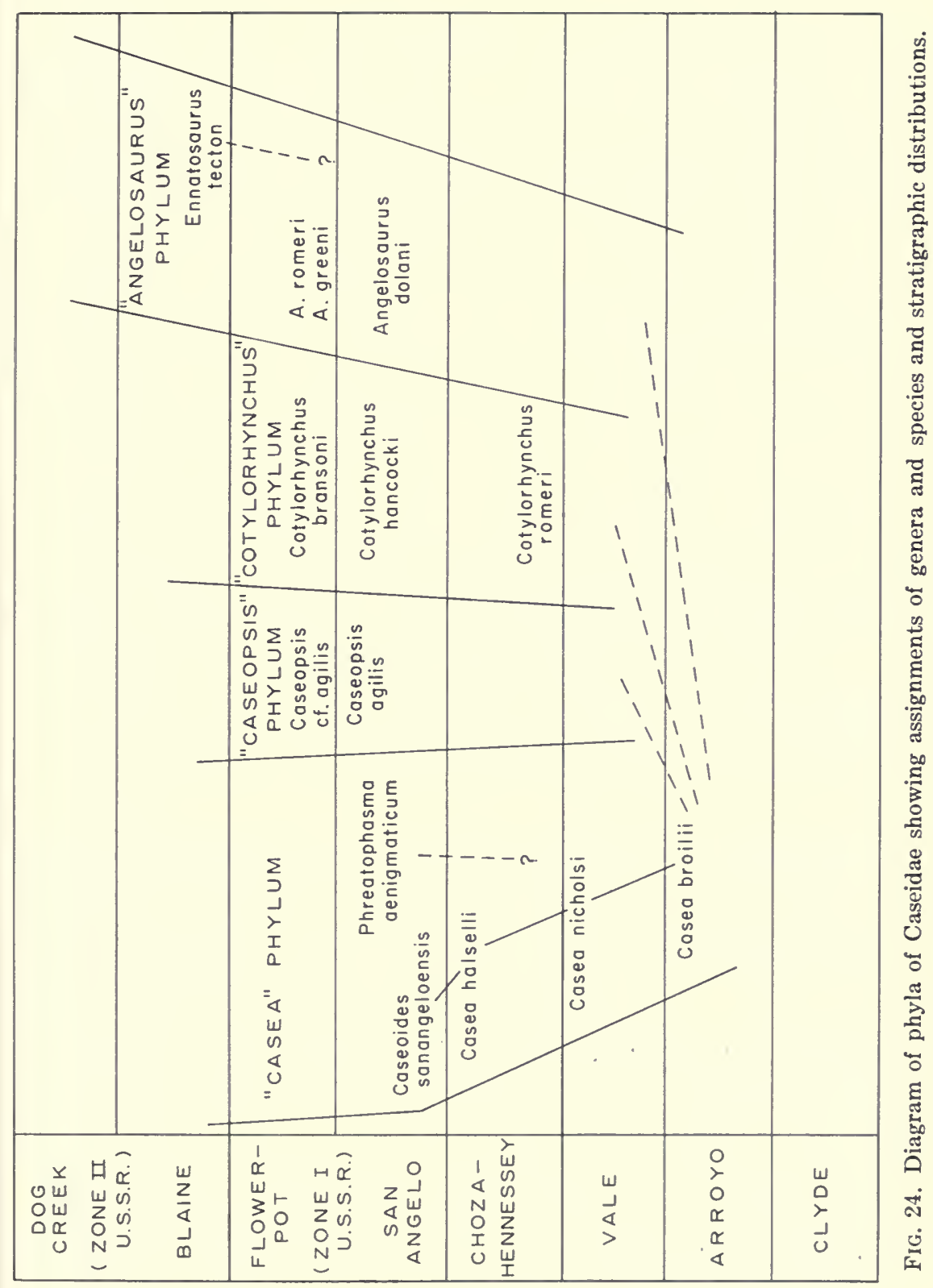


tion of a morphological ancestor quite well. The characteristics of the various phyla briefly are as follows:

I. Casea phylum: This is based in Casea broilii which is considered to be the actual ancestor of later members. Its evolution is marked by a moderate increase in size through C. nicholsi, C. halselli and Caseoides sanangeloensis. This is probably a valid phyletic sequence, or close to it. Limbs show progressive increase in relative massiveness and in relative reduction in length. Ungual phalanges remain rather small and become only moderately claw-like. The phalangeal formula, as shown in C. nicholsi, is somewhat less than the primitive reptilian number, but its condition in later species is not known. Phreatophasma aenigmaticum, known from a femur only, is Casea-like, and thus is provisionally referred to this phylum. It may, of course, merely be a relatively primitive caseid or possibly a somewhat divergent edaphosaurian. If Trichosaurus is a caseid, which is questionable, it is closer to this group than to any other.

II. Caseopsis phylum: This is known only from two specimens, one from the San Angelo (Caseopsis agilis) and one from the Flowerpot (Caseopsis cf. agilis). Limbs are relatively long and slender, girdles are light and the vertical portions are long and narrow. The skeletal structure in general conforms to this lack of massiveness. These are moderate-sized caseids, presumably adapted to somewhat more rapid locomotion than those in other phyla.

III. Cotylorhynchus phylum: Increase in size is the dominant aspect of this phylum. With this change there are various modifications in proportions of elements, especially in the increase in length of neural spines in the sacral region. The head is small in proportion to body size, but the proportions remain fairly constant throughout the phylum. Marginal dentition retains the three cuspule serration found in Casea, with some increase in the number of teeth. Palatal teeth are disposed in rather irregular rows and are fairly small and sharp. Parasphenoidal teeth are confined to the rostrum of this bone.

C. romeri of the Hennessey and C. hancocki of the San Angelo show the full development of the characteristics of the phylum. They are very large, claws are strong, the phalangeal formula is reduced to 22332, and the various aspects of caseid structure are carried to a peak of expression.

C. bransoni of the Chickasha is more conservative in size and is somewhat less massive in construction. Cuspules on the lateral 
marginal teeth, however, are more fully developed and the phalangeal formula is reduced to 22232 .

IV. Angelosaurus phylum: Increase in size is characteristic but this is less than that in the Cotylorhynchus group. The largest form, A. green $i$, is known only from fragmentary specimens. The dominant characteristic of this phylum is increase in massiveness of the bones with increased size. This is most clearly expressed in the limb bones, but is seen in other postcranial structures in large species. The smallest species, $A$. romeri, shows moderate development of the massiveness of limbs but little increase in the robustness of the vertebrae, which can be told only with difficulty from those of Cotylorhynchus. In large species, $A$ dolani and $A$. greeni, robustness is found throughout the skeleton.

Dentition, known principally from $A$. romeri, is characterized by the development of multiple cuspules on the crowns of the teeth, producing a markedly serrated, longitudinally diposed spatulate crown. The anterior teeth are short and blunt. It is not certain that this pattern pertains throughout this line, although it seems probable that this was the case. Teeth are present in $A$. dolani, but are so shattered that no interpretation is possible.

Palatal teeth are disposed in rows, as in Cotylorhynchus, but are heavy, rather blunt and relatively few in number. The parasphenoidal teeth are confined to the rostrum and are large and few in number.

It would appear that Angelosaurus had departed farther from the primitive dietary habits of caseids than had any other North American genus. Not only are the teeth patterns moderately distinctive, but the strong wear of both anterior and cheek teeth suggests a crushing or grinding action. Possibly hard seeds or cones of conifers may have become an important element in the diet.

For want of better association, Ennatosaurus of the U.S.S.R. has been included tentatively in this phylum. The association is based on the similarity of cheek teeth. However, it is important to note that the front teeth in Ennatosaurus were not modified in the same way as those of Angelosaurus. Furthermore, there is the very odd situation that the postcranium is much smaller in proportion to the skull than in any of the other caseids. This may have considerable significance with respect to mode of life, for relatively large body size seems to be an important adaptive element in all North American caseids. Presumably, it related directly to their habits. It is difficult to make any explanation of how skull and dental patterns very 
similar to those of other caseids can have developed in Ennatosaurus, while the postcranium followed a different course. There must have been a notable difference in the evolutionary path of Ennatosaurus and the other known caseids. Perhaps, of course, increase in body size was of minor importance in caseid evolution. Possibly the apparent associations of skull and postcranial elements in the deposits containing Ennatosaurus are spurious. This was my first inclination (see Olson, 1962), but additional study seems to rule this out.

In our considerations of the evolution in the phyla, emphasis has been put upon differences. The modifications in the course of exploitation of a rather limited life zone are considered as selective changes. From an overall point of view, however, it is the high degree of structural stability within the family rather than differences between phyla that is characteristic.

Whether or not any later group or groups of reptiles stemmed from the caseids is a matter upon which there is little concrete evidence. Earlier (Olson, 1962) it was suggested that this family may have been fairly close to the base of stocks that led to the anomodonts. The conclusion was based upon morphological resemblances and temporal relationships. Resemblances in general skull patterns between caseids and the presumed pre-amonodonts Otscheria Chudinov and Venjukovia Efremov are evident. Similarly, there are general postcranial resemblances between some caseids and primitive anomodonts. The stapes of Casea broilii described in this paper has a somewhat anomodont-like appearance. There are, of course, many important differences. These are evident in the evolutionary trends noted in the various phyla of caseids, which are clearly not those to be anticipated in ancestors of anomodonts or any other known reptilian group. Also there is the problem of the independent origin of the angular notch of therapsids, required by the assumption that caseids are ancestral to anomodonts. This was discussed in the earlier paper (Olson, 1962).

Very little information that bears on this problem has come to the fore since 1962. Thus the matter stands much as it did then, that is, that the caseids could be ancestral to anomodonts if the family is very broadly conceived, but that even at the level of Casea broilii specializations are such that trends away from the anomodont habitus have been established.

Beyond this possible relationship there is some possibility that caseids may bear some affinities to some of the large but obscure genera of the San Angelo, Tappenosaurus, Mastersonia or Driveria. 
These genera do show some caseid-like features, but seem to have been very different in the possession of more usual rib patterns and, it would seem, larger skulls. Before anything definite can be said much more information will be required and at present there seems little prospect of getting it. As now known the caseids form a discrete family, derived from the same stock as other edaphosaurians but evolving in a manner that brought them to the fore as the first dominant group of Permian herbivorous reptiles. 


\section{REFERENCES}

ABEL, O.

1919. Die Stämme der Wirbeltiere, Boden und Leipzig, $914 \mathrm{pp.}$

ARLDT, T.

1912. Die Fauna der alters Tierregionen des Festlands. Neues Jahrb. Min., Geol., Paleo., Beil.-Bd., 34, pp. 633-782.

BroIli, F.

1926. Ein neuer Fund von Pleurosaurus aus dem Malm Franken. Abhandl. Beyer. Akad., 30, Abh. 8, pp. 1-48.

BROOM, R.

1913. On a nearly perfect skull of a new species of the Gorgonopsia. Ann. S. African Mus., 12, pp. 8-12.

1921. On the structure of the reptilian tarsus. Proc. Zool. Soc. London, 1921, pp. 143-155.

1927. On a new type of mammal-like reptile from the South African Karroo beds (Anningia megalops). Proc. Zool. Soc. London, pp. 227-232.

CARroll, R. L.

1964. The earliest reptiles. Jour. Linn. Soc. (Zool.), 45, pp. 61-83.

CASE, E. C.

1915. The Permocarboniferous red beds of North America and their vertebrate fauna. Publ. Carnegie Inst. Wash., no. 207, $176 \mathrm{pp}$.

EASTMAN, C. R.

1912. Paleontology in America (Caseidae). Yearbook (1911), pp. 656-660.

Efremov, I. A.

1954. The fauna of terrestrial vertebrates in the Permian copper sandstones of the western Cis-Urals. Trans. Paleont. Inst., Acad. Sci. U.S.S.R., 56. 416 pp. 1956. American elements in the fauna of Permian reptiles of the U.S.S.R. Dokl. Acad. Sci. U.S.S.R., 111 (no. 5), pp. 1091-1094.

EFremov, I. A. and B. P. Vyushkov

1955. Catalogue of localities of Permian and Triassic terrestrial vertebrates in the territories of the U.S.S.R. Tru. Paleon. Inst. Acad. Sci. U.S.S.R., 46, pp. 1-185.

Fox, R. C.

1962. Two new pelycosaurs from the lower Permian of Oklahoma. Univ. Kansas Publ. Mus. Nat. Hist., 12, pp. 279-307.

GREGORY, W. K.

1926. The skeleton of Moschops capensis, a deinocephalian reptile from the Permian of South Africa. Bull. Amer. Mus. Nat. Hist., 56, pp. 179-251.

HAY, O. P.

1930. Second bibliography and catalogue of the fossil Vertebrata of NorthAmerica. Publ. Carnegie Inst. Wash., 390, II, p. 59 (Caseiformes, new name). 
HUENE F. VON

1913. The skull elements of the Permian Tetrapoda in the American Museum of Natural History, N. Y. Bull. Amer. Mus. Nat. Hist., 32, pp. 315-386.

1916. Beiträge zur Kenntnis der Ichthyosaurier in deutschen Muschelkalk. Palaeontographica, 62, pp. 1-68.

1925. Ein neuer Peolycosaurier aus der unteren Permformation Sachsens. Geols, Pal. Abhandl., Jena, XVIII (N. F. XIV), pp. 215-246.

LANGSTON, W. J., JR.

1965. Oedaleops campi (Reptilia: Pelycosauria), A new genus and species from the lower Permian of New Mexico, and the family Eothyrididae. Bull. Texas Memorial Mus., 9, pp. 5-47.

Lewis, G. E. and P. P. VAUghN

1965. Early Permian vertebrates from the Cutler formation of the Placerville area, Colorado. U. S. Geol. Surv., Prof. Paper, 503-C, 50 pp.

Nopsca, F.

1922. Bemerkungen zur Systematic der Reptilien. Paleont. Z., 5, pp. 107-118.

1923. Die Familien der Reptilien, Fortsch. Geol. Palaeont., H. 2, pp. 1-210.

1928. Paleontological notes on reptiles. Geol. Hungrica, ser. Palaeont., 1, p. 84.

OLson, E. C.

1939. Fauna of the Lysorophus pockets in the Clear Fork Permian, Baylor County, Texas. Jour. Geol., 47, pp. 389-393.

1952. The evolution of a Permian vertebrate chronofauna. Evolution, 6, pp. 181-196.

1954. Fauna of the Vale and Choza: 7. Pelycosauria, Family Caseidae. Fieldiana: Geology, 10, pp. 193-204.

1955. Parallelism in the evolution of the Permian reptilian faunas of the Old and New Worlds. Fieldiana: Zoology, 37, pp. 385-401.

1956. Fauna of the Vale and Choza: 11, Lysorophus, Vale and Choza; Diplocaulus, Cacops and Eryopidae, Choza. Fieldiana: Geology, 10, pp. 313-322.

1958. Fauna of the Vale and Choza: 14, Summary, review and integration of of geology and faunas. Fieldiana: Geology, 10, pp. 397-448.

1962. Late Permian terrestrial vertebrates, U.S.A. and U.S.S.R. Trans. Amer. Philos. Soc., 52, pt. 2, pp. 3-224.

1965. Vertebrates from the Chickasha formation, Permian of Oklahoma. Okla. Geol. Survey, Circ. 70, pp. 1-70.

1966. Community evolution and the origin of mammals. Ecology, 47, pp. 291302.

Olson, E. C. and J. R. BeERBower

1953. The San Angelo formation, Permian of Texas and its vertebrates. Jour. Geol., 61 , pp. 384-423.

Olson, E. C. and H. BARGHUSEN

1962. Vertebrates from the Flowerpot formation, Permian of Oklahoma, Pt. I of Permian Vertebrates from Oklahoma and Texas. Okla. Geol. Survey, Circ. 59, pp. 5-48.

OrLov, Y. A.

1964. Caseidae, pp. 242-244; Casea, Cotylorhynchus, Phreatophasma (Phreatosauridae), pp. 244, 245. In A. A. Rozhdestvenski and L. P. Tatarinov, Eds., Fundamentals of Paleontology. Paleont. Inst. Acad. Sci., U.S.S.R.

Pfannenstiel, M.

1932. Gehirnkapsel und Gehirn fossiler Amphibien, eine anatomisch-biologische Studie. Monogr. Geol., Paleo (2), 6, viii +85 pp. 
ROMER, A. S.

1928. Vertebrate faunal horizons in the Texas Permocarboniferous red beds. Bull. Texas Univ., 2801, pp. 67-107.

1935. Early History of Texas Redbed Vertebrates. Bull. Geol. Soc. Amer., 46, pp. 1597-1658.

1936. Studies on American Permocarboniferous tetrapods. Problems in Paleontology, U.S.S.R., 1, pp. 85-93.

1937. New genera a species of pelycosaurian reptiles. Proc. New England Zool. Club, 16, pp. 89-96.

1956. The Osteology of the reptiles (Caseidae, pp. 681-682). Univ. Chicago Press, Chicago. $772 \mathrm{pp}$.

1958. The Texas Permian redbeds and their vertebrate fauna. In T. S. Westoll, ed., Studies in Fossil Vertebrates. Athlone Press, Univ. London, pp. 157-179.

Romer, A. S. and L. I. Price

1940. Review of the Pelycosauria. Geol. Soc. Amer., Special Paper 28, 538 pp.

STEINER, H.

1921. Hand und Fuss der Amphibien, ein Beitrag zur Extremitätenfrage. Anat. Anz., 53, pp. 513-542.

1922. Die ontogenetische und phylogenetisch Entwicklung des Vogelflügel Skeletes. Acta. Zool., 3, pp. 307-360.

Stovall, J. W.

1937. Cotylorhynchus romeri, a new genus and species of pelycosaurian reptile from Oklahoma. Amer. Jour. Sci., ser. 5, 34, pp. 308-313.

1950. A new cotylosaur from north central Oklahoma. Amer. Jour. Sci., 248, pp. $46-54$.

Stovall, J. W., L. I. Price and A. S. Romer

1966. Cotylorhynchus romeri, a giant pelycosaur from the Permian of Oklahoma. Bull. Mus. Comp. Zool., 135, pp. 1-30.

VAUGHN, P. P.

1958a. On a new pelycosaur from the lower Permian of Oklahoma and the origin of the family Caseidae. Jour. Paleont., 32, pp. 981-991.

1958b. A specimen of the captorhinid reptile Captorhinikos chozaensis Olson, from the Hennessey formation. Lower Permian of Oklahoma. Jour. Geol., $66, \mathrm{pp} .327-332$.

VERSLUYS, F.

1919. Über die Phylogenie der Schäfengruben und Jockbogen bei den Reptilia, Sitz-Ber. Heidel. Akad. Wiss., 13, pp. 1-29.

WATson, D. M. S.

1914a. On a femur of reptilian type from the lower Carboniferous of Scotland. Geol. Mag., 1, pp. 347-348.

1914b. Broomia perplexa, gen. et. sp. n. A fossil reptile from South Africa. Proc. Zool. Soc. London, 1914, pp. 995-1010.

1917. A sketch classification of the pre-Jurassic tetrapod vertebrates. Proc. Zool. Sac. London, pp. 167-186.

1957. On Millerosaurus and the early history of sauropsid reptiles. Philos. Trans. Roy. Soc. London (B), 240, pp. 325-400.

Williston, S. W.

1910a. Cacops, Demospondylus: New genera of Permian vertebrates. Bull. Geol. Soc. Amer., 21, pp. 249-284.

1910b. New Permian reptiles; rhachitomous vertebrae. Jour. Geol., 18, pp. $590-594$. 
1911a. Permian reptiles. Science, 33, p. 631.

1911b. American Permian Vertebrates. University Chicago Press, Chicago, $146 \mathrm{pp}$.

1912. Primitive reptiles. Jour. Morphol., 23, pp. 637-663.

1913a. The skulls of Araeoscelis and Casea, Permian reptiles. Jour. Geol., 21, pp. 743-747.

1913b. Ostodolepis brevispinatus, a new reptile from the Permian of Texas. Jour. Geol., 21, pp. 363-366.

1914a. Restorations of some American Permocarboniferous amphibians and reptiles. Jour. Geol., 22, pp. 57-70.

1914b. The osteology of some American Permian vertebrates I. Contr. Walker Museum, 1, pp. 107-162.

1914c. American Permocarboniferous reptiles and amphibians. C. R. Congress Internat. Zool., Monaco, 1913, pp. 120-121.

1914d. Water reptiles of the past and present. Univ. Chicago Press. $251 \mathrm{pp}$. (fig. 30, p. 55, Casea, restoration).

1915a. New genera of Permian reptiles. Amer. Jour. Sci., ser. 4, 39, pp. 575579.

1915b. A new genus and species of American Theromorpha, Mycterosaurus longiceps. Jour. Geol., 23, pp. 554-559.

1916a. Synopsis of the American Permocarboniferous Tetrapoda. Contr. Walker Mus., 1, pp. 193-236.

1916b. The osteology of some American Permian vertebrates II. Contr. Walker Museum, 1, pp. 165-192.

1917. The phylogeny and classification of the reptiles. Jour. Geol,, 25, pp. 411-421.

1925. Osteology of the reptiles. Harvard Univ. Press, Cambridge, Mass. $300 \mathrm{pp}$. 


\section{Plate 1}

Cotylorhynchus romeri. Skeleton mounted in Stovall Museum, University of Oklahoma. UOSM 4-0-S7 (from catalog), Museum number 1251 ( $\times$ approximately $1 / 16)$. 
Plate 1

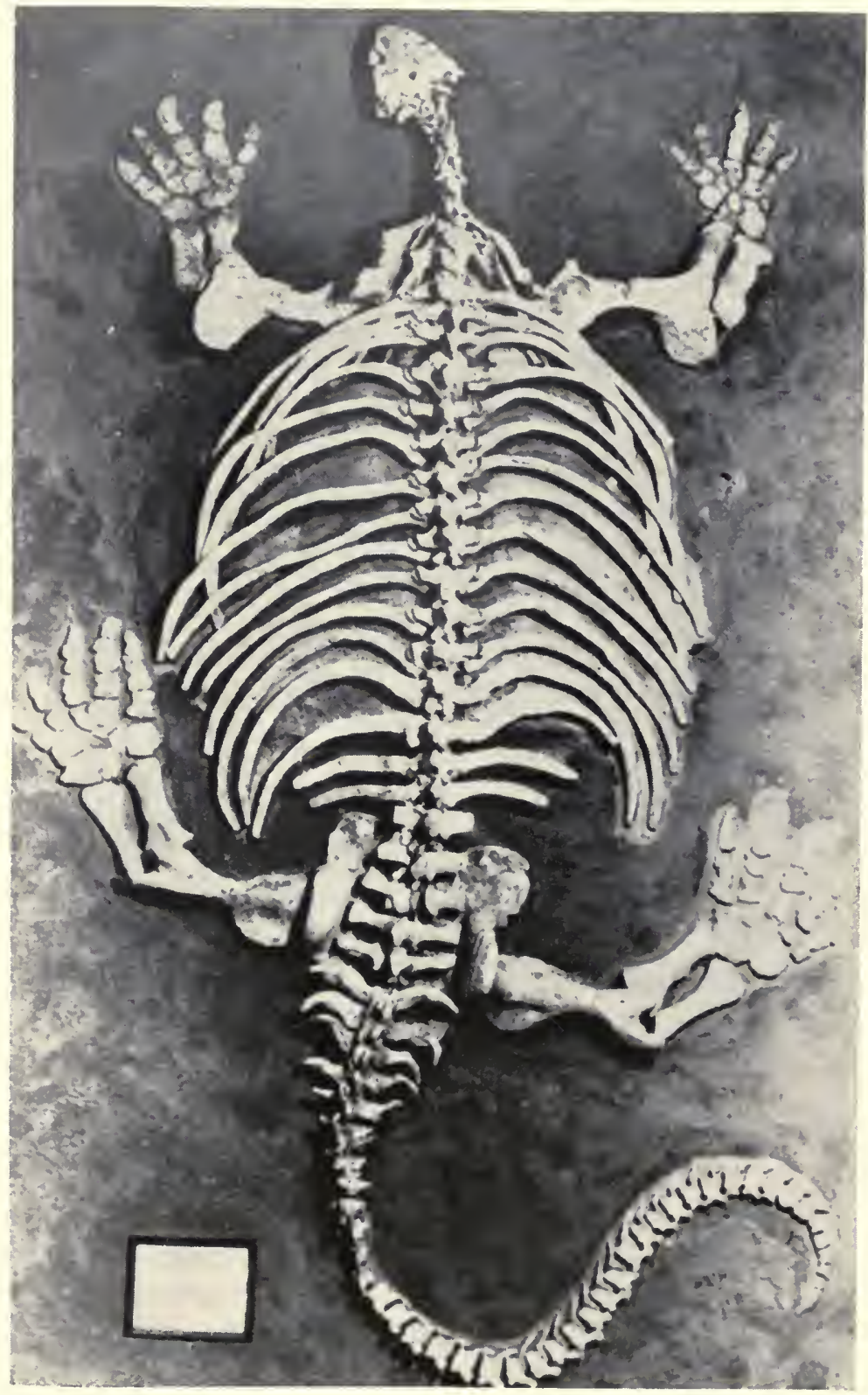




\section{Plate 2}

A, Casea broilii, skull in ventral view, UC $698(\times 1 / 2)$; B, Cotylorhynchus romeri, holotype, in lateral view ( $X$ approximately $1 / 4$ ); C, E, Cotylorhynchus romeri, skull and jaws in lateral and dorsal aspects, 4-1-S5 ( $X$ about $1 / 5) ; D$, Casea broilii, stereophotographs of tooth row in maxilla, UR 1011 ( $X$ approximately $1 / 4$ ); E, see under $\mathrm{C}$. 
Plate 2

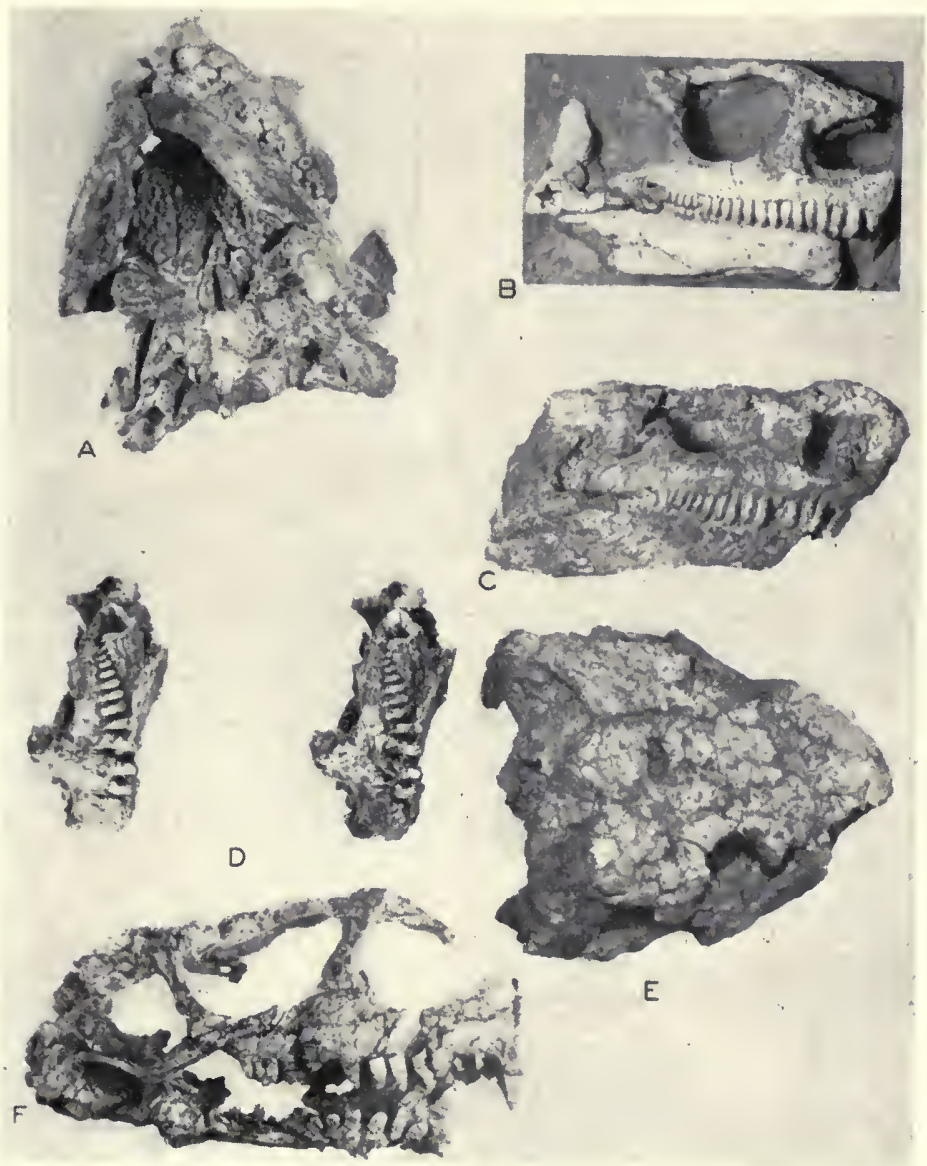




\section{Plate 3}

A, Humerus, Cotylorhynchus bransoni, UR 919 ( $\times 1 / 6)$; B, E, Humerus, Angelosaurus romeri, dorsal and ventral respectively, UR $909(\times 1 / 6)$; C, D, Humerus, Cotylorhynchus romeri, dorsal and ventral, PR $272(\times 1 / 9)$; E, see under C above; F, Scapulocoracoid, Cotylorhynchus bransoni, UR $919(\times 1 / 6) ; G$, Tail and hind limb, Cotylorhynchus romeri, UOSM 4-0-S2, Museum number 1249 ( $X$ approximately 1/50); H, Tibia, Cotylorhynchus romeri, PR $272\left(X^{1 / 6}\right)$; I, Sacral vertebra, Cotylorhynchus romeri, showing high spine, OUSM, number not certain $(X$ about $1 / 6)$; J, Pelvis, Cotylorhynchus romeri, lateral view. Probably UOSM 4-0-S16 ( $X$ approximately $1 / 9$ ); K, Femur, Angelosaurus romeri, ventral, UR 917 ( $X$ approximately $1 / 6$ ). 
Plate 3

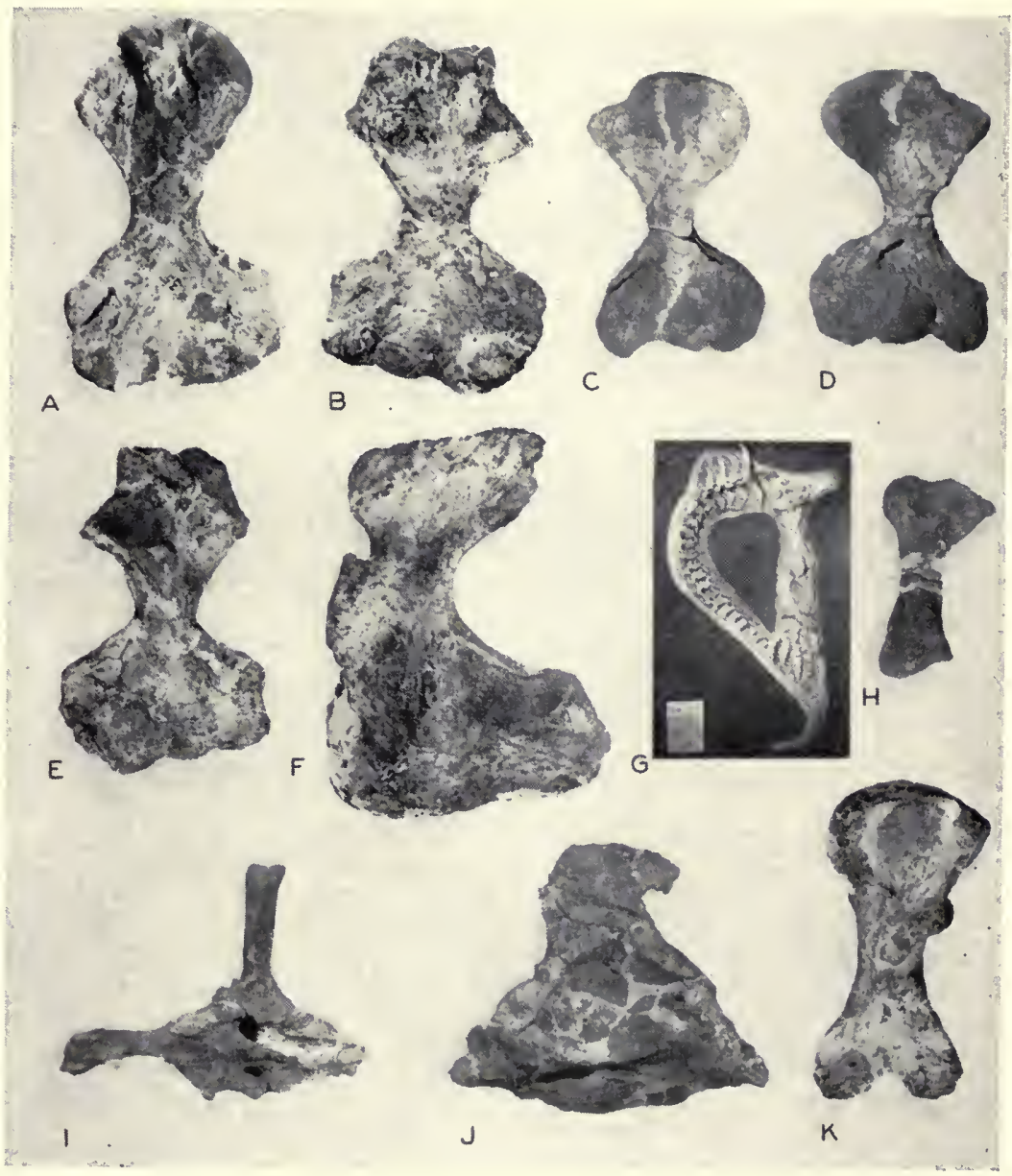




\section{Plate 4}

A, B, Lower jaw of Angelosaurus romeri, UR 933 ( $\times$ about $1 / 3$ ). C, Pterygoid of Angelosaurus romeri in ventral view, UR 931 ( $\times 1 / 2)$; D, Pterygoid of Cotylorhynchus bransoni, ventral view, UR 929 ( $\times 1 / 2)$; E, Braincase and basicranium of Angelosaurus romeri, ventral view, UR 927 ( $\times 1 / 3)$; F, Stereophotographs of braincase of Angelosaurus romeri, sagittal section, showing sinus development, UR 927. 
Plate 4
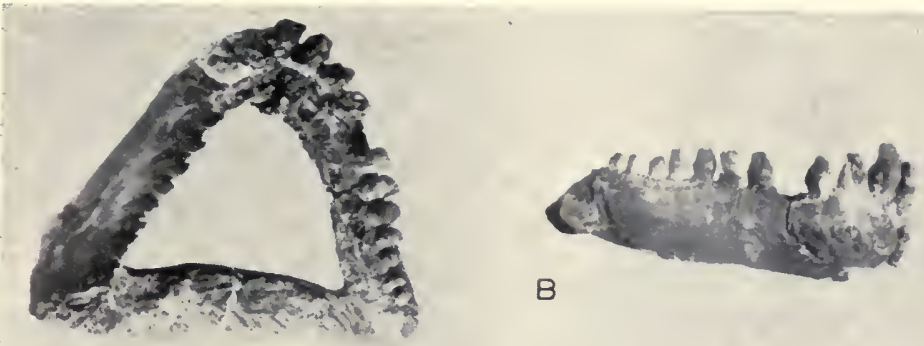

A
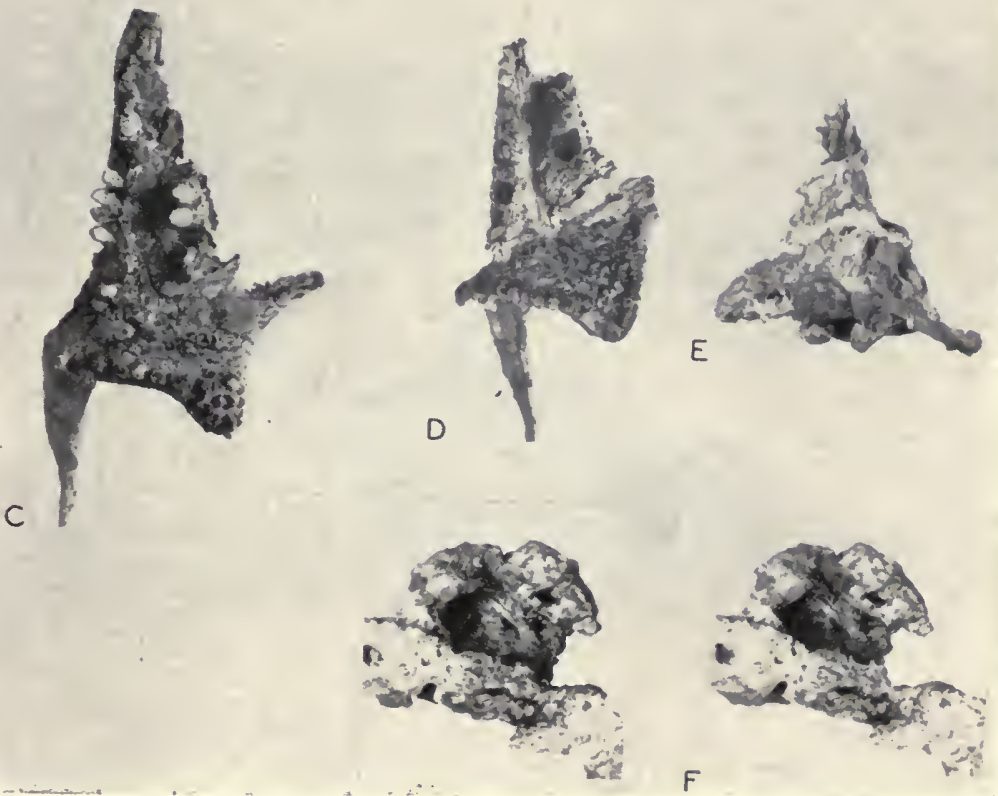


\section{Plate 5}

Skulls of Ennatosaurus tecton. All PIN. A, 1580/17, dorsolateral view ( $X$ approximately $1 / 5$ ); B, $1580 / 17$, anteroventral view (Xapproximately $1 / 5$ ); C, 1580/24, young individual, lateroventral view, somewhat from posterior ( $X$ approximately $1 / 3) ; \mathrm{D}, 1580 / 14$, anteroventral view ( $X$ approximately $1 / 5$ ); $\mathrm{E}, 1580 / 14$, from left rear to show otic notch showing in foreground of photograph. The damaged occiput is to the right and the temporal fenestra to the left with snout toward upper left side of photograph. The otic notch is emphasized by the distortion. These photographs were taken in the laboratories of the Paleontological Institute, Academy of Sciences, Moscow, U.S.S.R., for special use in this publication. 
Plate 5

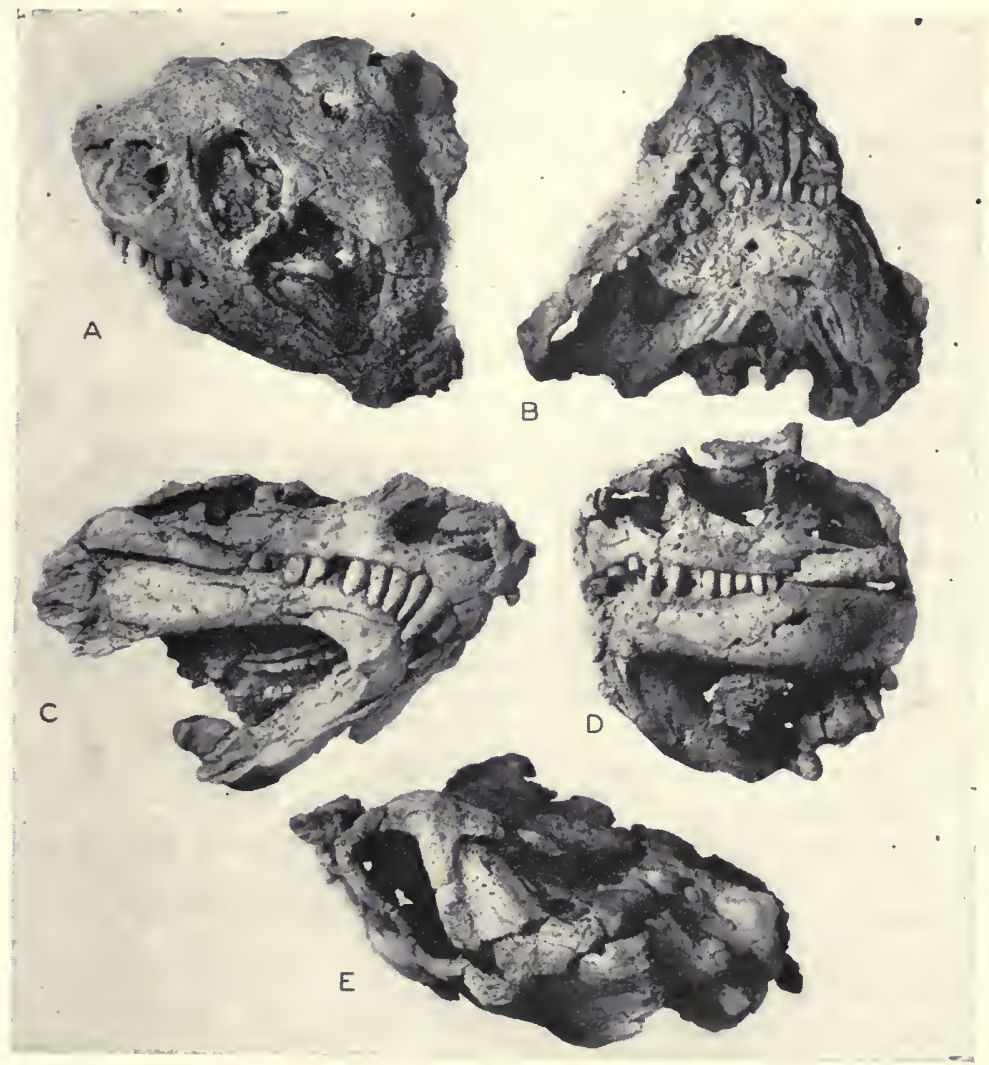




\section{Abbreviations Used in ApPendix Tables 1 to 4}

$\mathrm{Bw}$, basal width of tooth measured parallel to long axis of jaw

$\mathrm{Ch}$, crown height of tooth

Corl, coracoid length

$\mathrm{Fe}$, length of femur, maximum

$\mathrm{Fi}_{1}$, length of fibula, maximum

$\mathrm{Hu}$, length of humerus, maximum

$\mathrm{Il}_{\mathrm{ht}}$, height of ilium from top of acetabulum

Io $o_{w}$, maximum distance between orbits

$\mathrm{Lj}$, maximum length of lower jaw

$\mathrm{Na}$, maximum length of naris

$\mathrm{Ne}_{\mathrm{w}}$, width of neck of ilium

$\mathrm{O}_{\mathrm{l}}$, length of orbit measured parallel to midline of skull

$\mathrm{Pi}_{1}$, length of pineal opening, along midline of skull

$\mathrm{Pi}$-nal, distance along midline from anterior edge of pineal opening to tip of snout

$\mathrm{Pi}$-oc, distance along midline of skull from posterior edge of pineal opening to break from skull platform onto occiput

$\mathrm{Pi}_{\mathrm{w}}$, width of pineal opening normal to midline of skull

$\mathrm{Ra}$, length of radius, maximum

SC-COR, scapulocoracoid

Scapht, height of scapula measured from top of acetabulum to topmost point of scapula

$\mathrm{Sk}$, maximum length of skull from basioccipital condyle to tip of snout

Symphl, length of ventral symphysis of pelvis

$\mathrm{Tf}_{1}$, maximum length of temporal fenestra

$\mathrm{Ti}$, length of tibia maximum

Tr, length of tooth row

$U_{1}$, length of ulna, maximum 


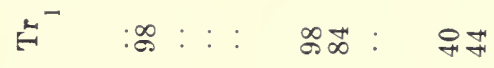

$\Xi^{-} \stackrel{\circ}{\circ}$

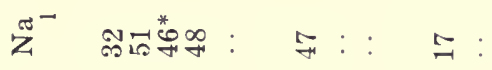

出 : : :

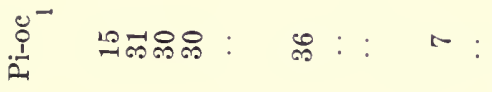

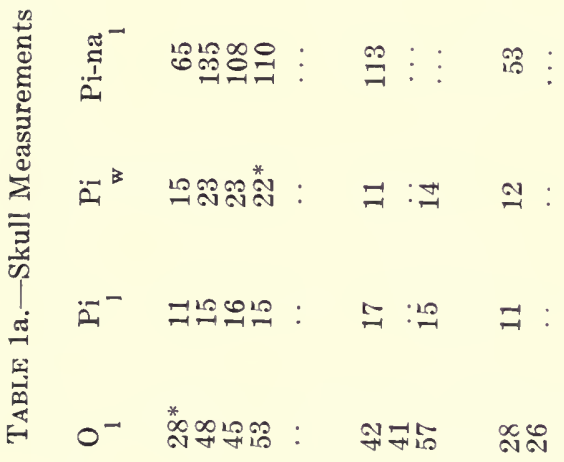

ㅇำ

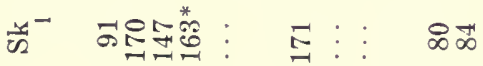

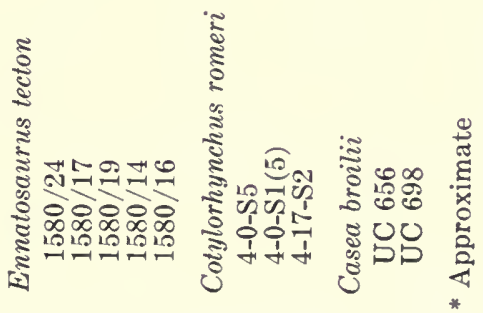




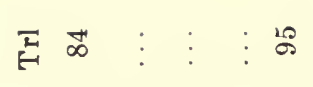

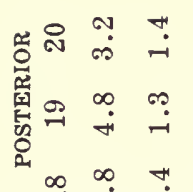$$
\stackrel{\infty}{\infty} \stackrel{\infty}{+}
$$$$
\text { I }
$$

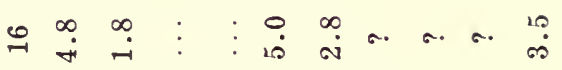

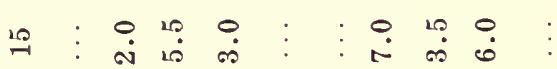

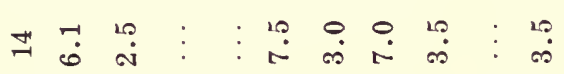

연

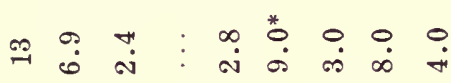

$$
\begin{aligned}
& \text { ง } \infty \text { : } \infty \text { : } 1000
\end{aligned}
$$

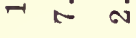$$
\not \begin{array}{ll}
-1 & \infty \\
- & \infty
\end{array}
$$$$
\text { o r i } 10
$$

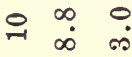$$
\text { or } \infty \text { i }
$$$$
\infty \quad \dot{0}
$$$$
-\begin{array}{llll}
-1 & \infty & 0 & 10
\end{array}
$$$$
\text { @ }
$$$$
\stackrel{0}{\infty} \quad 10
$$$$
\text { - }
$$$$
\infty
$$

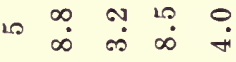$$
\text { - } \infty \infty \infty
$$$$
\text { : : }
$$

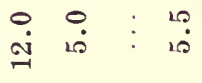$$
\text { 10 }
$$$$
\text { \& }
$$$$
\text { ષ }
$$

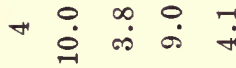$$
\text { 象 }
$$$$
\text { Z }
$$

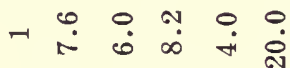$$
\Rightarrow \quad \text { is }
$$

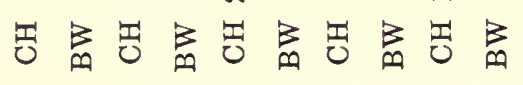

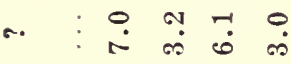

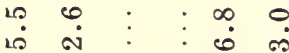
is में

$\begin{array}{llllll}0 & \infty & 10 & 0 & \wp & \ddots\end{array}$

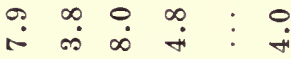

$$
\stackrel{0}{\stackrel{1}{*}} \dot{+}
$$

๑. $\infty$ ๆ 0 เ $\sigma$ ๙

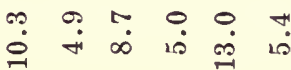
is.

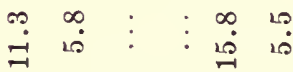

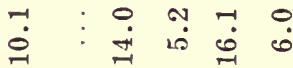

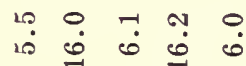
- 00010 1.

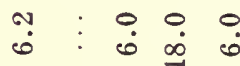

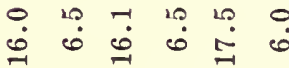
$: \begin{array}{llll}18 & 0 & \infty & 18 \\ 10 & 10 & 0\end{array}$

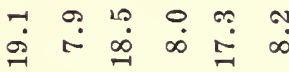

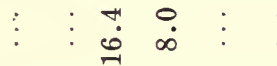
范焉焉空

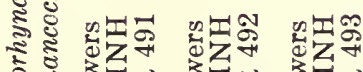

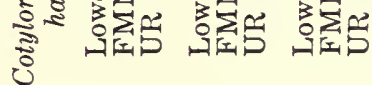


-

भin 
TABLE 3a.-Measurements of limb and girdle elements

$$
\mathrm{Hu}_{1} \mathrm{Ra}_{1} \mathrm{Ul}_{\mathrm{l}} \mathrm{Fe}_{\mathrm{l}} \mathrm{Ti}_{\mathrm{l}} \mathrm{Fi} \overbrace{\mathrm{Scap} \mathrm{ht}_{\mathrm{l}}^{\mathrm{Cor}}}^{\text {Sc-Cor }} \overbrace{\mathrm{l}_{\mathrm{ht}}^{\mathrm{Ne} \text { Symph }}}^{\text {Pelvis }}
$$

Casea broilii

UC 656

UC 883

$\begin{array}{lllll}86 & 62 & 58 & 76 & 55\end{array}$

$\begin{array}{lll}63 & 72 \quad 68\end{array}$

$\begin{array}{lll}33 & 17 & 71 \\ 28 & 16 & 68\end{array}$

Casea nicholsi UR 86

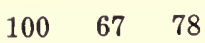

$\begin{array}{lll}70 & 72 \quad 85\end{array}$

$\begin{array}{lll}54 & 29 & 128\end{array}$

Casea halselli

UR 117

Caseoides sanangeloensis

\section{UR 151 \\ UR 152 \\ Caseopsis agilis \\ UR 253 \\ Caseopsis cf. agilis}

157

$\begin{array}{lll}145 & 93 & 101\end{array}$

$118 \quad 105 \quad 235$

10560

UR 255

Phreatophasma aenigmaticum

PIN 294/24

62

Cotylorhynchus romeri

4-0-S2
$4-0-\mathrm{S} 3$
$4-0-\mathrm{S} 4$
$4-0-\mathrm{S} 6$
$4-0-\mathrm{S} 13$
$4-0-\mathrm{S} 16$
OU $1250^{*}(\mathrm{R})$
FMNH PR 272
MCZ
USNM
AMNH
Cotylorhynchus
$\quad$ bransoni

UR 835

UR 836

UR 837

UR 839

UR 840

UR 918

UR 919

UR 970

$\begin{array}{llllll} & & & 315 & 190 & 193 \\ 190 & 105 & & & & \\ 338 & 188 & & 308 & 192 & 193 \\ 348 & 168 & & 313 & & \\ 196 & 115 & & 195 & & \\ 260 & 142 & 150 & 260 & 175 & \\ 225 & & & 288 & 170 & \\ 327 & 137 & 115 & 305 & 127^{*} & 174 \\ 246 & & & 239 & & \\ 263 & 127^{*} & & 251 & 147 & \\ & & & & 190 & \end{array}$


TABLE 3a.-Measurements of limb and girdle elements-Continued

Cotylorhynchus hancocki

UR 249

UR 488

UR 567

UR 571

UR 581

UR 621

UR 622

UR 623

UR 703

UR 707

UR 822

UR 874

UR 875

UR 878

UR 487

UR 879

UR 893

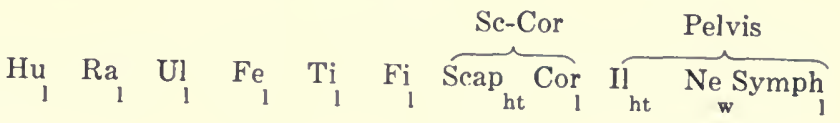

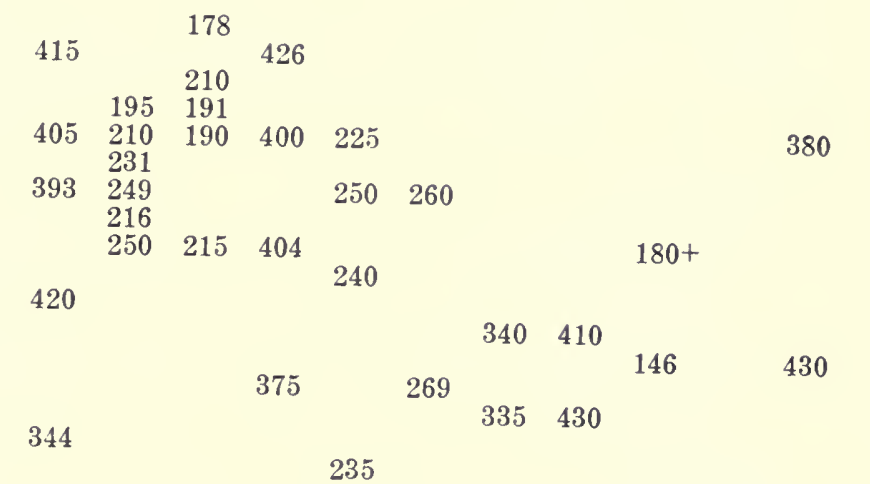

Angelosaurus dolani

UR 149

189

Angelosaurus greeni

UR 257

Angelosaurus

romeri

UR 827

UR 844

UR 904

UR 907

UR 909

UR 911

UR 917

UR 977

UR 979

UR 980

\section{Ennatosaurus}

$$
\text { tecton }
$$

PIN 1580/12

PIN 1580/102

PIN 1580/103

PIN 1580/104

PIN 1580/107

PIN 1580/110(1) 75

$216 \quad 155 \quad 169$

$60 \quad 195$

260

PIN 1580/110(2) 69

PIN 1580/114

PIN $1580 / 120$

$\begin{array}{lll}155 & 83 \quad 77\end{array}$

165

176

141

223

215

$96 \quad 54$

$92 \quad 220$

$90 \quad 50$

* Approximate 
TABLE 4a.-Measurements of vertebrae in the Caseidae

Key to measurements

1. Greatest central length, along the base of the centrum.

2. The height of the neural spine, measured from the top of the neural canal to the dorsal tip of the spine.

3. Width of the posterior zygapophyses, the greatest distance between the lateral margins of the right and left posterior zygapophysis.

4. Width of the transverse process, measured from the axial plane of the vertebrae to the lateral tip of the transverse process.

\section{Casea broilii}

$1 \quad 2 \quad 3 \quad 4$

FMNH UR 656

Cervical (3rd) ................ 10

Anterior dorsal. . . . . . . . . . . . 13

Mid-dorsal ..................... 17

Lumbar. . . . . . . . . . . . . . . . . . . . 17

Second sacral.................. 15

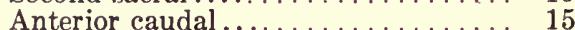

Mid-caudal. . . . . . . . . . . . . . . 10

$12-11-8$

Casea nicholsi

FMNH UR 85

Anterior dorsal ................. . $18 \quad 22 \quad 12$

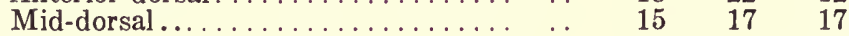

Lumbar. . . . . . . . . . . . . . . .

Caseopsis agilis

FMNH UR 253

Lumbar.................. 20

Cotylorhynchus romeri

UOSM 4-0-S2

Caudal (6)............... 40

Caudal (15) ................ 31

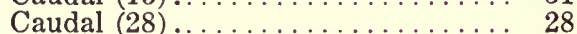

Caudal (41) ................ 22

UOSM - no number

Second sacral............... 4

Cotylorhynchus bransoni

FMNH UR 923

Second sacral................

FMNH UR 981

Lumbar (3rd presacral) .......... $34 \quad 36 \quad 49 \quad 56$

Anterior caudal................ $31 \quad \ldots \quad 21 \quad 45$

FMNH UR 937

Mid dorsal .................... 37

Anterior caudal............... 2

$\begin{array}{lll}45 & 28 & 78\end{array}$

FMNH UR 925

Anterior dorsal............. $31 \quad 47 \quad 22 \quad 84$ 
TABLE 4a.-Measurements of vertebrae in the Caseidae-Continued Key to measurements

Cotylorhynchus hancocki

FMNH UR 581

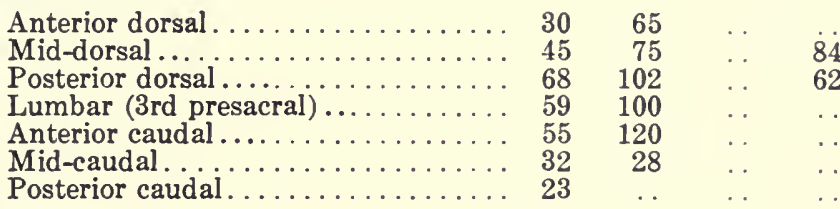

FMNH UR 621

Mid-dorsal .................... 46

Anterior dorsal

FMNH UR 622

Cervical (3rd)

Mid-dorsal.

$\begin{array}{llll}26 & 42 & \cdots & 28 \\ 55 & 70 & 91\end{array}$

FMNH UC 250

Mid-dorsal.

Angelosaurus dolani

FMNH UR 149

Mid dorsal .................... 39

Lumbar..................... 36

Second sacral .................. 45

Anterior caudal ...................... 35

Mid-caudal................. 25

Posterior caudal ............... 20

FMNH UR 904

Lumbar (3rd presacral) ........... $36 \quad 36 \quad 42 \quad 63$

Second sacral................. $28 \quad 45 \quad 25 \quad 45$

Anterior caudal................ $23 \quad 42 \quad 38 \quad 18$

Mid-caudal.................. 17

FMNH UR 916

Lumbar (2nd presacral) . . . . . . $28 \quad 28 \quad 39 \quad 39 \quad 59$

Ennatosaurus tecton

PIN 1580/24

Cervical (2nd)

PIN 1580/105

Anterior dorsal. ............ 18

60

PIN 1580/101

Cervical (3 or 4$) \ldots \ldots \ldots \ldots \ldots \ldots .16$

Anterior dorsal............... 20

Mid-dorsal...................... 21

$1580 / 111$

Anterior dorsal ................ 23

PIN 1580/19

Atlas. 





\section{Publication 1035}







UNIVERSITY OF ILLINOIS-URBANA

$550.5 \mathrm{FI}$

FIELOIANA, GEOLOGY CHGO

$171967 / 68$

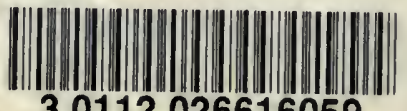

30112026616059 